\title{
ECOLOGIA E MANEJO DE ECOUNIDADES EM UM FRAGMENTO FLORESTAL NA REGIÃO DE PIRACICABA, SP
}

\section{ANDRÉ AUGUSTO JACINTO TABANEZ \\ Engenheiro Agrônomo}

Orientador: Prof. Dr. Virgílio Maurício Viana

\begin{abstract}
Dissertação apresentada Escola Superior de Agricultura 'Luiz de Queiroz", da Universidade de São Paulo, para obtenção do título de Mestre em Ciências, Área de Concentração: Ciências Florestais
\end{abstract}

PIRACICABA

Estado de São Paulo - Brasil

Novembro - 1995 


\title{
ECOLOGIA E MANEJO DE ECOUNIDADES EM UM FRAGMENTO FLORESTAL NA REGIÃO DE PIRACICABA, SP
}

\author{
ANDRÉ AUGUSTO JACINTO TABANEZ
}

Aprovada em: 13 de dezembro de 1995

Comissão julgadora:

Prof. Dr. Virgílio M. Viana

Prof. Dr. Paulo Y. Kageyama

Prof. Dr. Waldir Mantovani

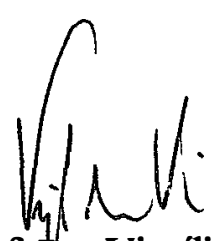

Prof. pr. Virgílio Maurício Viana

Orientador
ESALQ/USP

ESALQ/USP

Instituto de Biociências/USP 
Dados Internacionais de Catalogação na Publicação (CIP)

DIVISĀO DE BIBLIOTECA E DOCUMENTAÇĀO - Campus "Luiz de Queiroz"/USP

Tabanez, André Augusto Jacinto

Ecologia e manejo de ecounidades em un fragmento florestal na região de Piracicaba, SP. Piracicaba, 1995.

85p. ilus.

Diss. (Mestre) - ESALQ

Bibl iografia.

1. Ecologia florestal 2. Floresta - Manejo - Piracicaba, SP I. Escola Superior de Agricultura Luiz de Queiroz, Piracicaba

CDCDD 634.94 
Este trabalho é dedicado à Natureza, à minha família, e a todas as pessoas éticas e de bom senso. 


\section{AGRADECIMENTOS}

Às instituições que colaboraram financeiramente com o Projeto Biologia e Manejo de Fragmentos Florestais do Laboratório de Silvicultura Tropical da ESALQ/USP, e conseqüentemente para a realização deste trabalho: Fundação $O$ Boticário de Proteção Natureza, MacArthur Foundation, IPEF. Ao Fundo Mundial para a Vida Selvagem (WWF) pelo auxílio financeiro específico a esta tese. À FAPESP, pela concessão de bolsas desde o meu tempo de graduação, e pelo serviço extremamente competente que oferece comunidade científica brasileira.

À Usina Capuava, e em especial ao Sr. Caio Matthiessen Gudmon, um usineiro diferente, pelo apoio, inclusive financeiro, a mim e ao trabalho realizado. A todos os funcionários da Usina, pela simpatia e colaboração.

Às instituições que colaboraram com apoio logístico e institucional, ESALQ/USP e IPE - Instituto de Projetos e Pesquisas Ecológicas.

Ao Prof. Dr. Virgílio M. Viana, pela orientação, que apesar de bem pouco ortodoxa, funcionou bem.

Aos Prof. Dr. João F. Batista e Prof. Dr. José N. Garcia, por aceitarem participar da banca de qualificação em condições tão anárquicas quanto $s$ que foram obrigados, por motivos alheios minha vontade. Ao primeiro também pela consultoria estatística. Ao Prof. Dr. Waldir Mantovani, pelas infinitas sugestões durante a defesa.

Ao Prof. Dr. Antônio Natal Gonçalves, por brigar na Comissão de PósGraduação por direitos, não só meus, mas de todos os pós-graduandos.

À toda a moçada do Depto. de Ciências Florestais da ESALQ/USP, que sempre tratou esse agrônomo como um legítimo florestal ...em especial Fátima, Margareth, Maria Alice, Creiza, Magali, Amarildo, Maria... (logicamente devo estar esquecendo alguém...).

A todos os estagiários que participaram do Projeto Biologia e Manejo de Fragmentos Florestais desde 1990 até agora, e que espero tenham aprendido e curtido muito com tudo que viveram no projeto, incluindo os seus aspectos mais conspícuos e menos agradáveis, como os cipós, os espinhos, os mosquitos ... Em especial Adriana Oliva (Garapa), Cely M. Granja (DNA), Helena M. Maltez (Sapotí) e Marta O. Negrão (Manacá) pelo entusiasmo. Ao colega e assessor para assuntos computacionais Leandro Pinheiro (VASP) pelo mapa, pelas dicas, e pelo interesse sempre demonstrado. Aos meus "desorientados" Maurício M. R. da Silva (Teressa) e Janaína G. Arantes (Guavira) pelo trampo, pela convivência, pela paciência, etc, etc, etc.

Aos trabalhadores braçais que me auxiliaram no trabalho de campo, em especial ao Sr. Venâncio Simão, baiano que saiu corrido de sua terra e veio ajudar a erguer São Paulo, e que, apesar da idade avançada, ainda hoje mostra o que é trabalhar de verdade. 
Ao meu amigo viajandão Henrique $M$. Nascimento, pelo entusiasmo e companheirismo em todas (ou quase todas) as horas.

Aos amigos André da S. Dias (Lennon) e Maurício Castro-Schmitz, pela amizade e companheirismo (além, lógico, do trampo desmedido que os dois deram, incluindo as idas ao fragmento de bicicleta). Ao primeiro também pelos serviços de hotelaria e pelas dicas automobilísticas na fase final deste trabalho.

À Lindalva J. Tabanez pela ajuda finaceira esporádica mas quase sempre certa quando necessário. À Ana Paula J. Tabanez pelo uso abusivo de seu material computacional e FAX. À Adriana M. R Ometto pelos galhos quebrados.

Ao colega Prof. Dr. Paulo Y. Kageyama, pelas dicas e companheirismo.

Aos pesquisadores que auxiliaram na identificação do material botânico, que sabem e ensinam muito, e que merecem a minha profunda consideração: Prof. Dr. Ricardo R Rodrigues, Natália Ivanauskas (Tati), João B. Baitello, Geraldo A. D. Corrêa Franco, Osny T. Aguiar.

Às pessoas que colaboraram muito na minha formação pessoal e profissional, dando o exemplo: Mário P. Autuori e Werner C. A. Bokerman (in memoriam). Às pessoas que colaboraram da mesma maneira com dicas, apoio e amizade: Juan C. Guix, Milene F. Vieira e Paulo Martuscelli.

À Universidade Federal de Viçosa, pelos maravilhosos primeiros anos da minha vida universitária.

À minha esposinha Jeanofila specialis Tab. por esses anos todos de amizade e companheirismo, e pela paciência nos últimos meses da realização deste trabalho. A Menina, Bona, Suzi, Tula, e Jacó, pelos momentos de convivência. A Kevin Amold, Beakman, e Doug pelos momentos de entretenimento.

Ao lap-top do Laboratório de Silvicultura Tropical da ESALQ/USP, pelo trabalho incansável de horas e horas diárias, sem direito a finais de semana, feriados e $13^{\circ}$.

A todos aqueles que me apoiaram durante a realização deste trabalho, e que, direta ou indiretamente, colaboraram com ele, e que foram vilmente esquecidos na redação desses agradecimentos. 
LISTA DE FIGURAS

Página

LISTA DE TABELAS

iv

RESUMO

V

SUMMARY

vii

CAPÍTULO 1

1.1. INTRODUÇÃO.

1.1.1. O problema do desmatamento

1.1.2. Dinâmica de florestas naturais

1.1.3. Dinâmica de populações de espécies de cipó

1.1.4. Ecologia de fragmentos florestais.

1.1.5. Conceito de ecounidades.

1.1.6. Problema de pesquisa.

1.1.7. Hipóteses.

1.1.8. Predições.

1.1.9. Objetivos.

1.1.10. Estrutura da teses.

1.2. MATERIAL E MÉTODOS.

1.2.1. Caracterização da área.

1.2.1.1. Localização.

1.2.1.2. Clima.

1.2.1.3. Vegetação.

ix

CAPÍTULO 2 - ESTRUTURA DE ECOUNIDADES EM FRAGMENTOS DE FLORESTA ATLÂNTICA DE PLANALTO

2.1. INTRODUÇÃO.

2.1.1. Problema de pesquisa.

2.1.2. Hipótese.

2.1.3. Predição.

2.1.4. Objetivo.

2.2. MATERIAL E MÉTODOS..

2.2.1. Obtenção dos dados.

2.2.1.1. Escolha do fragmento.

2.2.1.2. Instalação das parcelas.

2.2.1.3. Coleta de dados dos indivíduos de espécies arbóreas............. 15

2.2.1.4. Mapeamento de ecounidades............................................ 16

2.2.1.5. Medição de cobertura foliar........................................... 16

2.2.2. Análise dos dados.................................................................. 17

2.2.2.1. Estrutura da vegetação................................................. 17

2.2.2.2. Diferenças entre ecounidades......................................... 18

2.3. RESULTADOS E DISCUSSÃO.

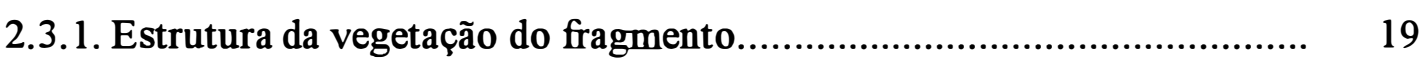

2.3.2. Estrutura das ecounidades...................................................... 21

2.3.2.1. Capoeira alta......................................................... 23

2.3.2.2. Capoeira baixa.......................................................... 24

2.3.2.3. Bambuzal................................................................ 24 
2.3.2.4. Mata madura.................................................................... 25

2.3.3. Estrutura de populações................................................................. 25

2.3.4. Conclusão................................................................................... 28

CAPÍTULO 3 - CONTROLE DE CIPÓS NO MANEJO DE ECOUNIDADES EM FRAGMENTOS DE FLORESTA DE PLANALTO

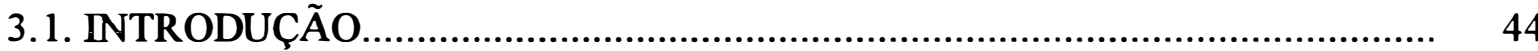

3.1.1. Problema de pesquisa................................................................ 45

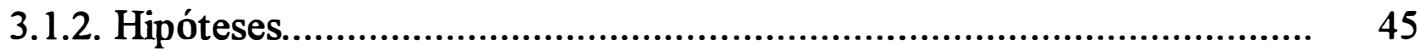

3.1.3. Predições................................................................................... 45

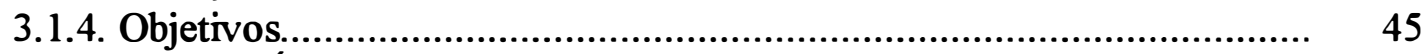

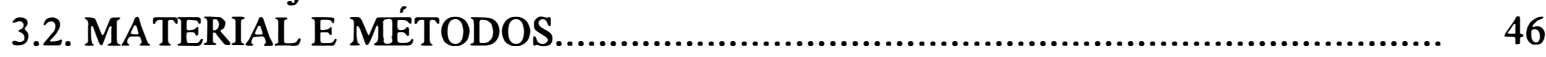

3.2.1. Obtenção dos dados........................................................................ 46

3.2.1.1. Manejo de capoeira baixa.................................................... 46

3.2.1.2. Manejo de capoeira alta...................................................... 48

3.2.2. Análise dos dados..................................................................... 48

3.2.2.1. Resultados do manejo em capoeira baixa................................ 49

3.2.2.1.1. Crescimento de árvores preexistentes..................... 49

3.2.2.1.2. Regeneração natural.............................................. 49

3.2.2.2. Resultado do manejo em capoeira alta.................................... 49

\subsection{RESULTADOS E DISCUSSÃO}

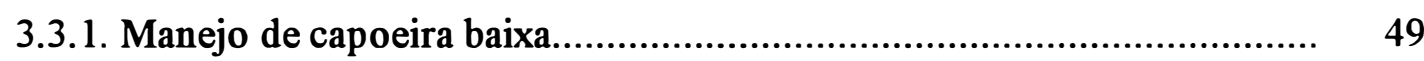

3.3.1.1 Crescimento de árvores preexistentes..................................... 50

3.3.1.2. Regeneração natural.............................................................. 53

3.3.1.3. Custos............................................................................ 58

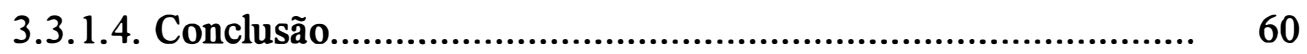

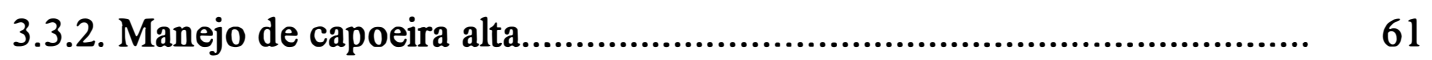

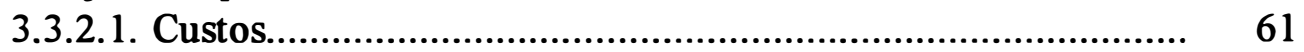

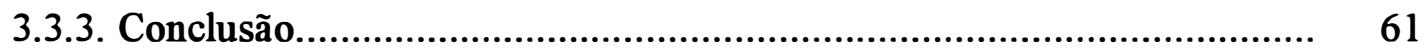

3.3.3.1. Perspectivas para o manejo de fragmentos florestais............... 61

3.3.3.2. Proposta preliminar de manejo............................................. 62

CAPÍTULO 4 - USO DE PLANTIO DE ENRIQUECIMENTO NO MANEJO DE ECOUNIDADES EM FRAGMENTOS DE FLORESTAS DE PLANALTO

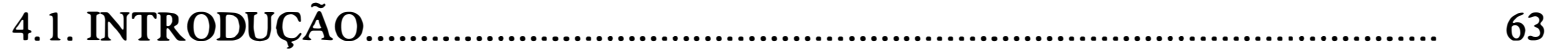

4.1.1. Problema de pesquisa................................................................... 63

4.1.2. Hipótese

4.1.3. Objetivos...................................................................................... 63

4.2. MATERIAL E MÉTODOS........................................................................... 64

4.2.1. Obtenção dos dados....................................................................... 64

4.2.1.1. Manejo de capoeira baixa................................................... 64

4.2.1.1.1. Instalação das parcelas........................................... 64

4.2.1.1.2. Espécies utilizadas no plantio de enriquecimento...... 65

4.2.1.1.3. Acompanhamento do crescimento de mudas

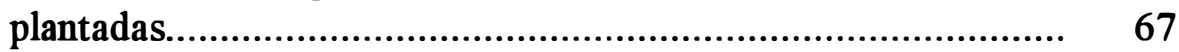

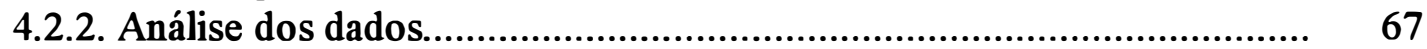

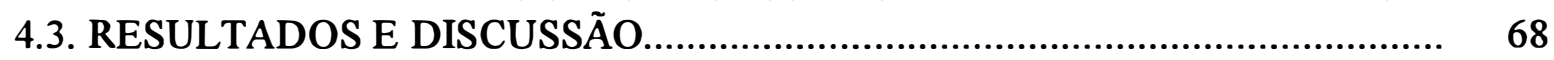

4.3.1. Plantio de enriquecimento.............................................................. 68

4.3.2. Conclusão.................................................................................. 72 


\section{CAPÍTULO 5}

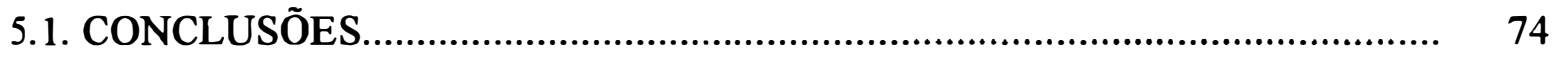

5.1.1. Conclusões gerais...................................................................... 74

5.1.2. Recomendações para experimentos de manejo..................................... 74

5.1.3. Prioridades para ação................................................................... 75

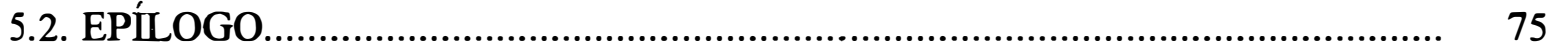

5.2.1. Polêmica do manejo de fragmentos florestais..................................... 75

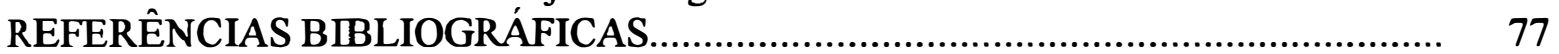




\section{CAPÍTULO 1}

Página

1. Diagrama climático de Piracicaba......................................................................... 7

CAPÍTULO 2

1. Perfis esquemáticos das quatro ecounidades consideradas neste estudo................... 10

2. Trecho da ecounidade capoeira baixa.............................................................. 11

3. Visão aérea da ecounidade capoeira alta.......................................................... 12

4. Visão aérea do fragmento estudado.................................................................. 14 5. Mapa do fragmento estudado......................................................................... 16

6. Percentual do IVC devido a diferentes categorias sucessionais, e a árvores mortas e cobertas por cipós em cada ecounidade................................................................ 25

7. Densidade relativa para diferentes categorias sucessionais, e para árvores mortas e cobertas por cipós em cada ecounidade do fragmento estudado.

8. Distribuição diamétrica das espécies tolerantes mais comuns no fragmento da Usina Capuava. 7 10 1 政

9. Distribuição diamétrica de duas espécies tolerantes, Holocalyx balansae e Securinega guaraiuva no fragmento da Usina Capuava............................................

10. Distribuição diamétrica da espécies oportunista Croton floribundus, no fragmento da Usina Capuava.

\section{CAPÍTULO 3}

1. Parcela esquemática de capoeira baixa, onde se observam as subparcelas de acompanhamento de regeneração natural.

2. Área basal média nas parcelas do experimento de manejo de capoeira baixa na instalação do experimento e 12 meses após, para árvores $\operatorname{com}$ DAP $\geq 5 \mathrm{~cm}$

3. Densidade média de indivíduos arbóreos (DAP $\geq 5 \mathrm{~cm}$ ) nas parcelas do experimento de manejo de capoeira baixa na instalação do experimento e 12 meses após.

4. Área média de copa $\left(\mathrm{m}^{2} / \mathrm{ha}\right)$ de indivíduos arbóreos $(\mathrm{DAP} \geq 5 \mathrm{~cm})$ nas parcelas do experimento de manejo de capoeira baixa na instalação do experimento e 12 meses após.

5. Área basal média na instalação do experimento de manejo de capoeira baixa, 6 meses e 12 meses após, para indivíduos de espécies arbóreas (altura $\geq 5 \mathrm{~cm}$ ).

6. Densidade média (plantas/ha) na instalação do experimento de manejo de capoeira baixa, 6 meses e 12 meses após, para indivíduos de espécies arbóreas (altura $\geq 5 \mathrm{~cm}$ ).

7. Área média de copa $\left(\mathrm{m}^{2} / \mathrm{ha}\right)$ na instalação do experimento de manejo de capoeira baixa, 6 meses e 12 meses após, para indivíduos de espécies arbóreas (altura $\geq 5 \mathrm{~cm}$ ). CAPÍTULO 4

1. Esquema de plantio utilizado no plantio de enriquecimento do manejo de capoeira baixa. 
CAPÍTULO 2

1. Dados sobre fragmentos estudados da região

2. Médias área basal e densidade da vegetação arbórea, cobertura foliar total, e percentual dessa cobertura devido a cipós e árvores, e índice de diversidade de Shannon-Weaver para cada ecounidade.

3. Área basal média por indivíduo em cada ecounidade.

4. Famílias mais diversas no fragmento da Usina Capuava, e número de espécies por família.

5. Percentual do IVC devido a árvores cobertas por cipós, mortas, espécies oportunistas, tolerantes, pioneiras e reprodutoras sombra em cada ecounidade........

6. Percentual de cada ecounidade encontrado em fragmentos da região de Piracicaba.

7. Lista de espécies encontradas no fragmento da Usina Capuava...............................

8. Análise fitossociológica do fragmento da Usina Capuava.

9. Análise fitossociológica da ecounidade capoeira baixa no fragmento da Usina Capuava

10. Análise fitossociológica da ecounidade bambuzal no fragmento da Usina Capuava.....

11. Análise fitossociológica da ecounidade capoeira alta no fragmento da Usina Capuava.

12. Análise fitossociológica da ecounidade mata madura no fragmento da Usina Capuava...

13. Classificação das espécies mais importantes, em IVC, na Usina Capuava, em categorias sucessionais, segundo o autor deste trabalho, e outros três autores.

CAPÍTULO 3

1. Área basal média $\left(\mathrm{m}^{2} / \mathrm{ha}\right)$ em $\mathrm{T} 1$ e $\mathrm{T} 2$ nas parcelas do experimento de manejo de capoeira baixa (DAP $\geq 5 \mathrm{~cm})$.

2. Densidade média de árvores (indivíduos/ha) em $\mathrm{T} 1$ e $\mathrm{T} 2$ nas parcelas do experimento de manejo de capoeira baixa (DAP $\geq 5 \mathrm{~cm}$ )

3. Área média de copa de vegetação arbórea $\left(\mathrm{m}^{2} / \mathrm{ha}\right)$ em $\mathrm{T} 1$ e $\mathrm{T} 2$ nas parcelas do experimento de manejo de capoeira baixa (DAP $\geq 5 \mathrm{~cm}$ ).

4. Área basal média $\left(\mathrm{m}^{2} / \mathrm{ha}\right)$ em $\mathrm{T} 1, \mathrm{~T} 2$ e T3 nas parcelas do experimento de manejo de capoeira baixa (altura $\geq 1,5 \mathrm{~m}$ )

5. Densidade média (plantas/ha) em T1, T2 e T3 nas parcelas do experimento de manejo de capoeira baixa (altura $\geq 5 \mathrm{~cm}$ ).

6. Área média de copa de vegetação arbórea $\left(\mathrm{m}^{2} / \mathrm{ha}\right)$ em T1, T2 e T3 nas parcelas do experimento de manejo de capoeira baixa (altura $\geq 1,5 \mathrm{~m}$ ).

7. Custo total para 1 ha do manejo de capoeira baixa, em dólares americanos, pelos tratamentos 1 a 3 .

8. Custo total para 1 ha do manejo de capoeira baixa, em dólares americanos, pelo tratamento 4

9. Custo total para 1 ha do manejo de capoeira alta, em dólares americanos. CAPÍTULO 4 
1. Espécies utilizadas no plantio de enriquecimento do experimento de manejo de capoeira baixa.

2. Associações utilizadas no experimento de manejo de capoeira baixa, e categoria sucessional a que pertence cada espécie.

3. Caracterização das espécies utilizadas no plantio de enriquecimento do experimento de manejo de capoeira baixa, quanto aos seguimtes atributos: velocidade de crescimento, porte final, capacidade de sombreamento e produção de alimentos para a fauna

4. Percentual de mortalidade por parcela devido geada, média entre parcelas, e coeficiente de variação entre elas, para as diferentes associações de plantio do experimento de manejo de capoeira baixa.

5. Mortalidade por espécie para as espécies utilizadas no plantio de enriquecimento, em três medições.

6. Incremento percentual médio em colo entre T1 e T2 (T1-T2) e entre T2 e T3 (T2-T3) para as espécies utilizadas no plantio de enniquecimento.

7. Incremento percentual médio em altura entre T1 e T2 (T1-T2) e entre T2 e T3 (T2T3) para as espécies utilizadas no plantio de enriquecimento.

8. Incremento percentual médio em copa entre T1 e T2 (T1-T2) e entre T2 e T3 (T2-T3) para as espécies utilizadas no plantio de enriquecimento 
ECOLOGIA E MANEJO DE ECOUNIDADES EM UM FRAGMENTO FLORESTAL NA REGIÃO DE PIRACICABA, SP

\author{
Autor: ANDRÉ A. J. TABANEZ \\ Orientador: Prof. Dr. VIRGÍlIO M. VIANA
}

\title{
RESUMO
}

Analisou-se a estrutura de ecounidades em relação a características quantitativas da floresta em um fragmento de floresta estacional semidecidual. Práticas de recuperação também foram estudadas. $O$ estudo foi desenvolvido em um fragmento florestal de 86 ha em Piracicaba, estado de São Paulo, Brasil. Não há conhecimento de que este fragmento tenha sofrido qualquer perturbação antrópica de grande intensidade, como incêndios intensos ou corte raso.

O estudo de ecounidades foi feito utilizando-se três transectos de $10 \mathrm{~m}$ de largura que cortam o fragmento de um lado a outro. Todas as árvores com $5 \mathrm{~cm}$ ou mais de DAP tiveram seu DAP medido e foram identificadas. A área total de estudo foi de 1,39ha. Quatro ecounidades foram identificadas, baseados na fisionomia da vegetação: "capoeira baixa", "bambuzal", capoeira alta" e "mata madura". As ecounidades diferiram em área basal e densidade de árvores, intensidade da cobertura por lianas, Índice de Diversidade de Shannon-Wiener, e também em IVC de árvores cobertas por cipós, pioneiras, oportunistas, tolerantes e reprodutoras sombra. A capoeira baixa é a ecounidade menos desenvolvida, seguida de perto pelo bambuzal. A capoeira alta é intermediária entre o bambuzal e a mata madura, a ecounidade mais desenvolvida. As espécies de cipós parecem ter um papel fundamental na dinâmica dessas ecounidades, especialmente nas capoeiras baixa e alta.

Com base nas análises de ecounidades, diferentes práticas de recuperação foram usadas em capoeiras baixa, assim como em capoeira alta. Cinco tratamentos foram aplicados em 25 parcelas de capoeira baixa: controle de cipós mais plantio de enriquecimento (foram usadas três associações diferentes de espécies, tratamentos 1,2 e 3 ), controle de cipós sem plantio de enriquecimento (tratamento 4), e testemunha (tratamento 5). Dois tratamentos foram aplicados em 10 parcelas de capoeira alta: controle de cipós (tratamento 1) e testemunha (tratamento 2).

Em 18 meses os tratamentos aplicados na capoeira baixa se mostraram bastante eficientes no aumento da densidade de indivíduos arbóreos e de sua área basal e área de copa, especialmente nos tratamentos 1 a 3 , comparados com o tratamento 5. Os custos para dois anos de tratamento foram de US $\$ 1,786.11 /$ ha para o tratamento 1,2 e 3 , e US $\$ 387.29 /$ ha para o tratamento 4 . Para o tratamento em capoeira alta apenas os custos são discutidos, já que o período de acompanhamento não foi suficientemente longo para permitir mais que uma medição, não permitindo comparações. Os custos de dois anos de tratamento 
foi de US\$116.13/ha. Os custos indicam que ambos experimentos de recuperação são técnicA e economicamente viáveis. Sugestões para futuros experimento são feitas no final. 


\author{
Author: ANDRÉ A. J. TABANEZ \\ Advisor: Prof. Dr. VIRGíl IO M. VIANA
}

\title{
SUMMARY
}

The structure of ecounits was evaluated in terms of quantitative features of the forest in a fragment of semi-deciduous forest. Restoration practices were also studied. The study was conducted in a 86 ha forest fragment in Piracicaba, state of São Paulo, Brazil. There are no records that this fragment suffered any large anthropic disturbance like extensive woodfires or clearcut.

The ecounits study was done using three $10 \mathrm{~m}$ wide transects which cut across the fragment from side to the other. All trees $5 \mathrm{~cm}$ DBH or more had their DBH measured and were identified. The total area of study was $1,39 \mathrm{ha}$. Four ecounits were identified within the fragment, based on the vegetation fisiognomy: "low 'capoeira", "bamboo forest", "high 'capoeira" and "mature forest". The ecounits differed in tree basal area and density, liana leaf cover, Shannon-Weaver diversity index, and also in importance of liana-dominated trees, light demanding pioneer, gap oportunists, shade tolerants and shade reproducing species. The "low "capoeira" proved to be the lowest developed ecounit, followed very closely by the "bamboo forest". High capoeira is intermediate between bamboo forest and mature forest, the most developed ecounit. The liana seems to play a fundamental role on the dynamic of these ecounits, specially in low and "high "capoeira".

Based on the ecounit analysis, different restoration practices were used in low and "high "capoeira" areas. In 25 plots of "low "capoeira" five treatments were applied: liana control with enrichment planting (three different tree associations were used, treatments 1,2 and 3), liana control without enrichment planting (treatment 4) and control (treatment 5). In 10 "high "capoeira" plots two treatments were applied: liana control (treatment 1 ) and control (treatment 2).

In 18 months the treatments in "low "capoeira" proved very effective in increasing the tree density, basal area and crown area in the plots, specially treatments 1 to 3 , compared to treatment 5. The costs for a two years treatment were US\$1,786.11/ha for treatment 1,2 and 3 and US $\$ 387.29 /$ ha for treatment 4. For "high "capoeira"' treatment just the costs are discussed, since the experiment period was not enough to have meaningful analysis of vegetation dynamics. The costs of a two years treatment were US $\$ 116.13 /$ ha. These costs indicate that both restoration experiments are technical and economic feasible. Sugestions for future experiments are done. 


\section{CAPÍTULO 1}

\subsection{INTRODUÇÃO}

\subsubsection{O problema do desmatamento}

O ser humano é reconhecidamente um fator de alteração ambiental desde antes do surgimento da agricultura, quando o fogo era utilizado para auxiliar a atividade de caça (FLENLEY, 1979). Com o surgimento da agricultura, começou o desmatamento em larga escala. No Brasil, o desmatamento foi feito de forma intensiva em toda a região oriental, restando poucas áreas de vegetação natural. Atualmente, o desmatamento no Brasil se concentra, principalmente, nas partes oriental e meridional da Amazônia (SKOLE \& TUCKER, 1993) onde são mais intensas as atividades madeireira e de expansão agrícola e pecuária, seguindo o mesmo padrão histórico de desordem e falta de planejamento. Esse tipo de ocupação proporciona o surgimento de um número muito grande de fragmentos de ecossistemas naturais, basicamente pelo não desmatamento de alguns trechos, por problemas de solo, topografia e, eventualmente, de legislação ou por opção individual de proprietários.

A conservação dos ecossistemas naturais está hoje ligada principalmente, e provavelmente estará ligada totalmente no futuro, à conservação de fragmentos de ecossistemas naturais. Um dos últimos grandes remanescentes de floresta tropical é a floresta amazônica. Mas, mesmo neste caso, já há uma forte tendência para que toda sua área seja transformada, com o tempo, em uma grande matriz de ecossitema agrícola salpicada por fragmentos florestais. Segundo SKOLE \& TUCKER (1993) os estados de Maranhão e Tocantins, por exemplo, apresentavam em 1988 31,02\% e 37,69\% de suas áreas originais de floresta desmatadas, e $2,11 \%$ e $7,61 \%$ do remanescente localizados em fragmentos menores que $10.000 \mathrm{ha}$, respectivamente. Os mesmos autores afirmam que, para um percentual total de $6 \%$ desmatado para a Amazônia legal, o percentual de sua área afetada é de $15 \%$ se levar em conta os prejuízos causados pela fragmentação e efeito de borda.

Para o caso específico da Mata Atlântica em São Paulo, sua área que ocupava originalmente $81,8 \%$ da superficie do estado, ocupava em 1990 somente $7.16 \%$ (FUNDAÇÃO SOS MATA ATLÂNTICA \& INPE, 1993). E esse desmatamento, que é a fonte primeira da formação de fragmentos florestais, ainda continua diminuindo a área dos poucos fragmentos restantes, ou fragmentando-os ainda mais. No período de 1985 a 1990 o Brasil perdeu 5,7\% de sua área remanescente de Mata Atlântica, São Paulo perdeu 3,44\%, e as regiões de Bauru e Campinas, onde está localizada Piracicaba, perderam 4,4\% e 3,8\%, respectivamente (FUNDAÇÃO SOS MATA ATLÂNTICA \& INPE, 1993).

\subsubsection{Dinâmica de florestas naturais}

O processo de formação de clareiras, e subsequente ocupação desta por espécies arbóreas, permite a constante regeneração da floresta. A variação das clareiras em tamanho e em freqüência temporal e espacial na sua formação são importantes na diferenciação temporal e espacial da estrutura de florestas tropicais (DENSLOW, 1980). No entanto, em áreas muito perturbadas, pode ser bastante dificultado o processo de regeneração da vegetação arbórea. UHL et al. (1988) e NEPSTAD et al. (1990), trabalhando em áreas de pastagens abandonadas na 
Amazônia paraense, próximas a trechos de floresta madura, estudaram diversos fatores que dificultam ou impossibilitam a regeneração florestal. PUTZ (1984) afirma que clareiras na tha de Barro Colorado podem demorar até vinte anos para começar a serem colonizadas por espécies arbóreas pioneiras, em função do domínio imicial das espécies de cipós. Em locais onde os cipós são muito abundantes o crescimento de vegetação arbórea em clareiras pode ser impedido por anos e até décadas (PUTZ, 1980). Nos fragmentos da região de Piracicaba, pode-se observar claramente esse problema (VIANA et al., 1992; TABANEZ et al., no prelo). Diversos trechos dos fragmentos são totalmente ocupados por cipós, que cobrem todos os indivíduos arbóreos existentes. TABANEZ et al. (no prelo) fornecem dados que demonstram que, mesmo no interior de um fragmento, mais de $70 \%$ da cobertura foliar, de um total de cerca de $90 \%$, pode ser devida aos cipós.

\subsubsection{Dinâmica de populações de espécies de cipós}

Os cipós são definidos, segundo QUER (1985), como plantas trepadeiras, volúveis ou não, geralmente de caules sarmentosos, que sobem até a copa das árvores em busca de luz, onde produzem folhas e flores.

Essas plantas, também conhecidas como lianas ou trepadeiras, possuem anatomia e hábito bastante diferenciados das demais espécies vegetais. No entanto, a classificação de uma planta como tal não é simples, havendo espécies que podem ser consideradas intermediánas entre eretas e trepadeiras, e mesmo espécies que podem apresentar um ou outro hábito, dependendo de condições ambientais, como phuviosidade, duração da época seca, condições enzimáticas locais, etc. (MENNINGER, 1970).

Muitos tipos diferentes de plantas, herbáceas ou lenhosas, dicotiledôneas ou monocotiledôneas, podem ser consideradas como cipós, que podem ser diferenciados em vários tipos. MENNINGER (1970) classifica-os como lianas, "scramblers", "straggling", e "creeping". É possível aindạ a divisão de cipós em pioneiros e não pioneiros (BUDOWSKI, 1963; 1965; CAMPBELL \& NEWBERY, 1993). Neste trabalho, cipó é considerado qualquer planta, incluindo arbustos escandentes, que seja incapaz de se sustentar sem auxilio de um suporte, seja ela lenhosa ou herbácea, provida ou não de estruturas especiais de fixação.

As florestas de terras baixas das regiões tropicais são freqüentemente ricas em cipós (JANZEN, 1980). PUTZ (1983b) encontrou $20 \%$ das plantas lenhosas menores que dois metros, e $4 \%$ da biomassa total aérea devidas aos cipós, na Tha de Barro Colorado, Panamá. PEÑALOSA (1985) cita valores entre 10 e $33 \%$ das espécies como trepadeiras, em regiões tropicais, e PUTZ (1984) cita vários trabalhos os quais mostram que normalmente quase $10 \% \mathrm{da}$ biomassa total das florestas é devida aos cipós. CATHARINO (1989), estudando a florística do município de Piracicaba, encontrou 30,2\% de espécies de cipós, para 331 espécies de Magnoliophyta lenhosas. Além de representar boa parte da biodiversidade das florestas tropicais, os cipós são importantes por comumente não apresentarem caducifolia, e produzirem flores e frutos na época seca (PUTZ \& WINDSOR, 1987) ou em épocas diferentes das espécies arbóreas (MORELLATO, 1991), sendo por isso fonte importante de alimentos na época seca para a fauna.

A biomassa, no entanto, não demonstra a real importância dos cipós no ecossistema florestal tropical. Sua estratégia de crescimento, que consiste no uso de plantas eretas 
como suporte, permite uma baixa taxa de investimento em tecidos de sustentação, quando comparadas com as espécies arbóreas (PEÑALOSA, 1985). Isso faz com que, ainda que possuam baixa biomassa em uma determinada área, sua influência possa ser muito grande no ecossistema como um todo.

Os cipós apresentam características que os tornam muito agressivos quando comparados às espécies arbóreas, tais como taxa de crescimento extremamente alta (PUTZ, 1984), baixa proporção de espécies decíduas (PUTZ, 1990; PUTZ \& WINDSOR, 1987), maior período de produção de folhas durante o ano do que a vegetação arbórea (PUTZ \& WINDSOR, 1987), grande capacidade de extensão dos tecidos, alta taxa de reprodução vegetativa e baixa taxa de investimento em tecidos de sustentação (PEÑALOSA, 1985). Essa alta taxa de crescimento permite aos cipós alcançarem a copa de uma árvore, cobrí-la com sua folhagem e passar para a copa de árvores vizinhas, cobrindo até $100 \%$ de sua copa.

Poucas espécies de cipós podem crescer no interior de uma floresta, por falta de luminosidade (ACEVEDO-RODRÍGUEZ \& WOODBURY, 1985). Assim, a ocorrência dessas plantas é normalmente maior nas clareiras e nas margens da floresta, junto aos cursos de água, e em áreas de desmatamento (PUTZ, 1984).

Todos esses fatores, conjugados, fazem com que os cipós exerçam importante papel na dinâmica da floresta. Isso principalmente em relação às clareiras, interferindo na taxa de queda de árvores, e no recrutamento de plântulas e arvoretas dessas espécies que, em última circunstância, propiciam a regeneração periódica da floresta.

A fragmentação, ao mudar o microclima da floresta, tomando-a mais ihuminada e menos úmida, pode favorecer as espécies pioneiras de cipós, adaptadas a ambientes mais iluminados e mais agressivas que as espécies arbóreas, ao mesmo tempo que essas espécies, principalmente as não pioneiras, são prejudicadas. Isso faz com que, na maioria dos fragmentos florestais, eles se tomem agentes secundários de degradação, havendo uma dominância dos cipós sobre a vegetação arbórea, com danos à sua conservação. PEÑALOSA (1985) cita diversos autores que enfatizaram a inibição da regeneração de espécies arbóreas pela ocupação por cipós de áreas florestais exploradas. Assim, os cipós, ao competirem com as espécies arbóreas, controlam seu desenvolvimento, constituindo fator importante a se considerar no manejo de florestas (ACEVEDO-RODRÍGUES \& WOODBURY, 1985; BAUR, 1968), seja para produção ou para conservação.

\subsubsection{Ecologia de fragmentos florestais}

Um fragmento florestal pode ser definido como qualquer floresta natural interrompida por barreiras antrópicas ou naturais, capazes de interromper ou diminuir significativamente o fluxo de animais, pólen e/ou sementes (VIANA, 1990). Neste trabalho, mais especificamente, o termo fragmento florestal é utilizado referindo-se a fragmentos formados por atividades antrópicas.

Um fragmento florestal apresenta uma série de características que o diferenciam da floresta contínua da qual se originou. A vegetação nas bordas passa a ser afetada por uma aumento na intensidade de radiação solar e de ventos, que causa aumento no 
déficit de pressão de vapor, na temperatura do ar e diminuição de umidade no solo (KAPOS, 1989; YOUNG \& MITCHELL, 1994). Os efeitos serão proporcionalmente maiores quanto menor for o fragmento, e variáveis para diferentes hábitats e taxa considerados (LAURANCE \& YENSEN, 1991). Essas alterações microclimáticas mudam a vegetação da borda, causando incremento nas populações de espécies pioneiras, na biomassa geral, na mortalidade e na presença de cipós (PALIK \& MURPHY, 1990; WILLIAMS-LINERA, 1990; YOUNG \& MITCHELL, 1994). Essas alterações, conhecidas como efeito de borda, são variáveis, em função do tempo decorrido desde o isolamento do fragmento, e de sua orientação (KAPOS, 1989; PALIK \& MURPHY, 1990; WILLIAMS-LINERA, 1990; YOUNG \& MITCHELL, 1994). A borda também afeta o comportamento da fauna, por exemplo elevando taxas de predação em ninhos (ANDRÉN \& ANGELSTAM, 1988).

Além do efeito de borda, há outros problemas na conservação dos fragmentos florestais. Um dos mais sérios é o isolamento de populações pequenas, que têm sua sobrevivência ameaçada por problemas genéticos (GILPIN \& SOULE, 1986; JÄRVINEN, 1982), e relativos à probabilidade de extinção por fatores estocásticos (SHAFFER, 1981).

\subsubsection{Conceito de ecounidade}

As florestas podem ser consideradas aglomerados de "retalhos" de comunidades secundárias de diversas idades, ou mosaico de unidades serais (RICHARDS, 1956), idéia primeiro sugerida por Aubrévile (RICHARDS, 1979). Esse mosaico é formado pelo processo de perturbação e regeneração da floresta, que ocorre através da formação, e subseqüente ocupação pela vegetação, das clareiras. HALLÉ et al. (1978) ao discutir fases silvigenéticas, ou de formação, primária ou secundária, da floresta, rediscutem o conceito de mosaico florestal. Esses autores introduzem a terminologia de conjuntos do futuro, do presente e do passado, para um local dominado por árvores em crescimento intenso, sem potencial de crescimento, e em decadência, respectivamente. $O$ termo ecounidade, introduzido por Oldeman (1981) (citado por OLDEMAN 1983), faz alusão a uma unidade espacial da vegetação que inicia seu crescimento em um momento e sobre uma superficie bem definidos, referindo-se basicamente aos "retalhos" da floresta. Esse e outros termos, como "fase da floresta", (CLARK et al., 1993) normalmente se referem ao estágio sucessional de uma determinada fração da floresta, como clareira, trecho em reconstrução, ou trecho maduro. Apesar das limitações, o uso desses conceitos permite descrição rápida e de alta repetibilidade da história de perturbações de uma floresta (CLARK et al., 1993), assim como do estado de conservação de um fragmento florestal (ENGEL, 1993).

A utilização do conceito de ecounidades no manejo de fragmentos florestais permite que se tome relativamente rápida e simples a definição das diferentes práticas de manejo, e de onde estas devem ser aplicadas dentro de um fragmento. Seu conceito para esse trabalho foi adaptado de OLDEMAN (1983), que definiu-a como a menor unidade sucessional da floresta. Para este trabalho o conceito de ecounidade perde o caráter obrigatório de escala sucessional; e toma-se dependente simplesmente da fisionomia, e não da seqüência sucessional. $\mathrm{O}$ mapeamento em ecounidades em fragmentos de floresta de planalto é uma evolução do uso de medição do Índice de Desenvolvimento Sucessional sugerido por TABANEZ et al. (no prelo) para estudos de efeito-de-borda. 
No trabalho com fragmentos não secundários de floresta estacional semidecidual, pertencente ao domínio latu sensu da Mata Atlântica, foram identificadas quatro ecounidades (TABANEZ \& VIANA, 1994; TABANEZ et al., no prelo; VIANA \& TABANEZ, submetido; VIANA et al., submetido), a saber: capoeira baixa (CB), bambuzal (BB), capoeira alta (CA) e mata madura (MM). Essas ecounidades podem ser reconhecidas no campo por pessoas com um bom treinamento e uma boa prática de campo, sem a necessidade de trabalhos longos e dispendiosos. No entanto, há uma carência muito grande de estudos quantitativos para determinar sua validade, o que é feito neste trabalho. Essas ecounidades, identificadas a partir de remanescentes não secundários, não incluem áreas que sofreram grandes perturbações antropogênicas, como corte raso e incêndios de grandes proporções.

Capoeira baixa é uma ecounidade semelhante a clareiras (senso BROKAW, 1982), sem ou com poucas árvores, mas geralmente coberta por cipós e arbustos escandentes. A ramagem dessas plantas, subindo umas sobre as outras, ou sobre arvoretas, formam emaranhados que alcançam desde $0,5 \mathrm{~m}$ até $4,0 \mathrm{~m}$ de altura. Essa é a ecounidade com vegetação arbórea menos desenvolvida. Essa ecounidade parece ser formada tipicamente por queda de árvores, como uma clareira normal. No entanto difere desta última por apresentar presença baixa ou nula de regeneração por espécies arbóreas de qualquer estágio sucessional. Considerando-se área degradada como aquela que após distúrbio tem eliminado seus meios de regeneração natural (KAGEYAMA et al., 1992), essa ecounidade pode ser considerada como tal.

Bambuzal é uma ecounidade caracterizada por domínio de espécies de bambu de colmo de diâmetro ao redor de $5 \mathrm{~cm}$ de diâmetro, e baixa densidade de indivíduos arbustivo-arbóreos.

Capoeira alta é uma ecounidade com dossel entre 10 e 15 metros de altura, mas também com presença de cipós na maioria dos indivíduos arbóreos. $O$ dossel não é contínuo, e o sub-bosque é também dominado por cipós.

A mata madura se caracteriza por ser a vegetação mais desenvolvida, com dossel contínuo a 20-25 metros de altura, e presença de indivíduos emergentes. Os cipós ocorrem em baixa densidade, e o sub-bosque é dominado por grande número de arvoretas de espécies típicas desse ambiente (esciófitas).

\subsubsection{Problema de pesquisa}

Os pequenos fragmentos florestais, mais sujeitos a alterações, e, pelo seu grande número, podendo representar uma gama muito grande da diversidade da paisagem, possuem especial importância para a conservação. Apesar da grande importância desses fragmentos, muito pouco se sabe sobre sua ecologia e manejo, importantes para o desenvolvimento de estratégias eficazes de conservação.

Este trabalho procura responder às seguintes questões: (i) são os fragmentos florestais auto-sustentáveis?; (ii) é possível auxiliar o processo de regeneração da vegetação 
arbórea através do manejo?. Essas questões são discutidas pelo estudo de ecounidades em um fragmento florestal e o efeito do manejo de populações de cipós sobre a sua dinâmica.

\subsubsection{Hipóteses}

i) o nível de degradação dos fragmentos florestais pode ser medido pela proporção entre as várias ecounidades que o formam;

ii) a sucessão nos fragmentos está estagnada, fazendo com que os fragmentos não sejam auto-sustentáveis;

iii) o cipó é, em clareiras de fragmentos florestais, um fator de estagnação da sucessão.

\subsubsection{Predições}

i) as ecounidades, identificadas fisionomicamente pela estrutura da vegetação, devem diferir significativamente entre si em diversidade, cobertura foliar de cipós, área basal, densidade de indivíduos arbóreos;

ii) as clareiras sem intervenção devem apresentar baixa taxa de regeneração de espécies arbóreas, pequeno crescimento de indivíduos arbóreos já existentes e dominância de cipós;

iii) o manejo de clareiras através do controle de cipós, e do controle de cipós mais plantio de enriquecimento, proporciona a facilitação do processo de sucessão natural da vegetação arbórea, com aumento significativo no recrutamento de indivíduos de espécies arbóreas, na densidade de indivíduos arbóreos e em sua área basal.

\subsubsection{Objetivos}

O primeiro objetivo desse trabalho é caracterizar as ecounidades encontradas em fragmentos de floresta estacional semidecidual, e analisar a correlação entre ecounidades identificadas com base nas características estruturais da floresta, com os dados quantitativos da vegetação arbórea.

O segundo objetivo é estudar o efeito do manejo dessas ecounidades para a conservação desses fragmentos.

\subsubsection{Estrutura da tese}

Esta tese é composta de capítulos que são praticamente trabalhos independentes entre si, ainda que cada um seja referência obrigatória dos outros. Esse primeiro capítulo serve como introdução geral ao assunto comum aos capítulos que seguem. Os três capítulos seguintes discutem trabalhos específicos, que serão publicados na forma de trabalhos independentes. $O$ último capítulo serve como conclusão geral. 


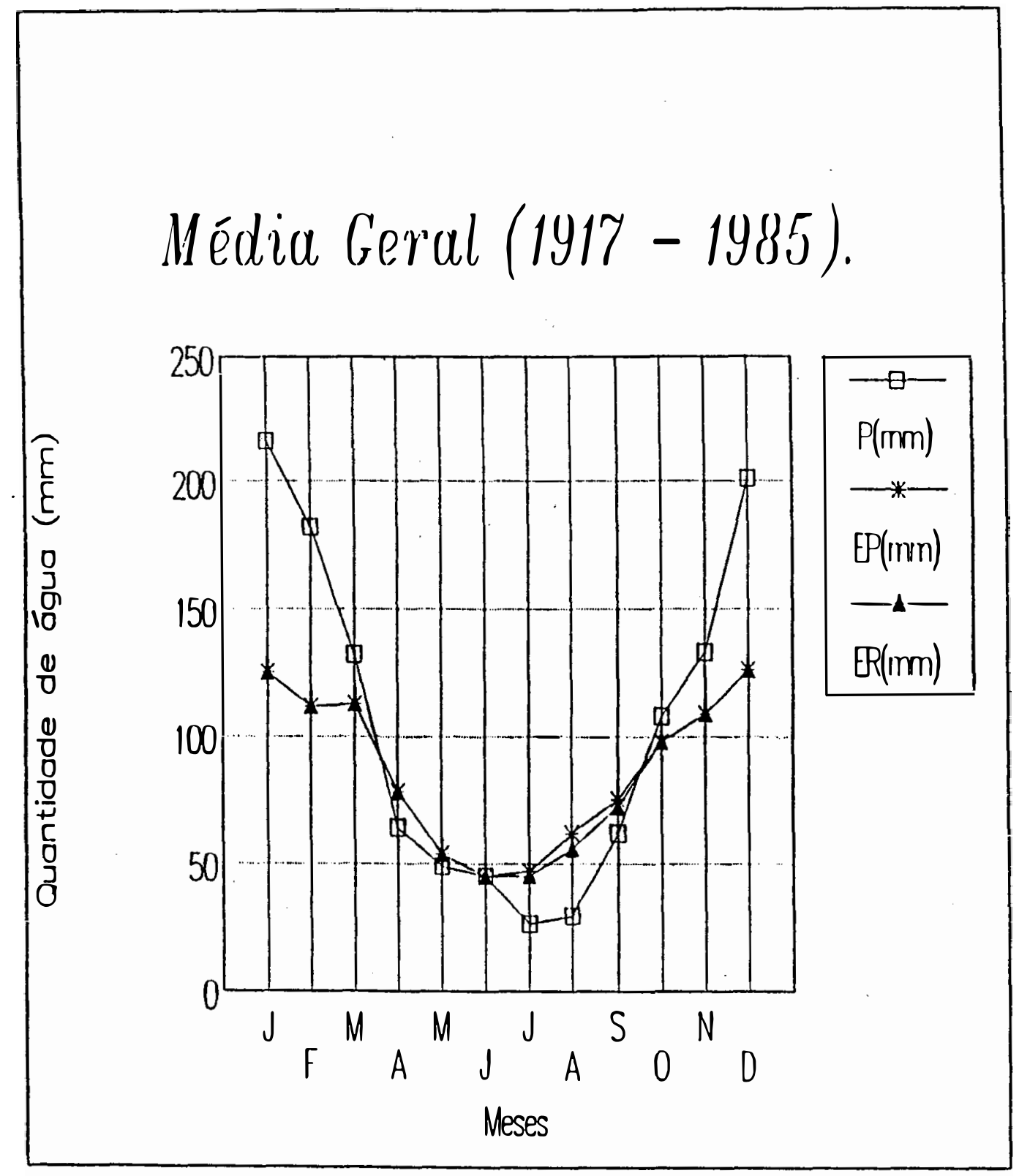

Figura 1 - Diagrama climático, método Thorntwaite \& Matter, para os anos de 1917 a 1985 (média), para Piracicaba, SP. Precipitação total de 1.247mm. Deficiência hídrica de $11 \mathrm{~mm}$. Extraído de CATHARINO (1989). 


\subsection{MATERIAL E MÉTODOS}

1.2.1. Caracterização da área

\subsubsection{Localização}

O estudo foi realizado em um fragmento de floresta estacional semidecidual no município de Piracicaba, na região central do estado de São Paulo. As coordenadas aproximadas do município são $22^{\circ} 43^{\prime} \mathrm{S}$ e $47^{\circ} 25^{\prime} \mathrm{W}$, e sua altitude $580 \mathrm{~m}$.

\subsubsection{Clima}

O clima da região é do tipo Cwa pelo sistema de Koeppen, mesotérmico ou subtropical úmido, com inverno seco. A pluviosidade média anual é de $1.247 \mathrm{~mm}$ (período de 1917 a 1985). De abril a setembro (6 meses) a pluviosidade é menor que $100 \mathrm{~mm}$ (CATHARINO, 1989). O diagrama climático do município é mostrado na Figura 1.

\subsubsection{Vegetação}

As formações vegetais naturais da região são: floresta estacional semidecidual, cerrado e floresta de várzea.

Atualmente a região é predominantemente coberta pela agricultura, principalmente da cana-de-açúcar. Provavelmente todos os remanescentes florestais da região sofreram algum tipo de alteração no passado, particularmente corte seletivo de espécies de maior valor econômico (CATHARINO, 1989). Os remanescentes de floresta nativa ocupam atualmente apenas $0,81 \%$ da região ao redor do município (TABANEZ et al., 1994). 
CAPÍTULO 2

\section{ESTRUTURA DE ECOUNIDADES EM UM FRAGMENTOS DE FLORESTA ESTACIONAL SEMIDECIDUAL}

\subsection{INTRODUÇÃO}

Um fragmento florestal pode ser definido como qualquer floresta natural interrompida por barreiras antrópicas ou naturais, capazes de interromper ou diminuir significativamente o fluxo de animais, pólen e/ou sementes (VIANA, 1990). Neste trabalho, mais especificamente, o termo fragmento florestal é utilizado referindo-se a fragmentos formados por atividades antrópicas. Esses fragmentos, após sua formação e isolamento, passam por processos diversos que afetam sua ecologia. $O$ efeito de borda e o isolamento de populações são fatores que afetam fortemente esses fragmentos, alterando-os e ameaçando sua conservação.

As florestas, aí compreendidos os fragmentos florestais, podem ser consideradas aglomerados de "retalhos" de comunidades secundárias de diversas idades, ou mosaico de unidades serais (RICHARDS, 1956). O termo ecounidade, introduzido por Oldeman (1981) (citado por OLDEMAN 1983), faz alusão a uma unidade espacial da vegetação que inicia seu crescimento em um momento e sobre uma superficie bem definidos, referindo-se basicamente aos "retalhos" da floresta. Apesar das limitações, o uso desses conceitos permite descrição rápida e de alta repetibilidade da história de perturbações de uma floresta (CLARK et al., 1993), assim como do estado de conservação de um fragmento florestal (ENGEL, 1993).

A utilização do conceito de ecounidades no manejo de fragmentos florestais permite que se torne relativamente rápida e simples a definição de diferentes práticas de manejo, e de onde estas devem ser aplicadas dentro de um fragmento. Para este trabalho o conceito de ecounidade perde o caráter obrigatório de escala sucessional (definido por OLDEMAN (1983)), e torna-se dependente simplesmente da fisionomia, e não da seqüência sucessional. $\mathrm{O}$ mapeamento em ecounidades em fragmentos de floresta de planalto é uma evolução do uso de medição do Índice de Desenvolvimento Sucessional sugerido por TABANEZ et al. (no prelo) para estudos de efeito-de-borda. Trabalhos com fragmentos não secundários de floresta estacional semidecidual, pertencente ao domínio latu sensu da Mata Atlântica, identificaram quatro ecounidades (TABANEZ \& VIANA, 1994; TABANEZ et al., no prelo; VIANA \& TABANEZ, submetido; VIANA et al., submetido), a saber: capoeira baixa (CB), bambuzal (BB), capoeira alta (CA) e mata madura (MM). Essas ecounidades podem ser reconhecidas no campo por pessoas com um bom treinamento e uma boa prática de campo, sem a necessidade de trabalhos longos e dispendiosos. No entanto há uma carência muito grande de estudos quantitativos para determinar sua validade, o que é feito neste trabalho. Essas ecounidades, identificadas a partir de remanescentes não secundários, não incluem áreas que sofreram grandes perturbações antropogênicas, como corte raso e incêndios de grandes proporções.

Capoeira baixa é uma ecounidade semelhante a clareiras (senso BROKAW, 1982), sem ou com poucas árvores, mas geralmente coberta por cipós e arbustos escandentes (Figuras 1 e 2). A ramagem dessas plantas, subindo umas sobre as outra, ou sobre arvoretas, 


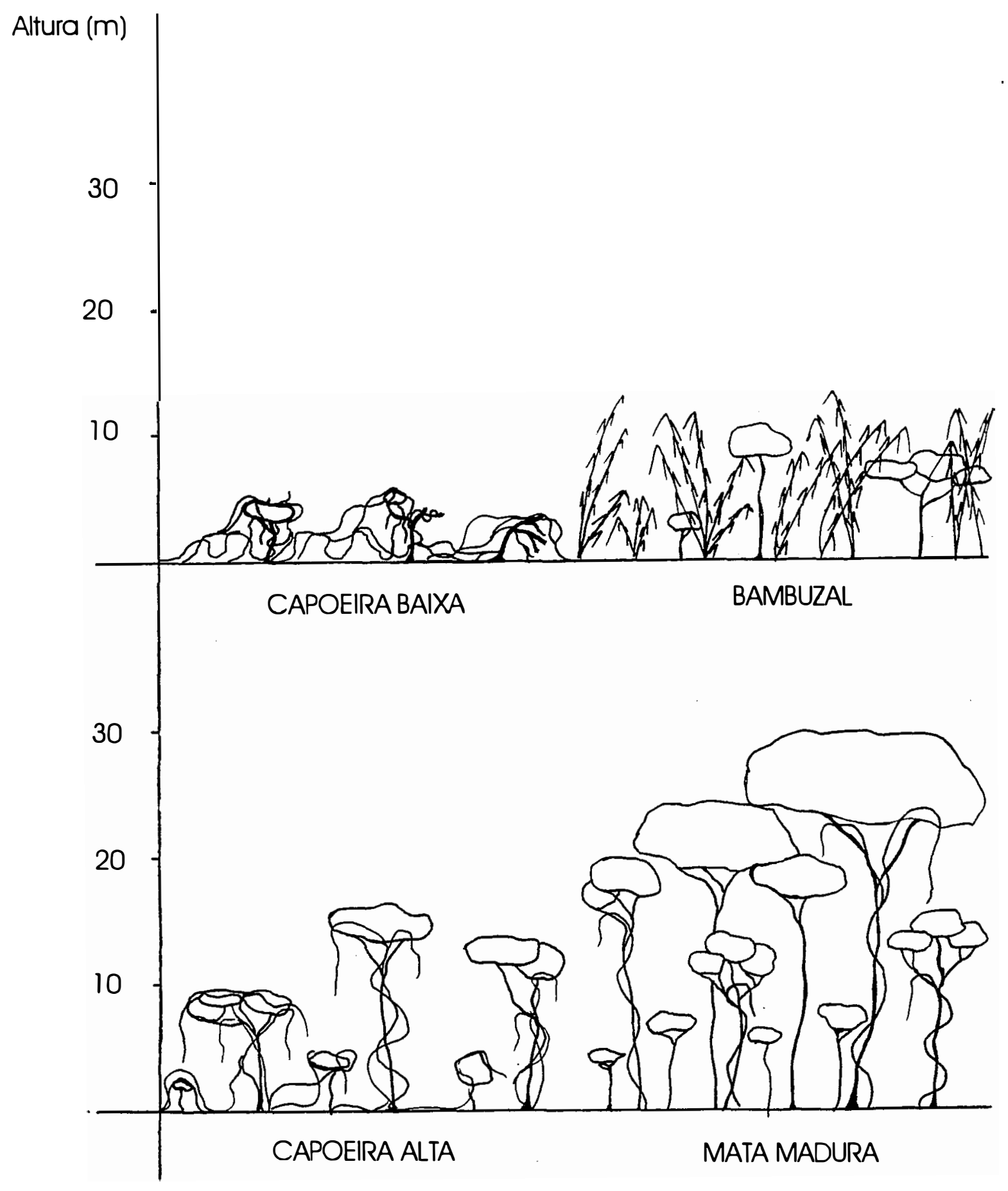

Figura 1 - Perfis esquemáticos das quatro ecounidades consideradas neste estudo. 


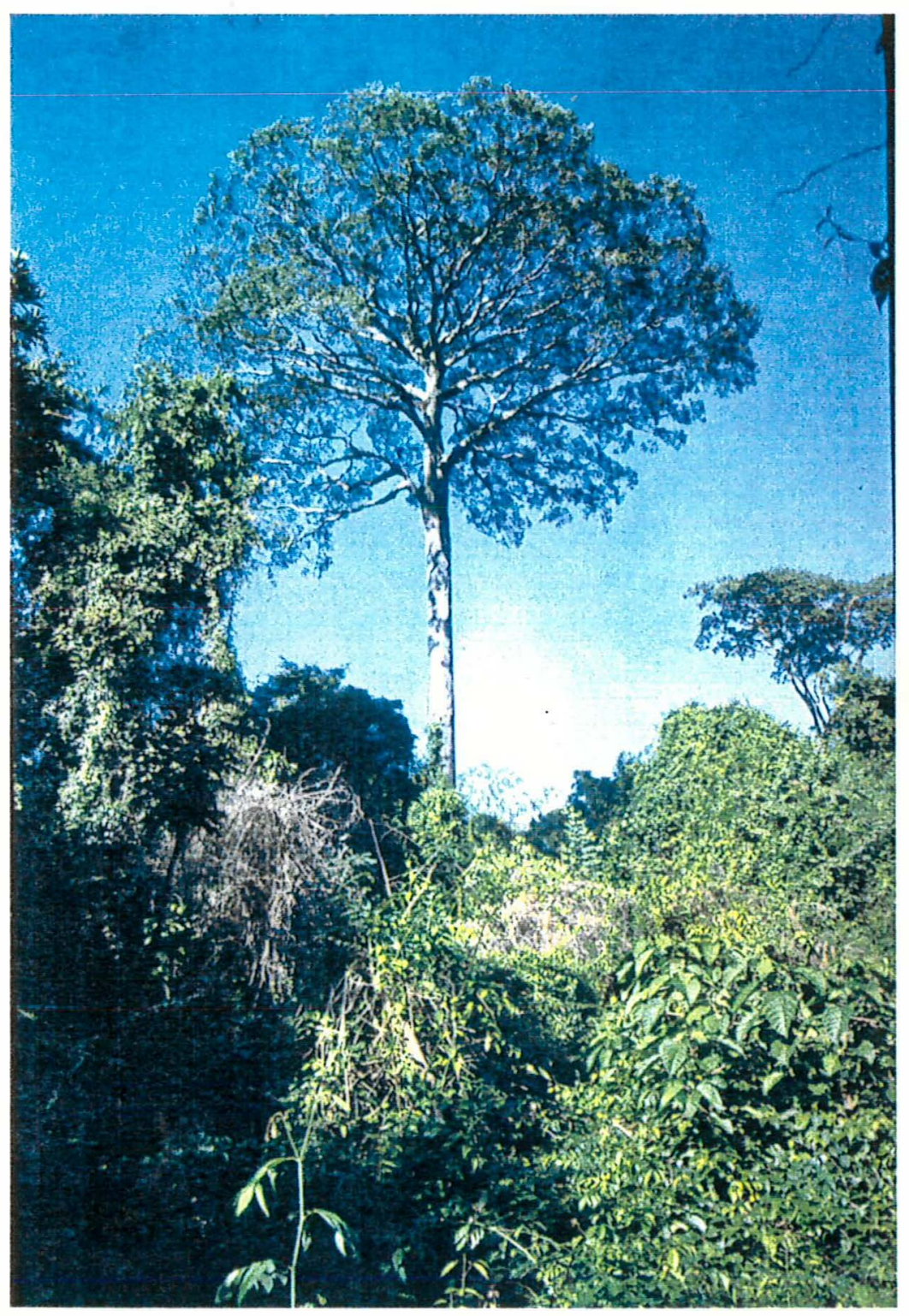

Figura 2 - Trecho da ecounidade capoeira baixa. Observe a diferença de altura entre a árvore isolada e a vegetação ao redor, dominada por espécies de lianas. 


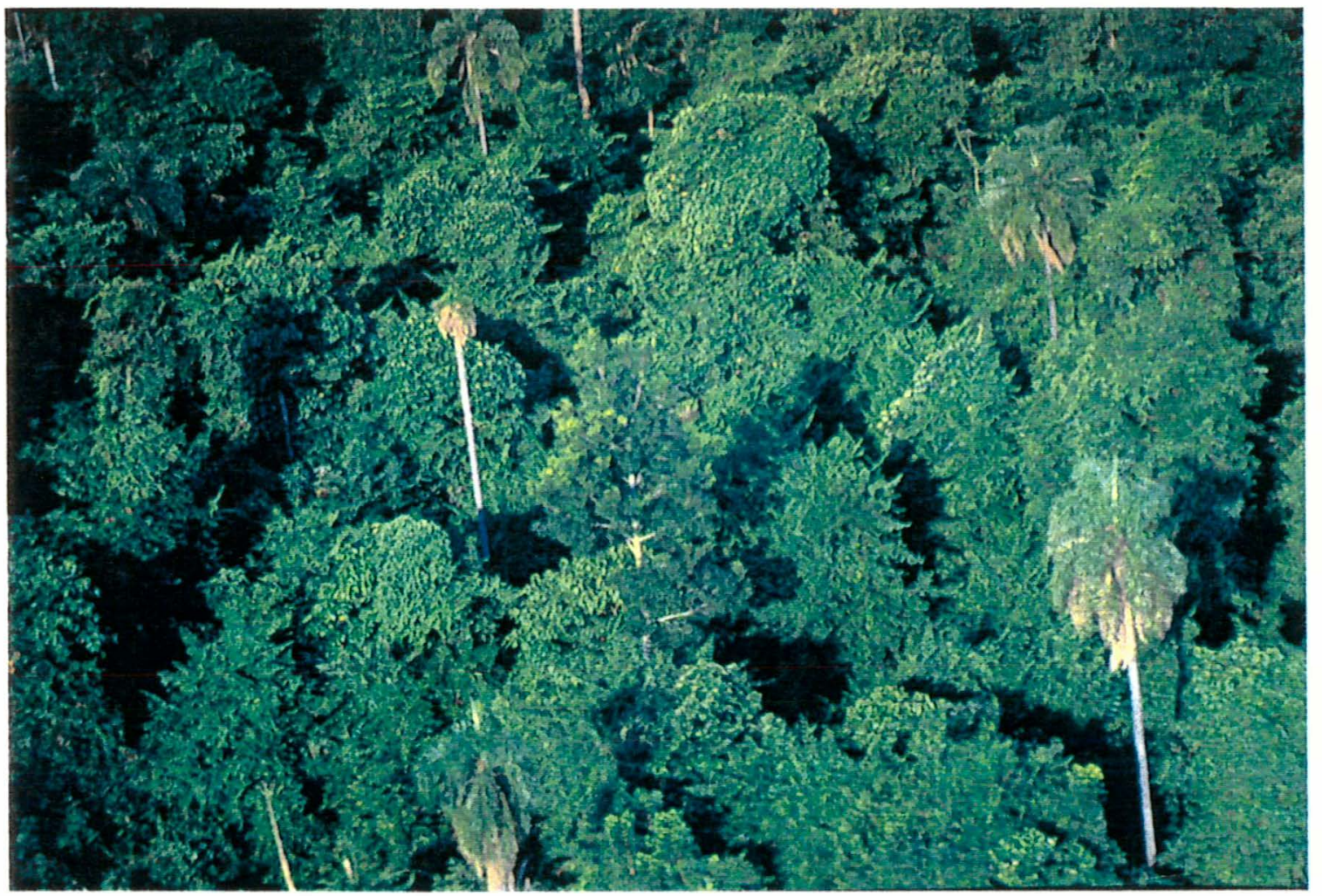

Figura 3 - Visão aérea da ecounidade capoeira alta. Observe a ocorrência de vários indivíduos com copa coberta por espécies de lianas. 
formam emaranhados que alcançam desde $0,5 \mathrm{~m}$ até $4,0 \mathrm{~m}$ de altura. Essa é a ecounidade com vegetação arbórea menos desenvolvida. Essa ecounidade parece ser formada tipicamente por queda de árvores, como uma clareira normal. No entanto difere desta última por apresentar presença baixa ou nula de regeneração por espécies arbóreas de qualquer estágio sucessional. Considerando-se área degradada como aquela que após distúrbio tem eliminado seus meios de regeneração natural (KAGEYAMA et al., 1992), essa ecounidade pode ser considerada como tal.

Bambuzal é uma ecounidade caracterizada por um forte domínio de espécies de bambu de médio calibre ( $\pm 5 \mathrm{~cm}$ de diâmetro), e baixa densidade de espécies arbustivoarbóreas (Figura 1).

Capoeira alta é uma ecounidade de vegetação arbórea com dossel entre 10 e 15 metros de altura, mas também com forte presença de cipós na maioria dos indivíduos arbóreos (Figuras 1 e 3). $\mathrm{O}$ dossel não é contínuo, e o sub-bosque é também dominado por cipós.

A mata madura se caracteriza por uma vegetação mais desenvolvida, com dossel contínuo a 20-25 metros de altura, e presença de indivíduos emergentes (Figura 1). Os cipós ocorrem em baixa densidade, e o sub-bosque é dominado por grande número de arvoretas de espécies típicas desse ambiente (esciófitas).

\subsubsection{Problema de pesquisa}

Os fragmentos florestais sofrem alterações na sua estrutura e na sua dinâmica em função de diversos fatores, entre os quais o seu histórico de perturbação, área, forma, tipo de vizinhança e grau de isolamento (VIANA, 1990). Essas alterações podem ser pesquisadas pelo estudo de ecounidades. Esse trabalho procura responder à seguinte questão: i) as ecounidades podem ser usadas para quantificar o grau de conservação de um fragmento florestal?

\subsubsection{Hipótese}

i) o nível de degradação dos fragmentos florestais pode ser medido pela proporção entre as várias ecounidades.

\subsubsection{Predição}

i) as ecounidades, reconhecidas pela estrutura da vegetação, devem diferir significativamente entre elas em diversidade, cobertura foliar total e por cipós, área basal e densidade de indivíduos arbóreos.

\subsubsection{Objetivo}

O objetivo deste trabalho é caracterizar as ecounidades encontradas em um fragmento de floresta estacional semidecidual, e analisar a correlação entre essas ecounidades 


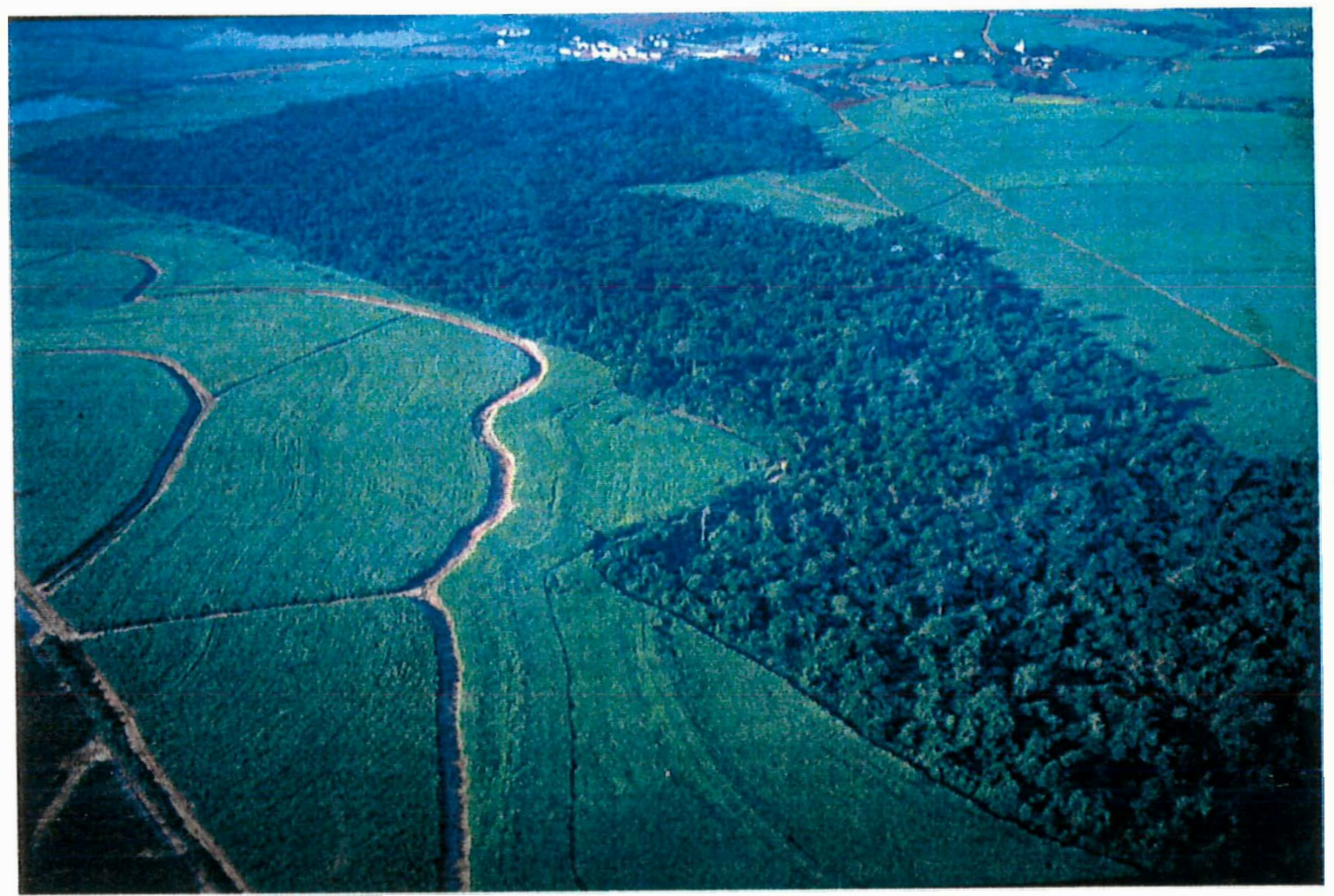

Figura 4 - Visão aérea do fragmento estudado. 
identificadas com base nas características estruturais da floresta, com os dados quantitativos da vegetação arbórea. '

\subsection{MATERIAL E MÉTODOS}

\subsubsection{Obtenção dos dados}

\subsubsection{Escolha do fragmento}

A escolha do fragmento para este estudo condicionou-se à representatividade da floresta em relação ao padrão da região, histórico de perturbação, tamanho, à concordância do proprietário em colaborar com o estudo e à facilidade de acesso.

Para conhecer o histórico de perturbação do fragmento, foram feitas entrevistas com o proprietários e funcionários e moradores da fazenda. As questões básicas que eram respondidas pelos entrevistados foram: tpo e intensidade de qualquer exploração ou uso anterior, época em que as atividades foram desenvolvidas, em que situação é mantida atualmente, e fatores históricos que levaram à sua preservação. $\mathrm{O}$ fragmento estudado tem como histórico a exploração de madeira de forma apenas seletiva, e limitada à primeira metade do século. Não há conhecimento de corte raso ou de incêndios de grandes proporções.

O fragmento estudado localiza-se na Fazenda Capuava, no município de Piracicaba, a cerca de 15 quilômetros do centro da cidade, às margens da rodovia SP-127 (Piracicaba-Rio Claro). Sua área é de 86 ha, coberta por uma floresta densa, mas de dossel bastante irregular. A presença de cipós também é marcante em diversos trechos do fragmento, formando densos emaranhados em alguns lugares. É cortado por uma pequena estrada e seu formato é longilíneo (Figuras 4 e 5). Seu isolamento em relação a outros fragmentos é total. Esse fragmento pode ser considerado padrão para a região, em relação a remanescentes primários, com excessão do seu tamanho, que é bastante grande.

\subsubsection{Instalação das parcelas}

O estudo foi feito com o uso de três transectos perpendiculares às bordas e paralelos entre si, que cruzam o fragmento, retangulares, com largura de 10 metros, e comprimento variável, de uma borda à outra (Figura 5). O transecto 1 mede $389,4 \mathrm{~m}$, enquanto os transectos 2 e 3 medem 538,0m e 413,5m respectivamente.

\subsubsection{Coleta de dados dos indivíduos de espécies arbóreas}

Dentro dos transectos todas as árvores com DAP (diâmetro à altura do peito) igual ou superior a $5 \mathrm{~cm}$ foram etiquetadas, identificadas, e tiveram seus DAPs anotados. A identificação foi feita no campo, com o uso de binóculos, ou comparando-se o material coletado, na sua grande maioria estéril, ao material do herbário da ESALQ/USP, e com consultas a especialistas. Algumas árvores não foram identificadas, ou porque eram muito altas, não permitindo a coleta, ou porque estivessem com a copa completamente cobertas por cipós, não permitindo a visualização da sua folhagem. Algumas espécies não foram identificadas, sendo classificadas como indeterminadas. 


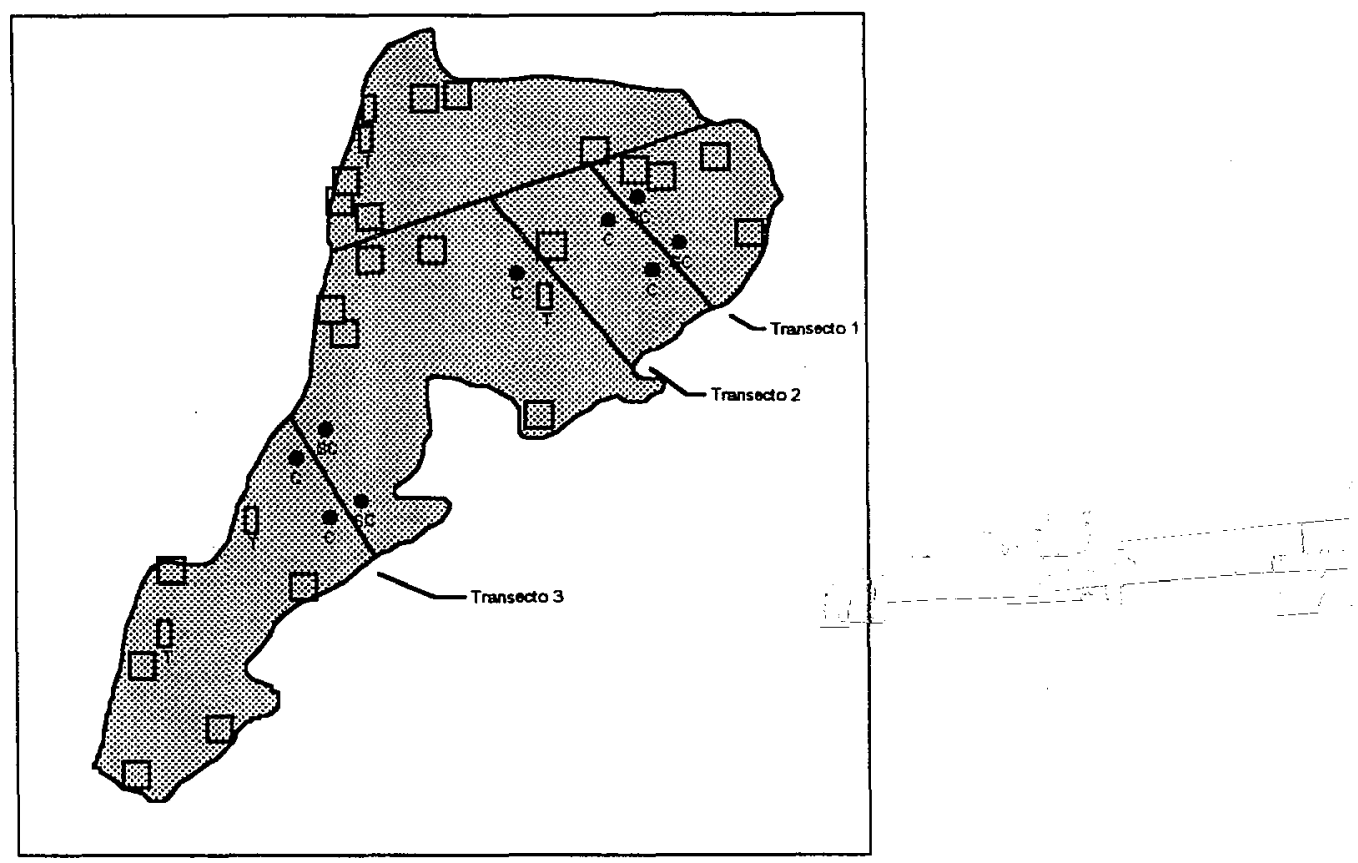

Figura 5 - Mapa do fragmento estudado, onde se vê a estrada que corta o fragmento, os transectos para estudo da vegetação, e as parcelas dos experimentos de manejo. Quadrados = parcelas do experimento de capoeira baixa dos tratamentos 1 a 4; retângulos $=$ parcelas testemunhas do mesmo experimento; círculos cheios $=$ parcelas do experimento de manejo de capoeira alta; $\mathrm{C}=$ parcelas com corte de cipós; $\mathrm{SC}=$ parcelas sem corte de cipós (testemunhas). Escala aproximada 1:21757.

\subsubsection{Mapeamento de ecounidades}

As ecounidades foram mapeadas dentro dos transectos, através de um levantamento expedito (ABATE, 1992). A vegetação da borda foi incluída no mapeamento. O levantamento expedito neste trabalho consistiu de caminhadas feitas pelos transectos dentro do fragmento, onde era observada a estrutura da vegetação e, conseqüentemente, a ecounidade que ocupava cada trecho. Esse mapeamento pode ser feito rapidamente e por um baixo custo por pessoas com bom conhecimento teórico e experiência de campo.

\subsubsection{Medição de cobertura foliar}

A medição da cobertura foliar total foi feita adaptando-se o método descrito em BROWER \& ZAR (1990), e já utilizada em TABANEZ et al. (no prelo), com o uso de uma armação quadrada de $0,5 \mathrm{~m}$ de lado, de cano de PVC, com fios de nylon formando um quadriculado no seu interior com quadrados de $10 \mathrm{~cm}$ de lado. Uma pessoa em pé olha para cima através dessa armação e conta o número de quadrados onde se vê mais de $50 \%$ de sua área coberta por folhas. $O$ percentual desses quadrados é considerado o percentual de cobertura foliar no local. A cobertura foliar foi medida em parcelas de $10,0 \mathrm{~m} \times 10,0 \mathrm{~m}$, dentro dos transectos de inventário da vegetação. Nessas parcelas de $100 \mathrm{~m}^{2}$ foram sorteados 25 quadrados de $0,5 \mathrm{~m}$ de lado, onde foi medida a cobertura foliar total. Utilizou-se uma parcela por ecounidade. Seguindo-se à medição de cobertura foliar total, foi estimado, visualmente, o percentual de cobertura por cipós da copa de cada árvore existente dentro 
parcela. Com o percentual de cobertura foliar total, e com o percentual médio de cobertura das árvores por cipó, por diferença encontrou-se o percentual de cobertura foliar devido às árvores e o percentual devido aos cipós. Esse método só considera a cobertura foliar acima de $2,2 \mathrm{~m}$, equivalente à altura de um homem adulto com o braço erguido. Em cada transecto foi medida a cobertura foliar em um ponto para capoeira baixa e alta, e na mata madura foi medida em dois transectos, por só existirem trechos dessa ecounidade em dois dos três transectos. No bambuzal a cobertura foliar não foi medida por se considerar que os cipós não são fator fundamental da dinâmica nessa ecounidade.

\subsubsection{Análise dos dados}

\subsubsection{Estrutura da vegetação}

Para a análise de estrutura da vegetação foram calculados os seguintes parâmetros fitossociológicos para as espécies estudadas:

$$
\begin{aligned}
& \mathrm{DA}_{\mathrm{i}}=\mathrm{x}_{\mathrm{i}} / \mathrm{á}_{\text {rea amostrada em ha }} \\
& \mathrm{DR}_{\mathrm{i}}=\left(\mathrm{x}_{\mathrm{i}} / \mathrm{x}_{\mathrm{i}}\right)^{*} 100 \\
& \mathrm{DoA}_{\mathrm{i}}=\mathrm{A}_{\mathrm{i}} / \text { área amostrada em ha } \\
& \mathrm{DoR}_{\mathrm{i}}=\mathrm{A}_{\mathrm{i}} / \mathrm{A}_{\mathrm{t}}{ }^{*} 100 \\
& \mathrm{FA}_{\mathrm{i}}=\left(\mathrm{N}_{\mathrm{i}} / \mathrm{N}_{\mathrm{t}}\right)^{*} 100 \\
& \mathrm{FR}_{\mathrm{i}}=\left(\mathrm{FAA}_{\mathrm{i}} / \mathrm{FA}\right)^{*} 100 \\
& \mathrm{IVC}_{\mathrm{i}}=\mathrm{DR}_{\mathrm{i}}+\mathrm{DoR}_{\mathrm{i}} \\
& \mathrm{IVI}_{\mathrm{i}}=\mathrm{DR}_{\mathrm{i}}+\mathrm{DoR}_{\mathrm{i}}+\mathrm{FR}_{\mathrm{i}}
\end{aligned}
$$

onde:

$$
\begin{aligned}
& D A_{i}=\text { densidade absoluta da espécie } i(\text { indivíduos/ha) } \\
& D R_{i}=\text { densidade relativa da espécie } \mathrm{i}(\%) \\
& D A_{i}=\text { dominância absoluta da espécie } \mathrm{i}\left(\mathrm{m}^{2} / \mathrm{ha}\right) \\
& \mathrm{DoR}_{\mathrm{i}}=\text { dominância relativa da espécie } \mathrm{i}(\%) \\
& \mathrm{FA}_{\mathrm{i}}=\text { freqüência absoluta da espécie } \mathrm{i}(\%) \\
& \mathrm{FR}_{\mathrm{i}}=\text { freqüência relativa }(\%) \\
& \mathrm{x}_{\mathrm{i}}=\text { número de indivíduos da espécie } \mathrm{i} \\
& \mathrm{x}_{\mathrm{t}}=\text { número de indivíduos total } \\
& \mathrm{A}_{\mathrm{i}}=\text { área basal total da espécie } \mathrm{i} \\
& \mathrm{A}_{\mathrm{t}}=\text { somatória da área basal de todas as espécies } \\
& \mathrm{N}_{\mathrm{i}}=\text { número de subparcelas em que a espécie i ocorre } \\
& \mathrm{N}_{\mathrm{t}}=\text { número de total de subparcelas } \\
& \mathrm{IVC}_{\mathrm{i}}=\text { de valor de cobertura da espécie } \mathrm{i} \\
& \mathrm{IVI}_{\mathrm{i}}=\text { de valor de importância da espécie } \mathrm{i}
\end{aligned}
$$

Para o cálculo de freqüência foi considerada uma sub-parcela a cada 10 metros lineares $\left(100 \mathrm{~m}^{2}\right)$ das parcelas de estudo.

Foi também calculado o índice de Shannon-Wiener, utilizando-se a fórmula:

$$
\begin{aligned}
& \mathrm{ID}=-\Sigma\left(\left(\mathrm{x}_{\mathrm{i}} / \mathrm{x}_{\mathrm{t}}\right)^{*} \mathrm{LN}\left(\mathrm{x}_{\mathrm{i}} / \mathrm{x}_{\mathrm{t}}\right)\right), \text { onde } \\
& \mathrm{LN}=\log \text { aritmo de base } e \text { (logaritmo neperiano) }
\end{aligned}
$$

Este índice foi calculado para o fragmento, assim como para cada ecounidade. Para o cálculo por ecounidade foram utilizados trechos de $100 \mathrm{~m}^{2}$ dentro de cada uma delas. 
O ID foi calculado para tantos trechos quanto permitia a área de cada ecounidade dentro das parcelas, com exceção da ecounidade capoeira alta. Esta ecounidade, por ser a que ocupa maior área dentro das parcelas, permitiria cálculo em área maior do que a utilizada, mas que não o foi para que sua área considerada não ficasse demasiado diferente das outras ecounidades.

Para converter o índice encontrado neste trabalho, calculado com logaritmo com base $e$, para um calculado com base 10 e com base 2, deve-se multiplicá-lo por 0,4343 e 1,4427, respectivamente (BROWER \& ZAR, 1990).

As árvores não identificadas (muito altas e cobertas por cipós) foram colocadas em categorias próprias na análise fitossociológica.

Para se analisar a estrutura de idade de algumas espécies presentes no fragmento, foram montados gráficos de distribuição diamétrica para as espécies mais comuns. Isso foi feito apenas para as espécies com 14 ou mais indivíduos no levantamento (as curvas feitas com números inferiores, normalmente, apresentavam muitos intervalos intermediários de diâmetro sem indivíduos, o que dificultava qualquer análise). As distribuições diamétricas dessas espécies foram comparadas usando o teste Kolmogorov-Smimov para comparação de duas distribuições (SOKAL \& ROHLF, 1981). Ramificações originadas abaixo de 1,3m (altura do DAP) foram consideradas como indivíduos para essa análise. Somente espécies de grande porte foram consideradas nessa análise, para que fosse possível a comparação das suas curvas sem restrições, ou seja, o tamanho adulto das diferentes espécies é aproximadamente o mesmo (acima de $70 \mathrm{~cm}$ de DAP). O intervalo de diâmetro considerado é de $5 \mathrm{~cm}$ para permitir comparações com outros estudos que discutem curvas de distribuição diamétrica em florestas do mesmo tipo.

Analisando-se separadamente cada uma das distribuições dessas espécies, percebeu-se a posteriori que as espécies tolerantes (ver definição à página 20) em geral apresentavam distribuições semelhantes entre si. $O$ mesmo acontecia com as espécies oportunistas. Assim, essas espécies foram agrupadas para permitir a análise comparativa entre grupos sucessionais, ao invés de espécies individuais. Para checar a adequação de se incluir cada espécie dentro de cada categoria, testou-se a curva de distribuição diamétrica de cada espécie contra a curva de sua categoria sucessional, sem os indivíduos da espécie sendo testada (teste Kolmogorov-Smimov para comparação de duas distribuições).

\subsubsection{Diferenças entre ecounidades}

As diferentes ecounidades foram comparadas, em termos de área basal, árvores por ha, cobertura foliar total, arbórea e de cipós, e índice de diversidade, com o uso de teste $\mathrm{F}$ de um fator, e em caso de significância, com um teste de Tukey. Essas variáveis foram todas calculadas em trechos de $100 \mathrm{~m}^{2}$, utilizando-se vários trechos por ecounidade para se ter sua média. 


\subsection{RESULTADOS E DISCUSSÃO}

\subsubsection{Estrutura da vegetação do fragmento}

A tabela 1 traz algumas informações sobre o fragmento estudado, assim como para outros fragmentos do mesmo ecossistema na região para efeito de comparação (TABANEZ \& VIANA, dados não publicados).

O número de espécies encontradas, ainda que alto, pode ser considerado subestimado. Isso porque há muitos indivíduos não identificados, a maioria por estar totalmente coberta por cipós, impedindo a coleta de qualquer material botânico (119 indivíduos), e um por ser alto demais $(10,4 \%$ e $0,09 \%$ dos indivíduos amostrados, respectivamente).

Tabela 1 - Dados sobre fragmentos estudados da região. O fragmento 3 é o fragmento estudado neste trabalho. Frag = fragmento; $I D=$ índice de diversidade de Shannon-Wiener; No. de espécies $=$ número de espécies encontradas; $\%$ spp raras $=$ percentual de espécies raras. Fonte: TABANEZ \& VIANA, dados não publicados.

\begin{tabular}{|c|c|c|c|c|c|c|c|c|}
\hline Frag & $\begin{array}{l}\text { Área total } \\
\text { (ha) }\end{array}$ & $\begin{array}{l}\text { Área } \\
\text { amostrada } \\
\text { (ha) }\end{array}$ & $\begin{array}{l}\text { Árvores } \\
\text { amostradas } \\
\text { (total) }\end{array}$ & \begin{tabular}{|l|} 
Árvores \\
mortas \\
$(\%)$
\end{tabular} & $\begin{array}{l}\text { Área } \\
\text { basal }\left(\mathrm{m}^{2} /\right. \\
\text { ha }\end{array}$ & ID & $\begin{array}{l}\text { No. de } \\
\text { espécies }\end{array}$ & $\begin{array}{l}\% \text { spp } \\
\text { raras }\end{array}$ \\
\hline 1 & 0,7 & 0,1045 & 167 & 14,4 & 12,50 & 2,73 & 38 & 65,8 \\
\hline 2 & 9,5 & 0,7670 & 713 & 10,1 & 12,53 & 3,83 & 101 & 38,6 \\
\hline 3 & 86,0 & \begin{tabular}{|l|}
1,3894 \\
\end{tabular} & 1141 & 8,1 & 15,62 & 4,89 & 128 & 34,4 \\
\hline 4 & 220,0 & 1,2000 & 953 & 13,8 & 15,12 & 3,94 & 119 & 36,1 \\
\hline
\end{tabular}

Ao mesmo tempo, o número de espécies encontradas pode ser considerado uma superestimativa. Isso porque um número desconhecido dessas espécies estariam em processo de extinção local pelo pequeno número de indivíduos existentes (ver discussão abaixo), falta de polinizadores (AIZEN \& FEINSINGER, 1994), e falta de condições ambientais para regeneração e/ou sobrevivência.

O índice de diversidade encontrado é semelhante ao de outros trabalhos feitos em florestas de planalto, mas é em geral maior, mesmo que os encontrados em fragmentos maiores (CAVASSAN et al., 1984; CESAR \& LEITÃO FILHO, 1990; COSTA, 1992; MARTINS, 1979; PAGANO, 1985). Esse alto índice, não só para o fragmento estudado como para os outros fragmentos da tabela 1 , mostra a importância desse fragmento na conservação da biodiversidade desse ecossistema.

Uma outra característica de todos os fragmentos da tabela 1 é o grande percentual de espécies raras (espécies das quais se encontrou apenas um indivíduo no levantamento), em geral ao redor de $36,5 \%$, chegando até a $65,8 \%$ para o fragmento 1 . Em levantamentos fitossociológicos de floresta de planalto têm sido encontrados valores menores (CAVASSAN et al., 1984; CESAR \& LEITẪ FILHO, 1990; COSTA, 1992; MARTINS, 1979; PAGANO, 1985) provavelmente devido a diferenças na amostragem, ou eventualmente em função de serem fragmentos de maior tamanho que os aqui estudados. 
As florestas tropicais apresentam normalmente um alto percentual de espécies raras (HUBBELL \& FOSTER, 1983), adaptadas a essa condição de raridade. No entanto, em fragmentos essa raridade implica em uma população total pequena, já que o isolamento limita ou impede a troca de material genético com outros fragmentos. Ainda que muitas espécies vegetais possam apresentar normalmente algum nivel de endocruzamento (SCHEMSKE \& LANDE, 1985), a maior parte das espécies arbóreas tropicais tem predominância de reprodução cruzada e/ou auto-incompatibilidade (BAWA, 1974; BAWA et al., 1985). Assim, a maior freqüência de endocruzamento e cruzamento entre parentes (endogamia) pode levar a uma redução acentuada no valor adaptativo dos indivíduos, mesmo em plantas que possam apresentar tanto auto-fecundação como fecundação cruzada (FUTUYMA, 1993). Essa diminuição no valor adaptativo aumenta o risco de extinção local das espécies, diminuindo a diversidade dos fragmentos. Além disso, processos estocásticos ambientais, demográficos, genéticos e catástrofes naturais tendem a aumentar o risco de extinção de populações de pequeno tamanho (SHAFFER, 1981). Os fragmentos citados na tabela 1 são todos isolados, e a troca de material genético entre eles, ou entre eles e outros fragmentos da redondeza, é pouco provável para a maioria das espécies. A extinção local é um fenômeno normal dentro da dinâmica de uma população regional, mas a recolonização também o é (FAHRIG \& MERRIAM, 1994). Na paisagem atual em que esses fragmentos estão imersos essa recolonização é pouco provável de ocorrer, pois a matriz dominada por extensas áreas de cultivo de cana-de-açúcar e a grande distância entre os fragmentos devem impedir a movimentação de propágulos e pólen de um fragmento para outro.

A tabela 7 mostra as espécies encontradas no fragmento estudado. $\mathrm{O}$ tabela 8 mostra a análise fitossociológica para esse fragmento, com as vinte espécies mais importantes em IVC classificadas em relação à sua categoria sucessional. Para se agrupar as espécies encontradas no fragmento em categorias sucessionais utilizou-se a classificação apresentada por VIANA (1989). Esse autor agrupou as espécies em "light-demanding pioneer", "gapoportunist", "shade-tolerant" e "shade-reproducing species". Os termos aqui foram traduzidos para pioneiras, oportunistas, tolerantes e reprodutora à sombra, respectivamente. Segundo este autor, pioneiras são espécies que normalmente têm sementes que exigem a formação de clareiras para germinação, e plântulas que não sobrevivem à sombra. As oportunistas são espécies com sementes que não requerem clareiras para germinar, com plântulas que sobrevivem à sombra, mas que necessitam de clareiras para chegar ao estágio adulto. As tolerantes têm sementes que também não necessitam de clareiras para germinar, as plântulas podem crescer até o estágio adulto sem a presença de clareiras, mas que não se reproduzem à sombra. As reprodutoras à sombra têm sementes que não necessitam de clareiras para germinar, crescem até o estágio adulto sob sombra, e se reproduzem na mesma situação. Para uma discussão mais detalhada deve-se consultar o trabalho original. As espécies mais importantes, em IVC, encontradas nesse estudo foram classificadas nas diversas categorias por consultas à bibliografia (CATHARINO, 1989; GANDOLFI, 1991; LORENZI, 1992) e observações pessoais (tabela 13). Somente foram classificadas as espécies mais importantes para não aumentar o erro na análise, o que seria inevitável caso se quizesse classificar todas as espécies encontradas. A classificação de espécies pouco comuns é dificil, seja por observação pessoal como por consulta à bibliografia.

As famílias mais importantes em riqueza de espécies são mostradas na tabela 4. Essas famílias são normalmente as mais diversas na floresta estacional semidecidual do 
interior do estado de São Paulo em diversos trabalhos feitos nesse ecossistema (LEITÃO FILHO, 1987). O fato da maior parte dessas famílias incluir muitas espécies tolerantes não significa que essas espécies sejam muito importantes no fragmento, e que este esteja em bom estado de coonservação, pois o que importa nesse caso é a densidade e o IVC dessas espécies (tabela 8). As espécies mais importantes em valores de cobertura e de importância podem ser observadas na tabela 8. O IVI é mostrado para permitir comparações com trabalhos feitos em outras florestas.

Em um fragmento que possui $24,19 \%$ de sua área ocupada por ecounidade capoeira baixa (tabela 6), considerando-se que as espécies pioneiras dependem de clareiras grandes para sua regeneração na floresta (HARTSHORN, 1980; PUTZ, 1983a; DENSLOW, 1987; UHL et al., 1988), seria de se esperar que essas espécies tivessem grande importância. No entanto, como pode-se ver pelas tabelas 8 e 5, essas espécies são pouco importantes em IVI. Considerando as dez espécies mais importantes em IVC, e as árvores mortas e cobertas por cipós, as espécies pioneiras são responsáveis por apenas $5,4 \%$ deste índice (tabela 5 ). Espécies pioneiras típicas como Solanum granuloso-leprosum, e Cecropia sp são espécies que ocorrem com uma densidade muito baixa no fragmento. Trema micrantha, uma pioneira bastante comum no banco de sementes de fragmentos da região (TABANEZ \& VIANA, dados não publicados) sequer foi encontrada dentro dos transectos (TABANEZ \& VIANA, submetido). Na tabela 5 observa-se também a pequena importância em IVC das espécies tolerantes e reprodutoras à sombra. As espécies oportunistas são as mais importantes.

As espécies pioneiras podem estar sendo prejudicadas no fragmento pela competição com os cipós. As árvores que caem formam clareiras que são rapidamente preenchidas pelos cipós que caem junto com elas, impedindo a luz de chegar ao solo e, conseqüentemente, de estimular a germinação das sementes dessas espécies. As espécies oportunistas, capazes de se regenerar sob o dossel, podem eventualmente escapar à competição com os cipós, e ocupar o local. É importante notar que espécies desse grupo sucessional facilmente tomam-se pioneiras antrópicas, espécies que não são pioneiras típicas, mas que podem invadir e ocupar densamente ambientes degradados (KAGEYAMA et al., 1992). Ou seja, espécies desse grupo podem ser favorecidas em relação às espécies de outros grupos por uma degradação "moderada" do ecossistema. Neste caso o efeito mais visível dessa degradação seria um aumento de luminosidade no ambiente. As espécies tolerantes, de crescimento mais lento, seriam muito prejudicadas por essa competição, tendendo a tomarem-se cada vez mais raras. As espécies reprodutoras à sombra seriam prejudicadas pelo emaranhado de cipós que ocorre na capoeira baixa e no sub-bosque da capoeira alta.

\section{- 2.3.2. Estrutura das ecounidades}

A primeira diferença fundamental entre as ecounidades se dá em área basal. A tabela 2 mostra, entre outras características, a área basal média de cada ecounidade. Percebese que a área basal na $\mathrm{CB}$, que é a ecounidade mais degradada, é extremamente baixa quando comparada com as ecounidades $C A$ e $M M$. A ecounidade $B B$, que não difere significativamente da CB em área basal, também é considerada uma ecounidade degradada, ainda que normalmente não tanto quanto a CB. Pode-se argumentar que uma clareira natural em uma floresta madura também mostraria uma baixa área basal. No entanto, com poucos anos após a formação da clareira o número de indivíduos em regeneração já é bastante alto 
(UHL et al., 1988). No caso da CB isso não acontece, já que o número de indivíduos encontrados nessa ecounidade também é muito baixo, bem menor que em CA e MM, como pode-se observar na mesma tabela. A mata madura, apesar de ser dominada por grandes árvores, tem uma área basal média por indivíduo apenas $18,83 \%$ maior que a capoeira alta (tabela 3). Isso pode ser explicado pelo fato do sub-bosque na mata madura ser ocupado por um grande número de arvoretas de espécies tolerantes e reprodutoras à sombra, que diminui a área basal média das árvores nessa ecounidade. $O$ fato de algumas diferenças não se mostrarem significativas, quando envolvem comparações que incluem BB e MM, é devido principalmente ao baixo número de amostras para essas duas ecounidades, pela sua própria escassez no fragmento, o que afeta a análise. Dois trechos, perfazendo $1,07 \%$ dos transectos, foram considerados, no mapeamento, intermediários entre CB e CA. No entanto, nas análises dos dados foram incorporados à $\mathrm{CB}$, ecounidade com a qual possuíam maior similaridade de dados.

Tabela 2 - Médias de área basal (AB) e densidade (Ind/ha) de indivíduos arbóreos, cobertura foliar total (Cob/total), e percentual dessa cobertura devido a cipós (Cob/cipó) e árvores (Cob/árv), e índice de diversidade de Shannon-Wiener (ID) para cada ecounidade (para $A B$ e Ind, $\mathrm{N}_{\mathrm{CB}}=17, \mathrm{~N}_{\mathrm{BB}}=4, \mathrm{~N}_{\mathrm{CA}}=19, \mathrm{~N}_{\mathrm{MM}}=2$; para cobertura foliar, $\mathrm{N}_{\mathrm{CB}}=3, \mathrm{~N}_{\mathrm{CA}}=3, \mathrm{~N}_{\mathrm{MM}}=2$; para D, $\mathrm{N}_{\mathrm{CB}}=31, \mathrm{~N}_{\mathrm{BB}}=8, \mathrm{~N}_{\mathrm{CA}}=33, \mathrm{~N}_{\mathrm{MM}}=5$ ).

\begin{tabular}{|c|c|c|c|c|c|c|}
\hline Eco & $\mathrm{AB}\left(\mathrm{m}^{2} / \mathrm{ha}\right)$ & Ind/ha & Cob/total(\%) & Cob/cipó(\%) & Cob/árv(\%) & ID \\
\hline CB & $6,63^{\mathrm{a}}$ & $489,83^{a}$ & $66,25^{\mathrm{a}}$ & $56,67^{\mathrm{a}}$ & $43,33^{\mathrm{a}}$ & $0,94^{\mathrm{a}}$ \\
\hline$\overline{\text { BB }}$ & $8,47^{\mathrm{ab}}$ & $664,97^{\mathrm{ab}}$ & - & - & - & $1,21^{\mathrm{ab}}$ \\
\hline $\mathbf{C A}$ & $19,28^{b}$ & $895,42^{b}$ & $89,58^{a}$ & $54,10^{\mathrm{a}}$ & $45,90^{\mathrm{a}}$ & $1,81^{\mathrm{c}}$ \\
\hline $\mathbf{M M}$ & $27,73^{b}$ & $1083,78^{b}$ & $100,00^{\mathrm{a}}$ & $23,44^{\mathrm{a}}$ & $76,57^{a}$ & $1,69^{\mathrm{bc}}$ \\
\hline
\end{tabular}

Médias seguidas pelas mesmas letras não diferem significativamente $(\mathrm{p}=0,05)$ pelo teste de Tukey.

A cobertura foliar total também diferencia as ecounidades (tabela 2), embora não significativamente. O percentual de cobertura foliar devido aos cipós, apesar das médias bem distintas, também não difere significativamente entre as ecounidades CB, CA e MM. A análise estatística foi prejudicada pelo baixo número de amostras consideradas. Essa cobertura total, como citado no método, considera somente a vegetação acima de $2,2 \mathrm{~m}$. $\mathrm{CB}$, além de ter pouca cobertura acima desta altura, a maior parte dela é devida aos cipós, que abaixo desta altura cobre totalmente o solo. Os valores encontrados de cobertura total e por cipós para $\mathrm{CB}$ são muito próximos de valores encontrados em clareiras de outro fragmento da região (TABANEZ et al., no prelo). A CA, mesmo tendo grande percentual de cobertura foliar, possui mais da metade desta cobertura devido aos cipós, o que não acontece com a MM, que apresenta cobertura foliar total semelhante.

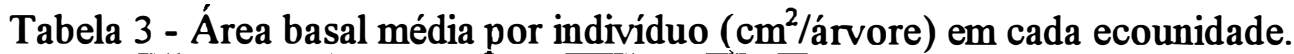

\begin{tabular}{||c|l||}
\hline \hline Ecounidade & $\mathbf{A B}$ \\
\hline Capoeira baixa & 135,35 \\
\hline Bambuzal & 127,37 \\
\hline Capoeira alta & 215,32 \\
\hline Mata madura & 255,86 \\
\hline
\end{tabular}


$O$ índice de diversidade também diferencia as ecounidades. $O$ índice aumenta da ecounidade menos desenvolvida (capoeira baixa), para a mais desenvolvida (capoeira alta), sem levar em consideração a mata madura. A capoeira alta tem um I.D. 92,6\% maior que a capoeira baixa e $49,6 \%$ maior que o bambuzal. A capoeira alta, ainda que considerada uma ecounidade menos madura que a mata madura, tem uma diversidade maior que esta $(7,1 \%$ maior), ainda que essa diferença não seja significativa. A mata madura é ocupada basicamente por grandes árvores, e seu sub-bosque por algumas poucas espécies reprodutoras à sombra, típicas desse ambiente, como Actinostemum communis, Metrodoea nigra e Allophyllus edulis, que são $53,5 \%$ dos indivíduos nessa ecounidade (tabela 12). Isso pode fazer com que o I.D., considerado em trechos pequenos como o utilizado para o cálculo de comparação de ecounidades $\left(100 \mathrm{~m}^{2}\right)$, origine números menores do que para a capoeira alta, dominada por árvores menores, conseqüentemente com espaço para mais indivíduos e espécies. Em uma comparação que leve em conta uma grande área de cada ecounidade (não disponível nesse fragmento para mata madura) o maior I.D. deve ser da mata madura.

\subsubsection{Capoeira alta}

As tabelas 9 a 12 trazem a análise fitossociológica por ecounidade para 0 fragmento, enquanto a tabela 5 mostra o percentual do IVC ocupado por cada categoria sucessional (para as dez espécies mais importantes em IVC), mais árvores mortas e cobertas por cipós.

$\mathrm{Na} \mathrm{CA}$ a dominância das espécies oportunistas é bastante clara, especialmente das espécies Acacia polyphylla, Croton floribundus e Astronium graveolens. Considerandose apenas árvores mortas, cobertas por cipós, e as dez espécies de maior IVC, essas espécies ocupam 26,40\% desse índice nessa ecounidade (tabela 5 e tabela 11; veja também Figura 6). Como discutido anteriormente, essas espécies podem ser favorecidas por uma degradação moderada do ambiente, que é a situação em que se acredita estar a capoeira alta.

Deve-se notar também a grande importância dos indivíduos cobertos por cipós ( $10,53 \%$ do IVC). Apesar desses indivíduos serem apenas aqueles onde a cobertura por cipós foi total, impedindo sua identificação, e não todos os indivíduos cobertos, eles servem como indicativo do grau de ocupação do ambiente por essas plantas. A presença marcante de árvores cobertas por cipós é típica de florestas degradadas por exploração madeireira recente (PINARD \& PUTZ, 1994) ou em um estágio não maduro (BALÉE \& CAMPBELL, 1990). É de se esperar que esses indivíduos estejam sendo bastante prejudicados em sua capacidade fotossintetizante pela competição com os cipós. Competição radicular por nutrientes (DILLENBURG, et al., 1993), estrangulamento de ramos arbóreos (STEVENS, 1987), competição por luz, aumento do peso da árvore, com maior risco de tombamento, aumento do risco de quedas múltiplas de árvores, diminuição da taxa de crescimento de arvoretas presentes em clareiras por sombreamento e danos mecânicos (PUTZ, 1984) são alguns dos prejuízos que podem estar sendo causados por esses cipós. $O$ resultado disso é que os cipós podem estar atuando como fatores secundários de degradação, causando a mortalidade de indivíduos arbóreos, com ou sem queda de árvores, e impedindo a regeneração de espécies arbóreas nessas clareiras recém formadas (CB, ver discussão abaixo e capítulo 3). 
Tabela 4 - Familias maior riqueza de espécies no fragmento da Usina Capuava, e número de espécies por família.

\begin{tabular}{|l|c||}
\hline Familia & Número de espécies \\
\hline |Fabaceae & 10 \\
\hline |Lauraceae & 10 \\
\hline Euphorbiaceae & 9 \\
\hline Rutaceae & 8 \\
\hline Myrtaceae & 7 \\
\hline |Caesalpinaceae & 6 \\
\hline Rubiaceae & 5 \\
\hline |Annonaceae & 4 \\
\hline Boraginaceae & 4 \\
\hline Mimosaceae & 4 \\
\hline Indeterminadas & 4 \\
\hline |Flacourtiaceae & 3 \\
\hline |Sapotaceae & 3 \\
\hline OUutras & 45 \\
\hline \hline
\end{tabular}

Deve-se notar a pequena importância em IVC das espécies tolerantes e reprodutoras à sombra, típicas de ambientes mais maduros.

\subsubsection{Capoeira baixa}

$\mathrm{Na}$ CB a árvores mortas e cobertas por cipós são responsáveis por $27,35 \%$ do IVC (tabela 5 e tabela 9). Essa dominância mais uma vez denota o estado de degradação desta ecounidade, quando comparada com as outras. Além disso o IVC devido às espécies pioneiras é relativamente baixo, mostrando a falta de regeneração da vegetação arbórea, apesar de ser um ambiente aberto. O IVC de espécies tolerantes e reprodutoras à sombra é de apenas $2,75 \%$.

Tabela 5 - Percentual do IVC devido a árvores cobertas por cipós (Cipó), mortas, espécies oportunistas (Opor), tolerantes (Tol), pioneiras (Pio) e reprodutoras à sombra (RS) em cada ecounidade do fragmento estudado. Total=percentual do IVC considerado.

\begin{tabular}{|c|c|c|c|c|c|c|c|}
\hline Ecounidade & Cipó & Mortas & Pio & Opor & Tol & $\mathbf{R S}$ & Total \\
\hline $\mathbf{C B}^{*}$ & 11,97 & 15,38 & 16,30 & 24,51 & 2,75 & 0,00 & 70,91 \\
\hline BB* $^{*}$ & 29,60 & 8,84 & 10,04 & 29,73 & 2,37 & 3,18 & 83,76 \\
\hline $\mathbf{C A}^{*}$ & 10,53 & 13,27 & 3,34 & 26,40 & 4,53 & 3,54 & 61,61 \\
\hline MM* & 0,00 & 9,58 & 11,52 & 11,70 & 29,29 & 25,79 & 87,88 \\
\hline Capuava* & 10,75 & 13,05 & 5,40 & 20,50 & 5,12 & 3,46 & 58,28 \\
\hline
\end{tabular}

*Considerando-se para classificação em categorias sucessionais as dez espécies mais importantes em IVC.

\subsubsection{Bambuzal}

A ecounidade BB tem uma distribuição de IVC relativamente semelhante à $\mathrm{CB}$, o que era esperado, já que as duas ecounidades são consideradas ecounidades 
degradadas (tabela 5 e tabela 10). Árvores mortas e cobertas por cipós são responsáveis por $38,44 \%$ do IVC. As árvores cobertas por cipó são bastante importantes, o que não era esperado a princípio. O IVC de espécies tolerantes e reprodutoras à sombra é de apenas $5,55 \%$.

\subsubsection{Mata madura}

Na MM é perceptível a mudança bastante acentuada na distribuição do IVC. As espécies reprodutoras à sombra e tolerantes passam a dominar (55,08\% do IVC), especialmente Actinostemum communis e Esenbeckia leiocarpa, enquanto cai a zero a importância dos indivíduos cobertos por cipós (tabela 5 e tabela 12). Quando é considerado a densidade relativa, as tendências gerais continuam sendo observadas (Figura 7). Uma das diferenças mais marcantes é o aumento da importância relativa de espécies reprodutoras à sombra, tipicamente de pequeno porte, e diminuição de importância de espécies tolerantes, tipicamente de grande porte, na MM. Essas diferenças devem-se ao fato do IVC considerar a área basal dos indivíduos

\subsubsection{Estrutura de populações}

A curva de distribuição diamétrica das espécies tolerantes foi feita com as espécies Aspidosperma polyneuron, Securinega guaraiuva e Holocalyx balansae. A curva de distribuição diamétrica das espécies oportunistas foi feita com as espécies Centrolobium tomentosum, Piptadenia gonoacantha, Croton floribundus, Astronium graveolens e Acacia polyphylla. Essas curvas podem ser observadas na Figura 8.

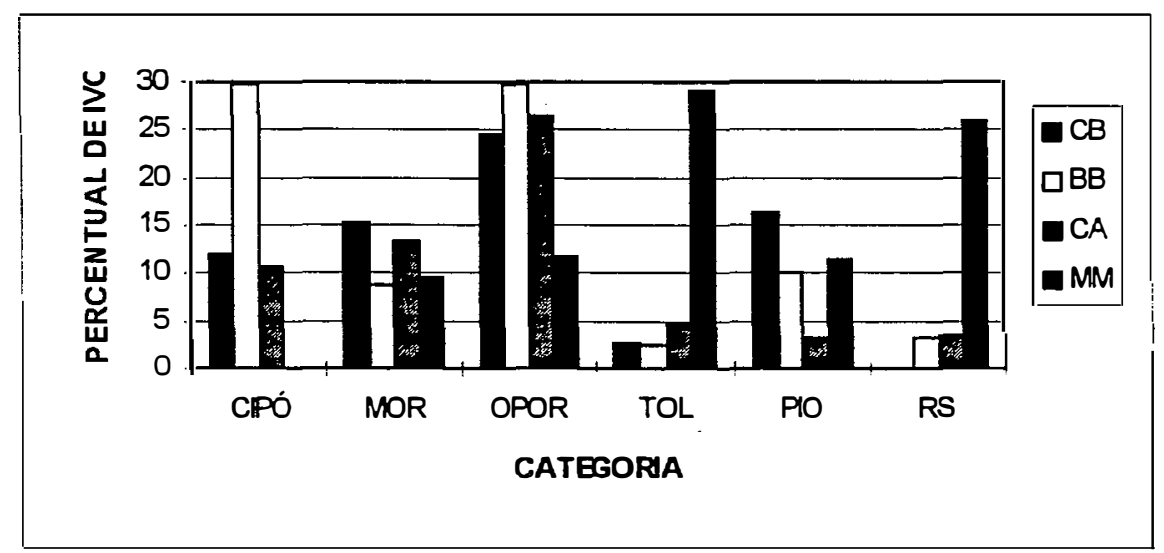

Figura 6 - Percentual do IVC para diferentes categorias sucessionais, e para árvores mortas (MOR) e cobertas por cipós (CIPÓ) em cada ecounidade do fragmento estudado. $\mathbf{C B}=$ capoeira baixa; $\mathbf{B B}=$ bambuzal; $\mathbf{C A}=$ capoeira alta $; \mathrm{MM}=$ mata madura $; \mathrm{OPOR}=$ espécies

oportunistas; TOL $=$ espécies tolerantes; $\mathrm{PIO}=$ espécies pioneiras; $\mathrm{RS}=$ espécies reprodutoras à sombra. 
Figura 7 - Densidade relativa para diferentes categorias sucessionais, e para árvores mortas

(MOR) e cobertas por cipós (CIPÓ) em cada ecounidade do fragmento estudado. $\mathrm{CB}=$ capoeira baixa; $\mathrm{BB}=$ bambuzal; $\mathrm{CA}=$ capoeira alta: $\mathrm{MM}=$ mata madura; $\mathrm{OPOR}=$ espécies oportunistas; TOL = espécies tolerantes; $\mathrm{PIO}=$ espécies pioneiras; $\mathrm{RS}=$ espécies reprodutoras à sombra.

Florestas naturais, com indivíduos de diferentes idades, apresentam curvas de distribuição diamétrica na forma de um $\mathrm{J}$ invertido (LEAK, 1965). Isso é causado pelo maior número de indivíduos de uma classe de tamanho em relação à classe posterior (de maior diâmetro).A distribuição diamétrica é um elemento que pode mostrar o equilíbrio de uma população, quando esta possui séries completas de classes de diâmetro (DAUBENMIRE, 1968). Maior densidade nas classes mais baixas de diâmetro é uma garantia de sobrevivência da espécie, enquanto ausência de indivíduos menores pode indicar a substituição de uma espécie na sucessão, e ausência de indivíduos maiores o surgimento de uma nova espécie no local (FERREIRA, 1988).

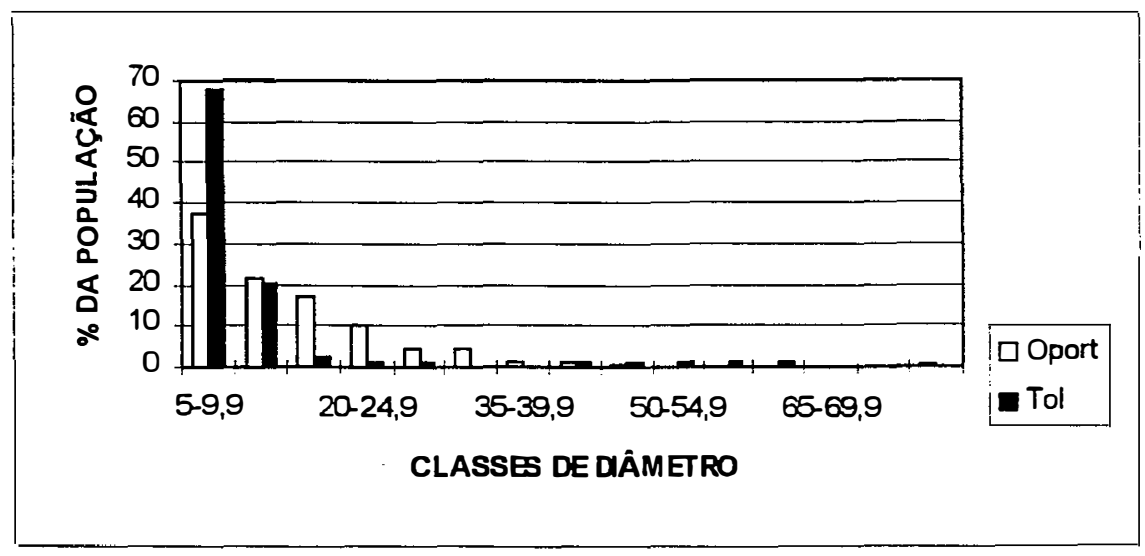

Figura 8 - Distribuição diamétrica das espécies tolerantes e oportunistas mais comuns no fragmento da Usina Capuava. Intervalo de diâmetro de $5 \mathrm{~cm}$. $\mathrm{N}_{\mathrm{oporr}}=210 ; \mathrm{N}_{\mathrm{tol}}=79$.

A curvas de distribuição diamétrica de tolerantes é estatisticamente diferente $(p=0,001)$ da curvas das oportunistas. A diferença mais clara está no modo como a curva é mais abrupta no grupo das tolerantes. Nesse grupo a queda em número de indivíduos de uma classe de menor tamanho para a próxima classe ocorre de forma mais acentuada. É perceptível também a falta de várias categorias de tamanho para esse grupo, principalmente as de maior tamanho. Algumas espécies são ilustrativas dessas tendências, como Holocalyx 
balansae e Securinega guaraiuva (Figura 9). Isso pode denotar problemas de regeneração dentro do fragmento para essas espécies em particular, e para todo esse grupo sucessional em geral. Uma hipótese seria que está havendo reprodução dessas espécies, através de alguns poucos indivíduos adultos, mas a sobrevivência dos indivíduos a partir de um determinado tamanho estaria comprometida. As curvas de nenhuma espécie tolerante difere da curva do grupo sucessional das tolerantes.

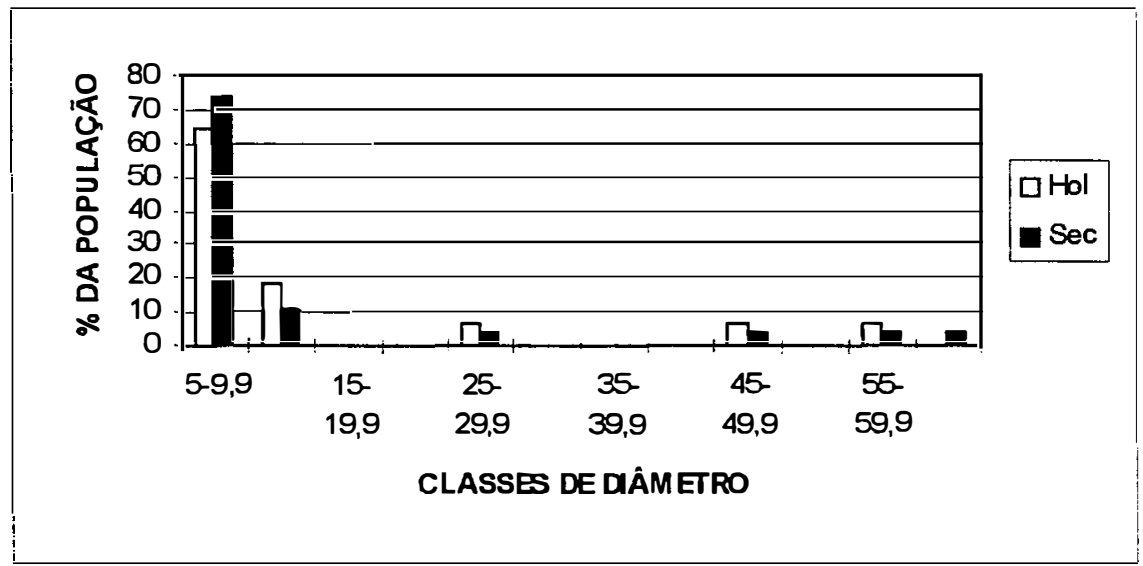

Figura 9 - Distribuição diamétrica de duas espécies tolerantes, Holocalyx balansae e Securinega guaraiuva no fragmento da Usina Capuava. Intervalo de diâmetro de $5 \mathrm{~cm}$. $\mathrm{N}_{\mathrm{Hol}}=17 ; \mathrm{N}_{\mathrm{Sec}}=27$.

No caso das espécies oportunistas as curvas apresentam queda menos acentuada de número de indivíduos entre classes de tamanho sucessivas. Para essas espécies não parece haver maiores problemas de dinâmica populacional, concordando com os dados de estrutura de vegetação da tabela 5 , que mostra que essas espécies são atualmente as melhor estabelecidas, conseqüentemente com maior IVC. Com exceção de Astronium graveolens, nenhuma espécie deste grupo difere significativamente $(p=0,001)$ de seu grupo na distribuição diamétrica de sua população.

A população de Croton floribundus não difere da categoria das oportunistas a $\mathrm{p}=0,001$, mas difere a um $\mathrm{p}$ maior $(0,01)$, apresentando uma distribuição com menor número de indivíduos na primeira classe de tamanho do que na segunda (Figura 10). Esse padrão é semelhante estatisticamente ao padrão encontrado em outros fragmentos estudados na região, citados na tabela 1 (TABANEZ \& VIANA, dados não publicados). A curva dessa espécie fica mais próxima a um padrão de normalidade do que de "J invertido". Essa população apresenta uma distribuição diferente da distribuição das oportunistas. Uma explicação para este fato seria que poderia estar havendo uma falta recente de regeneração para esta espécie, diferentemente das outras espécies oportunistas. 


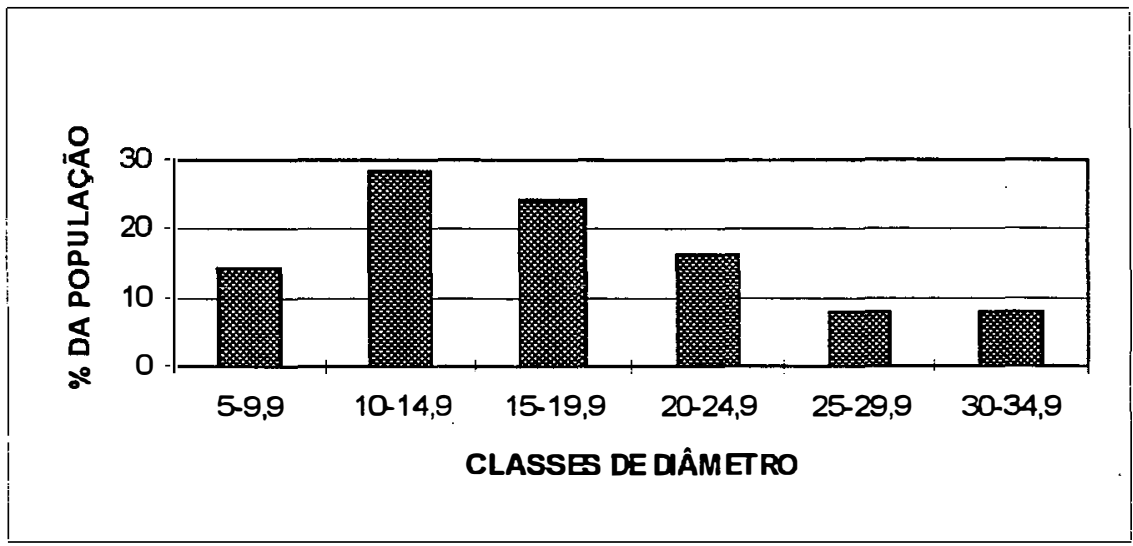

Figura 10 - Distribuição diamétrica da espécies oportunista Croton floribundus, no fragmento da Usina Capuava. Intervalo de diâmetro de $5 \mathrm{~cm}$. N=49.

\subsubsection{Conclusão}

A hipótese do trabalho foi aceita. A proporção entre as diversas ecounidades nesse fragmento pode ser usada para quantificar o grau de degradação desse fragmento, já que apresentam características de desenvolvimento bastante distintas. Isso mostra que o método de levantamento expedito pode ser utilizado com eficácia no levantamento de condições de conservação de florestas semideciduais estacionais.

As clareiras fazem parte da dinâmica natural de ecossistemas florestais. Os trechos de ecounidade de CB e BB poderiam ser considerados como parte integrante da dinâmica natural dos fragmentos florestais. No entanto eles ocupam uma área muito maior do que a ocupada por clareiras em florestas naturais bem conservadas (tabela 6), e não apresentam regeneração de vegetação arbórea. As clareiras novas (com cerca de um ano) ocupam, considerando-se diferentes ecossistemas florestais, cerca de $1 \%$ da área de uma floresta (HARTSHORN, 1978; RUNKLE, 1982). Para o fragmento estudado o percentual de capoeira baixa mais bambuzal é de 30,75\%. Mesmo considerando-se que os trechos de CB e BB incluem "clareiras" mais velhas do que um ano, seria necessário "acumular" mais de $\mathbf{3 0}$ anos de formação de "clareiras" para chegarmos a esses percentuais. Esse alto percentual principalmente de $\mathrm{CB}$ deve antes ser entendido como um indício do estado precário de conservação desses fragmentos.

Tabela 6 - Percentual de cada ecounidade encontrado em fragmentos da região de Piracicaba (TABANEZ \& VIANA, dados não publicados). O fragmento de número 3 é o estudado neste trabalho. Referir-se à tabela 1 para maiores informações sobre cada um desses fragmentos.

\begin{tabular}{||l|l|l|l|l||}
\hline & \multicolumn{4}{|c||}{ Percentual de ecounidade } \\
\hline |Fragmento & CB & BB & CA & MM \\
\hline $\mathbf{1}$ & 31,51 & 0,00 & 68,49 & 0,00 \\
\hline $\mathbf{2}$ & 26,08 & 7,29 & 60,44 & 6,19 \\
\hline $\mathbf{3}$ & 24,19 & 6,56 & 65,05 & 4,20 \\
\hline $\mathbf{4}$ & 17,38 & $\mathbf{1 8 , 7 9}$ & $\underline{63,82}$ & $\underline{0,00}$ \\
\hline
\end{tabular}


O baixo percentual de MM encontrado nesses fragmentos também denota problemas de conservação. Essa ecounidade, considerada como o núcleo bem preservado do fragmento, ocupa uma área muito pequena, ou até nula, mesmo em fragmentos grandes para a região $(3$ e 4$)$.

Assim a hipótese de trabalho é confirmada. A estimativa da proporção de cada ecounidade dentro de um fragmento floresta de floresta semidecídua pode ser utilizado como uma estimativa do nível de degradação deste fragmento. $O$ método de levantamento expedito baseado nessas ecounidades para este tipo de floresta permite o estudo das condições de conservação em um grande número de fragmentos, cobrindo uma área extensa, com um investimento relativamente pequeno e em curto espaço de tempo, se comparado com estudos mais detalhados.

Tabela 7 - Lista de espécies encontradas no fragmento da Usina Capuava.

\begin{tabular}{|c|c|}
\hline Família & Espécie \\
\hline Anacardiaceae & Astronium graveolens Jacq. \\
\hline Anacardiaceae & Tapirira guianensis Aubl. \\
\hline Annonaceae & Annona cacans Warm. \\
\hline Annonaceae & Guatteria nigrescens Mart. \\
\hline Annonaceae & |Rollinia sylvatica Mart. \\
\hline Annonaceae & Xylopia brasiliensis Spreng. \\
\hline |Apocynaceae & |Aspidosperma polyneuron Muell. Arg. \\
\hline Apocynaceae & Aspidosperma ramiflorum Muell. Arg. \\
\hline |Asteraceae & Asteraceae \\
\hline Asteraceae & Vernonia diffusa Less. \\
\hline Bignoniaceae & Jacaranda micrantha Cham. \\
\hline Bombacaceae & Eriotheca candolleana (K Schum.) A. Rob. \\
\hline Boraginaceae & |Cordia ecalyculata Vell. \\
\hline Boraginaceae & Cordia sellowiana Cham. \\
\hline Boraginaceae & Cordia superba Cham. \\
\hline Boraginaceae & Cordia trichotoma (Vell.) Stendel \\
\hline |Burseraceae & |Protium widgrenii Engl. \\
\hline Caesalpinaceae & Bauhinia forficata Link. \\
\hline |Caesalpinaceae & Copaifera langsdorffii Desf. \\
\hline Caesalpinaceae & Holocalyx balansae Mich. \\
\hline |Caesalpinaceae & Hymenaea courbaril L. \\
\hline Caesalpinaceae & Peltophorum dubium (Spreng.) Taub. \\
\hline |Caesalpinaceae & Senna multijuga (L.C. Rich) Irwin et Barn. \\
\hline |Caricaceae & Jacaratia spinosa (Aubl.) A. DC. \\
\hline |Cecropiaceae & Cecropia sp \\
\hline |Celastraceae & Maytenus aquifolium Mart. \\
\hline ||Celastraceae & Maytenus robusta Reiss. \\
\hline Elaeocarpaceae & Sloanea cf guianensis Benth. \\
\hline Elaeocarpaceae & Sloanea monosperma Vell. \\
\hline
\end{tabular}




\begin{tabular}{|c|c|}
\hline Euphorbiaceae & Actinostemum communis Muell. Arg. \\
\hline Euphorbiaceae & Actinostemum concolor (Sprengel) Muell. Arg. \\
\hline Euphorbiaceae & Alchornea glandulosa Casar. \\
\hline Euphorbiaceae & Croton floribundus Spreng. \\
\hline Euphorbiaceae & Croton salutaris Casar. \\
\hline Euphorbiaceae & Pera glabrata Baill. \\
\hline Euphorbiaceae & Sapium glandulosum (Vell.) Pax \\
\hline Euphorbiaceae & Sebastiania serrata Muell. Arg. \\
\hline Euphorbiaceae & Securinega guaraiuva Kuhlm. \\
\hline Fabaceae & Centrolobium tomentosum Guill. \\
\hline Fabaceae & Lonchocarpus guilleminianus (Tul.) Malme \\
\hline Fabaceae & Machaerium aculeatum Raddi \\
\hline Fabaceae & |Machaerium nictitans (Vell.) Benth. \\
\hline Fabaceae & Machaerium stiptatum Vog. \\
\hline Fabaceae & Machaerium vestitum Vog. \\
\hline Fabaceae & Machaerium villosum Vog. \\
\hline Fabaceae & Myroxylon peruiferum (L.) Harms \\
\hline Fabaceae & Poecilanthe parviflora Benth. \\
\hline Fabaceae & Sweetia fruticosa Spreng. \\
\hline Flacourtiaceae & Casearia gossypiosperma Brinquet \\
\hline Flacourtiaceae & Casearia obliqua Spreng. \\
\hline Flacourtiaceae & Casearia sylvestris $\mathrm{Sw}$. \\
\hline Icacinaceae & Citronella megaphylla (Miers.) Howard \\
\hline Indeterminada & Ind A \\
\hline Indeterminada & Ind B \\
\hline Indeterminada & Ind C \\
\hline Indeterminada & Ind D \\
\hline Lauraceae & Cryptocarya aschersoniana $\mathrm{Mez}$ \\
\hline Lauraceae & Endlicheria paniculata (Spreng.) J.F.Macbr. \\
\hline Lauraceae & Nectandra megapotamica (Spreng.) Mez \\
\hline Lauraceae & Ocotea cf. beulahiae Baitello \\
\hline Lauraceae & Ocotea corymbosa (Meisn.) Mez \\
\hline Lauraceae & Ocotea diospyrifolia (Meisn.) Mez \\
\hline Lauraceae & Ocotea elegans $\mathrm{Mez}$ \\
\hline Lauraceae & Ocotea silvestris Vatt.-Gil \\
\hline Lauraceae & Ocotea sp \\
\hline Lauraceae & Persea venosa Nees \\
\hline Lecythidaceae & Cariniana estrellensis (Raddi.) O. Kuntze \\
\hline Lecythidaceae & Cariniana legalis (Mart.) O. Kuntze \\
\hline Malpighiaceae & Dicella holosericea \\
\hline Malvaceae & Bastardiopsis densiflora (Hook.\&Am.) Hassler \\
\hline Meliaceae & Cabralea canjerana (Vell.) Mart. \\
\hline Meliaceae & Cedrella fissilis Vell. \\
\hline Meliaceae & Trichilia catigua A. Juss. \\
\hline
\end{tabular}




\begin{tabular}{|c|c|}
\hline Meliaceae & Trichilia clausenii A. DC. \\
\hline Meliaceae & Trichilia elegans A. Juss. \\
\hline Meliaceae & Trichilia pallida Sw. \\
\hline Mimosaceae & Acacia polyphylla DC. \\
\hline Mimosaceae & Inga sp \\
\hline Mimosaceae & Mimosaceael \\
\hline Mimosaceae & Piptadenia gonoacantha (Mart.) Macbr. \\
\hline Moraceae & Chlophora tinctoria (L.) Gaudich. \\
\hline Moraceae & Ficus sp \\
\hline Myrsinaceae & Rapanea umbellata Mart. \\
\hline Myrtaceae & Campomanesia sp \\
\hline Myrtaceae & Camponesia aff. guaviroba (DC.) Kiaersk. \\
\hline Myrtaceae & Eugenia moraviana Berg \\
\hline Myrtaceae & Eugenia spl \\
\hline Myrtaceae & Eugenia sp2 \\
\hline Mvrtaceae & Marlieria sp \\
\hline Myrtaceae & Neomitrantes glomerata (Legr.) Legr. \\
\hline Nyctaginaceae & Guapira opposita (Vell.) Reitz \\
\hline Nyctaginaceae & Pisonia ambigua Heimerl. \\
\hline Olacaceae & Heisteria silvanii Schwacke \\
\hline Olacaceae & Linociera cf mandiocana Eichl. \\
\hline Palmae & Euterpe edulis Mart. \\
\hline Palmae & Syagrus romanzoffiana (Cham) Glassman \\
\hline Phytolaccaceae & Seguieria langsdorffii Mog. \\
\hline Piperaceae & Piper amalago (Jacq.) Yuncker \\
\hline Rhamnaceae & Colubrina glandulosa Perkins \\
\hline Rhamnaceae & Rhaminidium elaeocarpum Reiss. \\
\hline Rosaceae & Prunus sellowii Kochne \\
\hline Rubiaceae & Amaioua guianensis Subl. \\
\hline Rubiaceae & Coffea arabica $\mathrm{L}$. \\
\hline Rubiaceae & Coutarea hexandra (Jacg.) K. Schum. \\
\hline Rubiaceae & Randia armata DC. \\
\hline Rubiaceae & Simira sampaioana (Standl.) Steyer. \\
\hline Rutaceae & Balfourodendron riedelianum Muell. Arg. \\
\hline Rutaceae & Esenbeckia febrifuga A. Juss. \\
\hline Rutaceae & Esenbeckia leiocarpa Engl. \\
\hline Rutaceae & Galipea multiflora Schlecht. \\
\hline Rutaceae & Metrodorea nigra St. Hil. \\
\hline Rutaceae & Zanthoxylum chiloperone (Mart.) Engl. \\
\hline Rutaceae & Zanthoxylum hiemale St. Hil. \\
\hline Rutaceae & Zanthoxvlum rhoifolium Lam. \\
\hline Sapindaceae & Allophyllus edulis (St. Hil.) Radlk. \\
\hline Sapindaceae & Cupania vernalis Camb. \\
\hline Sapindaceae & Diatenopteryx sorbifolia Radlk. \\
\hline
\end{tabular}




\begin{tabular}{||l|l||}
\hline Sapotaceae & Chrysophyllum gonocarpum (Mart. et Eichl.) Engl. \\
\hline Sapotaceae & Chrysophyllum marginatum (Hook. \& Arn.) Radlk \\
\hline Simaroubaceae & Picramnia warmingiania \\
\hline Solanaceae & cf Solanum inaequale Vell. \\
\hline |Solanaceae & Solanum granuloso-leprosum Dunal \\
\hline |Sterculiaceae & Guazuma ulmifolia Lam. \\
\hline |Thymelacaceae & Daphnopsis fasciculata (Meissn.) Nevl. \\
\hline |Tiliaceae & Luehea divaricata Mart. \\
\hline |Ulmaceae & Celtis glycycarpa Mart. \\
\hline Urticaceae & Urera baccifera (L.) Gaudich. \\
\hline Verbenaceae & Aegiphila sellowiana Cham. \\
\hline
\end{tabular}

Tabela 8 - Análise fitossociológica do fragmento da Usina Capuava. $\mathbf{M = i n d i v i ́ d u o s ~ m o r t o s , ~}$ $\mathrm{C}=$ =individuos não identificados por estarem cobertos por cipós; $\mathbf{C S}=$ categoria sucessional (para as 20 espécies mais importantes em IVC); $\mathrm{P}=$ pioneiras; $\mathrm{O}=$ oportunistas; $\mathrm{T}=$ tolerantes; $\mathrm{RS}=$ reprodutoras à sombra; Ind=número de individuos; $\mathrm{ABt}=$ área basal total da espécie; $\mathrm{DA}=$ densidade absoluta da espécie; $\mathrm{DR}=$ densidade relativa da espécies; $\mathrm{Do} A=$ dominância absoluta da espécie; $D o R=$ dominância relativa da espécie; IVC=índice de valor de cobertura da espécie; IVI=índice de valor de importância da espécie.

\begin{tabular}{|c|c|c|c|c|c|c|c|c|c|}
\hline Espécie & $\overline{\mathrm{CS}}$ & Ind & $\overline{\mathbf{A B t}}$ & $\overline{\mathbf{D A}}$ & $\overline{\mathbf{D R}}$ & $\overline{\mathrm{DoA}}$ & $\overline{\mathbf{D o R}}$ & IVC & IVI \\
\hline $\mathbf{M}$ & & 92 & 4,152 & 68,61 & 8,06 & 3,096 & 18,03 & 26,09 & 28,68 \\
\hline |C & & 119 & 2,548 & 88,75 & 10,43 & 1,900 & $11,07 \mid$ & 21,50 & $\overline{29,01}$ \\
\hline Acacia polyphylla & 0 & 45 & 2,376 & 33,56 & 3,94 & 1,772 & 10,32 & 14,26 & 18,70 \\
\hline |Croton floribundus & 0 & 47 & 1,381 & 35,05 & 4,12 & 1,030 & $6,00 \mid$ & 10,12 & 13,19 \\
\hline Astronium graveolens & 0 & 57 & 0,562 & 42,51 & 5,00 & 0,419 & 2,44 & 7,44 & 12,61 \\
\hline Metrodorea nigra & RS & 67 & 0,241 & 49,97 & 5,87 & 0,180 & 1,05 & 6,92 & 11,23 \\
\hline Esenbeckia leiocarpa & $\mathrm{T}$ & 21 & 0,888 & 15,66 & 1,84 & 0,662 & 3,86 & 5,70 & 7,17 \\
\hline Bauhinia forficata & $\underline{\mathbf{P}}$ & 37 & 0,524 & 27,59 & 3,24 & $0,391 \mid$ & 2,28 & 5,52 & 8,84 \\
\hline |Urera baccifera & $\underline{\mathbf{P}}$ & 29 & 0,629 & 21,63 & 2,54 & 0,469 & 2,73 & 5,27 & 8,23 \\
\hline |Centrolobium tomentosum & 0 & 26 & 0,580 & 19,39 & 2,28 & 0,433 & 2,52 & 4,80 & 7,02 \\
\hline Aspidosperma polyneuron & $\mathrm{T}$ & 36 & 0,317 & 26,85 & 3,16 & 0,236 & 1,38 & 4,53 & 7,61 \\
\hline Inga sp & 0 & 38 & 0,239 & 28,34 & 3,33 & 0,178 & 1,04 & 4,37 & 8,19 \\
\hline Securinega guaraina & & 24 & 0,406 & 17,90 & 2,10 & 0,303 & 1,76 & $3,87 \mid$ & 5,84 \\
\hline Holocalyx balansae & & 14 & 0,581 & 10,44 & 1,23 & 0,433 & 2,52 & 3,75 & 5,35 \\
\hline |Piptadenia gonoacantha & & 16 & 0,496 & 11,93 & 1,40 & 0,370 & 2,15 & 3,56 & 5,28 \\
\hline Diatenopteryx sorbifolia & & 9 & 0,532 & 6,71 & 0,79 & 0,396 & 2,31 & 3,10 & 4,08 \\
\hline Aegiphila sellowiana & & 17 & 0,369 & 12,68 & 1,49 & 0,275 & 1,60 & 3,09 & 4,82 \\
\hline Ficus $s p$ & & 8 & 0,534 & 5,97 & 0,70 & 0,398 & 2,32 & 3,02 & 4,01 \\
\hline |Galipea multiflora & & 27 & 0,126 & 20,14 & 2,37 & 0,094 & 0,55 & 2,91 & 5,25 \\
\hline |Machaerium nictitans & & 13 & 0,368 & 9,69 & 1,14 & 0,274 & 1,60 & 2,74 & 4,09 \\
\hline |Cecropia sp & & 11 & 0,343 & 8,20 & 0,96 & 0,256 & 1,49 & 2,45 & 3,81 \\
\hline |Actinostemum communis & & 22 & 0,091 & 16,41 & 1,93 & 0,068 & 0,39 & 2,32 & 3,68 \\
\hline Syagrus romanzoffiana & & 9 & 0,352 & 6,71 & 0,79 & 0,263 & $1,53 \mid$ & 2,32 & 3,18 \\
\hline |Croton salutaris & & 12 & 0,234 & 8,95 & 1,05 & 0,175 & 1,02 & 2,07 & 2,93 \\
\hline Machaerium stiptatum & & 17 & 0,128 & 12,68 & 1,49 & 0,096 & 0,56 & 2,05 & 3,52 \\
\hline |Alchornea glandulosa & & 8 & 0,233 & 5,97 & 0,70 & 0,174 & 1,01 & 1,71 & 2,58 \\
\hline
\end{tabular}




\begin{tabular}{|c|c|c|c|c|c|c|c|c|}
\hline Asteraceae & 7 & 0,212 & 5,22 & 0,61 & 0,158 & 0,92 & 1,53 & 2,27 \\
\hline muito alta & $1 \mid$ & 0,331 & 0,75 & 0,09 & $0,247 \mid$ & $1,44 \mid$ & 1,53 & 1,65 \\
\hline Trichilia pallida & $14 \mid$ & 0,061 & 10,44 & 1,23 & 0,046 & $0,27 \mid$ & 1,49 & $2,97 \|$ \\
\hline Esenbeckia febrifuga & $14 \mid$ & 0,056 & 10,44 & 1,23 & 0,042 & 0,24 & 1,47 & 2,95 \\
\hline Balfourodendron riedelianum & $11 \mid$ & 0,115 & 8,20 & 0,96 & 0,085 & $0,50 \mid$ & 1,46 & $2,69 \mid$ \\
\hline Nectandra megapotamica & 81 & 0,174 & $5,97 \mid$ & $0,70 \mid$ & 0,130 & 0,76 & 1,46 & 2,32 \\
\hline Allophyllus edulis & $13 \mid$ & 0,063 & 9,69 & 1,14 & 0,047 & $0,27 \mid$ & 1,41 & $3,01 \|$ \\
\hline Daphnopsis fasciculata & 7 & 0,177 & 5,22 & 0,61 & 0,132 & 0,77 & 1,38 & 2,00 \\
\hline Aspidosperma ramiflorum & 7 & $0,151 \mid$ & 5,22 & $0,61 \mid$ & 0,112 & 0,66 & 1,27 & 2,13 \\
\hline Cordia ecalyculata & $7 \mid$ & 0,099 & 5,22 & $0,61 \mid$ & 0,074 & 0,43 & 1,04 & $1,91 \|$ \\
\hline Actinostemum concolor & $10 \mid$ & 0,032 & 7,46 & 0,88 & 0,024 & $0,14 \mid$ & 1,01 & 1,75 \\
\hline Jacaranda micrantha & 6 & 0,112 & $4,47 \mid$ & 0,53 & 0,083 & $0,49 \mid$ & 1,01 & 1,75 \\
\hline Neomitrantes glomerata & 8 & 0,068 & $5,97 \mid$ & $0,70 \mid$ & 0,051 & $0,29 \mid$ & 1,00 & 1,73 \\
\hline Chrysophyllum gonocarpum & 8 & 0,054 & 5,97 & $0,70 \mid$ & 0,040 & 0,23 & 0,93 & 1,80 \\
\hline Zanthoxylum chiloperone & 기 & 0,064 & 5,221 & 0,61 & 0,047 & 0,28 & 0,89 & 1,63 \\
\hline |Trichilia catigua & 81 & 0,036 & $5,97 \mid$ & 0,70 & 0,027 & 0,16 & 0,86 & 1,84 \\
\hline Sebastiania serrata & 81 & 0,026 & 5,97 & 0,70 & 0,019 & $0,11 \mid$ & 0,81 & 1,55 \\
\hline Jacaratia spinosa & 5 & 0,083 & 3,73 & 0,44 & 0,062 & 0,36 & 0,80 & 1,42 \\
\hline Cariniana le galis & $3 \mid$ & 0,120 & 2,24 & 0,26 & 0,089 & $0,52\}$ & 0,78 & 1,15 \\
\hline Celtis glycicarpa & $4 \mid$ & 0,090 & 2,98 & 0,35 & 0,067 & 0,39 & 0,74 & 1,23 \\
\hline cf Solanum inaequale & $4 \mid$ & 0,078 & 2,98 & 0,35 & 0,058 & $0,34 \mid$ & 0,69 & 1,18 \\
\hline Machaerium vestitum & 51 & $0,057 \mid$ & 3,73 & 0,44 & 0,042 & 0,25 & 0,69 & 1,30 \\
\hline Rhaminidium elaeocarpum & $4 \mid$ & 0,076 & 2,98 & 0,35 & 0,056 & 0,33 & 0,68 & 1,17 \\
\hline |Cabralea canjerana & 51 & 0,052 & 3,73 & 0,44 & 0,039 & 0,23 & 0,66 & 1,16 \\
\hline Seguieria langsdorffii & 4 & 0,063 & 2,98 & 0,35 & 0,047 & 0,27 & 0,62 & 1,11 \\
\hline |Guapira opposita & $6 \mid$ & 0,021 & $4,47 \mid$ & 0,53 & 0,016 & 0,09 & 0,62 & 1,36 \\
\hline |Ocotea elegans & $3 \mid$ & 0,076 & $2,24 \mid$ & 0,26 & $0,057 \mid$ & $0,33 \mid$ & 0,59 & 0,96 \\
\hline Pisonia ambigua & $4 \mid$ & 0,054 & 2,98 & 0,35 & 0,040 & 0,23 & 0,58 & 1,08 \\
\hline |Vernonia diffusa & $3 \mid$ & 0,070 & 2,24 & 0,26 & 0,052 & 0,31 & 0,57 & 0,94 \\
\hline Cordia trichotoma & $4 \mid$ & 0,050 & 2,98 & 0,35 & 0,037 & 0,22 & 0,57 & 1,06 \\
\hline |Hymenaea courbaril & $4 \mid$ & 0,046 & 2,98 & 0,35 & 0,035 & $0,20 \mid$ & 0,55 & 1,04 \\
\hline |Cariniana estrellensis & 4 & 0,028 & 2,98 & 0,35 & 0,021 & 0,12 & 0,47 & 0,96 \\
\hline Annona cacans & 21 & 0,068 & 1,49 & 0,18 & 0,051 & 0,29 & 0,47 & 0,72 \\
\hline |Rollinia sylvatica & 31 & 0,032 & $2,24 \mid$ & 0,26 & 0,024 & 0,14 & 0,40 & 0,77 \\
\hline |Endlicheria paniculata & 31 & 0,024 & $2,24 \mid$ & 0,26 & 0,018 & 0,11 & 0,37 & 0,74 \\
\hline |Cordia sellowiana & 31 & 0,020 & $2,24 \mid$ & 0,26 & 0,015 & 0,09 & 0,35 & 0,72 \\
\hline Chlorophora tinctoria & 31 & 0,019 & $2,24 \mid$ & 0,26 & 0,014 & 0,08 & 0,35 & 0,72 \\
\hline Ocotea corymbosa & 31 & 0,019 & $2,24 \mid$ & 0,26 & 0,014 & 0,08 & 0,34 & 0,71 \\
\hline Eriotheca candolleana & 31 & 0,018 & 2,24 & 0,26 & 0,014 & 0,08 & 0,34 & 0,71 \\
\hline |Ocotea diospyrifolia & 31 & $0,017 \mid$ & 2,24 & 0,26 & 0,013 & 0,08 & 0,34 & 0,59 \\
\hline Mavtenus aquifolium & 31 & $0,017 \mid$ & $2,24 \mid$ & 0,26 & 0,013 & 0,07 & 0,34 & 0,71 \\
\hline Lonchocarpus guilleminianus & 21 & $0,037 \mid$ & 1,49 & 0,18 & 0,027 & 0,16 & 0,34 & 0,58 \\
\hline Eugenia moraviana & 31 & $0,016 \mid$ & 2,24 & 0,26 & 0,012 & 0,07 & 0,33 & 0,70 \\
\hline Guazuma ulmifolia & 21 & 0,036 & 1,49 & 0,18 & 0,027 & 0,15 & 0,33 & 0,58 \\
\hline Coutarea hexandra & 3) & 0,013 & $2,24 \mid$ & 0,26 & 0,010 & 0,06 & 0,32 & 0,69 \\
\hline Colubrina glandulosa & 21 & 0,033 & $1,49 \mid$ & 0,18 & 0,025 & 0,14 & 0,32 & 0,57 \\
\hline Copaifera langsdorffii & 2 & 0,033 & 1,49 & 0,18 & 0,025 & 0,14 & 0,32 & 0,57 \\
\hline
\end{tabular}




\begin{tabular}{|c|c|c|c|c|c|c|c|c|}
\hline Guatteria nigrescens & & 0,009 & $2,24 \mid$ & 0,26 & 0,006 & \begin{tabular}{|c|}
0,04 \\
\end{tabular} & $0,0,30$ & $0,67 \|$ \\
\hline Trichilia clausenii & 3 & 0,008 & 2,24 & $0,26 \mid$ & 0,006 & 0,03 & 0,30 & $0,67 \|$ \\
\hline Zanthoxylum rhoifolium & 2 & 0,026 & 1,49 & 0,18 & 0,019 & 0,11 & 0,29 & 0,41 \\
\hline Cordia superba & 2 & 0,025 & 1,49 & 0,18 & 0,019 & 0,11 & 0,28 & 0,53 \\
\hline Ind A & 1 & 0,045 & 0,75 & 0,09 & 0,033 & 0,19 & 0,28 & 0,41 \\
\hline Bastardiopsis densiflora & 1 & 0,042 & 0,75 & 0,09 & 0,032 & 0,18 & 0,27 & 0,39 \\
\hline Prunus sellowii & 2 & 0,016 & 1,49 & 0,18 & 0,012 & 0,07 & 0,24 & 0,49 \\
\hline Peltophorum dubium & 2 & 0,015 & 1,49 & 0,18 & 0,011 & 0,07 & 0,24 & 0,49 \\
\hline Casearia sylvestris & 2 & 0,013 & 1,49 & 0,18 & 0,010 & 0,06 & 0,23 & 0,48 \\
\hline Citronella megaphylla & 2 & 0,011 & 1,49 & 0,18 & 0,008 & 0,05 & 0,22 & 0,47 \\
\hline |Cryptocaria aschersoniana & 2 & 0,011 & 1,49 & 0,18 & 0,008 & 0,05 & 0,22 & 0,34 \\
\hline Pera glabrata & 2 & 0,009 & 1,49 & 0,18 & 0,006 & 0,04 & 0,21 & 0,46 \\
\hline Sloanea monosperma & 2 & 0,008 & 1,49 & 0,18 & 0,006 & 0,03 & 0,21 & 0,45 \\
\hline Eugenia sp2 & 1 & 0,027 & 0,75 & 0,09 & 0,020 & 0,12 & 0,21 & 0,33 \\
\hline Sweetia fruticosa & 2 & 0,006 & 1,49 & 0,18 & 0,005 & 0,03 & 0,20 & 0,45 \\
\hline Marlieria sp & 2 & 0,006 & $\mid 1,49$ & 0,18 & 0,004 & 0,03 & 0,20 & $\mid 0,45$ \\
\hline Camponesia aff. guaviroba & 2 & 0,005 & 1,49 & 0,18 & 0,004 & 0,02 & 0,20 & 0,45 \\
\hline Cedrella fissilis & 1 & 0,024 & 0,75 & 0,09 & 0,018 & 0,10 & 0,19 & 0,32 \\
\hline Ocotea sp. & 1 & 0,024 & 0,75 & 0,09 & 0,018 & 0,10 & 0,19 & 0,32 \\
\hline Zanthoxylum hiemale & 1 & 0,023 & 0,75 & 0,09 & 0,017 & 0,10 & 0,19 & 0,31 \\
\hline Sapium glandulosum & 1 & 0,022 & 0,75 & 0,09 & 0,017 & 0,10 & 0,18 & 0,31 \\
\hline Luehea divaricata & 1 & 0,017 & 0,75 & 0,09 & 0,012 & 0,07 & 0,16 & 0,28 \\
\hline |Ocotea silvestris & 1 & 0,014 & 0,75 & 0,09 & 0,010 & 0,06 & 0,15 & 0,27 \\
\hline Piper amalago & 1 & 0,012 & 0,75 & 0,09 & 0,009 & 0,05 & 0,14 & 0,26 \\
\hline Senna multijuga & 1 & $0,011 \mid$ & 0,75 & 0,09 & 0,008 & 0,05 & 0,14 & 0,26 \\
\hline Ind B & 1 & $0,011 \mid$ & 0,75 & 0,09 & 0,008 & 0,05 & 0,13 & 0,26 \\
\hline Machaerium aculeatum & 1 & 0,010 & 0,75 & 0,09 & 0,007 & 0,04 & 0,13 & 0,25 \\
\hline Casearia obliqua & 1 & 0,009 & 0,75 & 0,09 & 0,007 & 0,04 & 0,13 & 0,25 \\
\hline Dicella holosericea & 11 & 0,009 & 0,75 & 0,09 & 0,007 & $0,04 \mid$ & $0,13 \mid$ & 0,25 \\
\hline |Sloanea cf guianensis & $1 \mid$ & 0,008 & 0,75 & 0,09 & 0,006 & 0,04 & 0,12 & 0,25 \\
\hline Machaerium villosum & $1 \mid$ & 0,008 & 0,75 & 0,09 & 0,006 & 0,04 & 0,12 & 0,25 \\
\hline Rapanea umbellata & 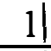 & 0,008 & 0,75 & 0,09 & 0,006 & 0,03 & 0,12 & 0,25 \\
\hline Mimosaceae 1 & $1 \mid$ & 0,007 & 0,75 & 0,09 & 0,005 & 0,03 & 0,12 & 0,24 \\
\hline Ind C & 1 & $0,007 \mid$ & 0,75 & 0,09 & 0,005 & 0,03 & 0,12 & 0,24 \\
\hline Myroxylon peruiferum & 1 & 0,007 & 0,75 & 0,09 & 0,005 & 0,03 & 0,12 & 0,24 \\
\hline Euterpe edulis & 1 & 0,006 & 0,75 & 0,09 & 0,005 & 0,03 & 0,12 & 0,24 \\
\hline |Persea venosa & 1) & 0,006 & 0,75 & 0,09 & 0,005 & $0,03 \mid$ & 0,12 & 0,24 \\
\hline Heisteria silvianii & 1 & 0,006 & 0,75 & 0,09 & 0,005 & 0,03 & $0,11 \mid$ & 0,24 \\
\hline Campomanesiasp & $1 \mid$ & 0,006 & 0,75 & 0,09 & 0,004 & 0,03 & $0,11 \mid$ & 0,24 \\
\hline Casearia gossypiosperma & 1 & 0,005 & 0,75 & 0,09 & 0,004 & 0,02 & $0,11 \mid$ & 0,23 \\
\hline |Poecilanthe parviflora & 1 & 0,005 & 0,75 & 0,09 & 0,004 & 0,02 & 0,11 & 0,23 \\
\hline |Protium wiedgrenii & 1 & 0,002 & 0,75 & 0,09 & 0,004 & 0,02 & 0,11 & 0,23 \\
\hline |Picramnia warmingiania & 1 & 0,005 & 0,75 & 0,09 & 0,004 & 0,02 & 0,11 & 0,23 \\
\hline Mavtenus robusta & $1 \mid$ & 0,005 & 0,75 & 0,09 & 0,004 & 0,02 & $0,11 \mid$ & 0,23 \\
\hline Amaioua guianensis & 1 & 0,004 & 0,75 & 0,09 & 0,003 & 0,02 & 0,11 & 0,23 \\
\hline |Ocotea cf. beulahiae & 1 & 0,004 & 0,75 & 0,09 & 0,003 & 0,02 & 0,11 & 0,23 \\
\hline Solanum granuloso-leprosum & 1 & 0,004 & 0,75 & 0,09 & 0,003 & 0,02 & 0,11 & 0,23 \\
\hline
\end{tabular}




\begin{tabular}{|c|c|c|c|c|c|c|c|c|}
\hline$\sqrt{\text { Coffea arabica }}$ & 1 & 0,003 & 0,75 & 0,09 & 0,002 & 0,01 & 0,10 & 0,23 \\
\hline Chrysophyllum marginatum & 11 & 0,003 & 0,75 & 0,09 & 0,002 & 0,01 & 0,10 & 0,22 \\
\hline Randia armata & $1 \mid$ & 0,003 & 0,75 & 0,09 & 0,002 & 0,01 & 0,10 & 0,22 \\
\hline Linociera cf mandiocana & 1 & 0,003 & 0,75 & 0,09 & 0,002 & 0,01 & 0,10 & 0,22 \\
\hline Ind D & 1 & 0,003 & 0,75 & 0,09 & 0,002 & 0,01 & 0,10 & 0,22 \\
\hline |Xylopia brasiliensis & 1 & 0,002 & 0,75 & 0,09 & 0,002 & 0,01 & 0,10 & 0,22 \\
\hline Cupania vernalis & 1 & 0,002 & 0,75 & 0,09 & 0,002 & 0,01 & 0,10 & 0,22 \\
\hline Tapirira guianensis & 1 & 0,002 & 0,75 & 0,09 & 0,002 & 0,01 & 0,10 & 0,22 \\
\hline Trichilia elegans & 1 & 0,002 & 0,75 & 0,09 & 0,002 & 0,01 & 0,10 & 0,22 \\
\hline Eugenia spl & 1 & 0,002 & 0,75 & 0,09 & 0,002 & 0,01 & 0,10 & 0,22 \\
\hline |Simira sampaioana & 1 & 0.002 & 0,75 & 0,09 & 0,002 & 0,01 & 0,10 & 0,22 \\
\hline
\end{tabular}

Tabela 9 - Análise fitossociológica da ecounidade capoeira baixa no fragmento da Usina Capuava. Somente as 10 espécies mais importantes em IVC estão classificadas em categorias sucessionais (CS). $\mathrm{M}=$ indivíduos mortos, $\mathrm{C}=$ indivíduos não identificados por estarem cobertos por cipós; $\mathrm{P}=$ =pioneiras; $\mathrm{O}=$ oportunistas; $\mathrm{T}=$ tolerantes; $\mathrm{RS}=$ reprodutoras à sombra; Ind=número de indivíduos; $\mathrm{ABt}=$ área basal total da espécie; $\mathrm{DA}=$ densidade absoluta da espécies; $\mathrm{DR}=$ densidade relativa da espécies; $\mathrm{Do} A=$ dominância absoluta da espécie; $\mathrm{DoR}=$ dominância relativa da espécie; IVC=índice de valor de cobertura da espécie.

\begin{tabular}{|c|c|c|c|c|c|c|c|c|}
\hline Espécie & $\overline{\mathrm{CS}}$ & Ind & $\overline{\mathbf{A B t}}$ & $\overline{\mathbf{D A}}$ & $\overline{\mathbf{D R}}$ & $\overline{\mathbf{D o A}}$ & DoR & IVC \\
\hline $\mathbf{M}$ & & 16 & 0,575 & 49,34 & 11,11 & 1,774 & 19,64 & 30,75 \\
\hline $\mathrm{C}$ & & 21 & 0,274 & 64,75 & 14,58 & 0,845 & 9,35 & 23,93 \\
\hline Urera baccifera & $\mathrm{P}$ & 9 & 0,326 & 27,75 & 6,25 & 1,006 & 11,14 & 17,39 \\
\hline Acacia polyphylla & $\mathrm{O}$ & 5 & 0,259 & 15,42 & 3,47 & 0,799 & 8,85 & 12,32 \\
\hline Piptadenia gonoacantha & $\mathrm{O}$ & 7 & 0,180 & 21,58 & 4,86 & 0,556 & 6,15 & 11,01 \\
\hline Astronium graveolens & 0 & 5 & 0,185 & 15,42 & 3,47 & 0,570 & 6,31 & 9,78 \\
\hline Aegiphila sellowiana & $\mathbf{P}$ & 6 & 0,111 & 18,50 & 4,17 & $0,343 \mid$ & 3,80 & 7,97 \\
\hline Asteraceae & $\mathbf{P}$ & 4 & 0,131 & 12,33 & 2,78 & 0,403 & 4,46 & $7,24 \mid$ \\
\hline Centrolobium tomentosum & $\mathrm{O}$ & 5 & 0,089 & 15,42 & 3,47 & 0,274 & 3,03 & 6,50 \\
\hline Aspidosperma polyneuron & $\mathrm{T}$ & 5 & 0,059 & 15,42 & 3,47 & 0,183 & 2,02 & 5,50 \\
\hline |Croton floribundus & 0 & 3 & 0,089 & 9,25 & 2,08 & 0,273 & 3,02 & 5,11 \\
\hline |Jacaranda micrantha & $\mathrm{O}$ & 3 & 0,065 & 9,25 & 2,08 & 0,200 & 2,21 & 4,30 \\
\hline Alchornea glandulosa & & 2 & 0,070 & 6,17 & 1,39 & 0,217 & 2,40 & 3,79 \\
\hline Bauhinia forficata & & 3 & 0,045 & 9,25 & 2,08 & 0,139 & 1,54 & 3,62 \\
\hline |Cordia ecalyculata & & 2 & 0,058 & 6,17 & 1,39 & 0,178 & 1,97 & 3,36 \\
\hline Inga sp & & 4 & 0,013 & 12,33 & 2,78 & 0,039 & 0,43 . & 3,21 \\
\hline |Cecropiasp & & 1 & 0,073 & 3,08 & 0,69 & 0,226 & 2,50 & 3,20 \\
\hline Holocalyx balansae & & 1 & 0,060 & 3,08 & 0,69 & 0,186 & 2,06 & 2,76 \\
\hline Metrodorea nigra & & 3 & 0,013 & 9,25 & 2,08 & 0,040 & 0,45 & 2,53 \\
\hline Machaerium nictitans & & 2 & 0,020 & 6,17 & 1,39 & 0,062 & 0,68 & 2,07 \\
\hline |Cabralea canjerana & & 2 & 0,019 & 6,17 & 1,39 & 0,060 & 0,66 & 2,05 \\
\hline |Zanthoxylum chiloperone & & 2 & 0,013 & 6,17 & 1,39 & 0,041 & 0,45 & 1,84 \\
\hline Esenbeckia leiocarpa & & 2 & 0,013 & $6,17 \mid$ & 1,39 & 0,039 & 0,43 & 1,82 \\
\hline Securinega guaraiuva & & 2 & 0,010 & 6,17 & 1,39 & 0,032 & 0,35 & 1,74 \\
\hline Pisonia ambigua & & 1 & 0,031 & 3,08 & 0,69 & 0,094 & 1,04 & 1,74 \\
\hline |Trichilia catigua & & 2 & 0,008 & $|6,17|$ & 1,39 & 0,026 & 0,28 & 1,67 \\
\hline Marlieria $s p$ & & 2 & 0,006 & 6,17 & 1,39 & 0,019 & 0,21 & 1,59 \\
\hline
\end{tabular}




\begin{tabular}{|c|c|c|c|c|c|c|c|}
\hline Jacaratia spinosa & 1 & $\overline{0,015}=$ & $\overline{3,08}$ & $0,0,69$ & $\mid \overline{0,045}$ & 0,50 & 1,20 \\
\hline Seguieria langsdorffii & 1 & 0,012 & 3,08 & 0,69 & 0,038 & 0,43 & $1,12 \|$ \\
\hline Cordia sellowiana & 1 & 0,010 & 3,08 & 0,69 & 0,030 & 0,34 & 1,03 \\
\hline Casearia obliqua & 1 & 0,009 & 3,08 & 0,69 & 0,028 & 0,31 & $1,01 \|$ \\
\hline Eugenia moraviana & 1 & 0,007 & 3,08 & 0,69 & 0,022 & 0,25 & 0,94 \\
\hline Myroxylon peruiferum & 1 & 0,007 & 3,08 & 0,69 & 0,020 & 0,22 & 0,92 \\
\hline Persea venosa & 1 & 0,006 & 3,08 & 0,69 & 0,020 & 0,22 & 0,91 \\
\hline Cordia trichotoma & 1 & 0,006 & 3,08 & 0,69 & 0,017 & 0,19 & 0,89 \\
\hline Aspidosperma ramiflorum & 1 & 0,005 & 3,08 & 0,69 & 0,016 & 0,18 & 0,87 \\
\hline Ocotea diospyrifolia & 1 & 0,005 & 3,08 & 0,69 & 0,016 & 0,17 & 0,87 \\
\hline Casearia gossypiosperma & 1 & 0,005 & 3,08 & 0,69 & 0,016 & 0,17 & 0,87 \\
\hline Vernonia diffusa & 1 & 0,005 & 3,08 & 0,69 & 0,014 & 0,16 & 0,85 \\
\hline Cariniana estrellensis & 1 & 0,004 & 3,08 & 0,69 & 0,012 & 0,14 & 0,83 \\
\hline cf Solanum inaequale & 1 & 0,004 & 3,08 & 0,69 & 0,012 & 0,13 & 0,83 \\
\hline Machaerium stiptatum & 1 & 0,004 & 3,08 & 0,69 & 0,012 & 0,13 & 0,83 \\
\hline Coutarea hexandra & 1 & 0,004 & 3,08 & 0,69 & 0,012 & 0,13 & 0,82 \\
\hline Allophyllus edulis & 1 & 0,004 & 3,08 & 0,69 & 0,011 & 0,13 & 0,82 \\
\hline Actinostemum communis & 1 & 0,004 & 3,08 & 0,69 & 0,011 & 0,12 & 0,81 \\
\hline Casearia sylvestris & 1 & 0,004 & 3,08 & 0,69 & 0,011 & 0,12 & 0,81 \\
\hline Esenbeckia febrifuga & 1 & 0,004 & 3,08 & 0,69 & 0,011 & 0,12 & 0,81 \\
\hline |Chrysophyllum marginatum & 1 & 0,003 & 3,08 & 0,69 & 0,010 & 0,11 & 0,80 \\
\hline Neomitrantes glomerata & 1 & 0,003 & 3,08 & 0,69 & 0,009 & 0,10 & 0,80 \\
\hline Solanum granuloso-leprosum & 1 & 0,003 & 3,08 & $0,69 \mid$ & 0,009 & 0,10 & 0,80 \\
\hline Galipea multiflora & 1 & 0,002 & 3,08 & 0,69 & 0.007 & 0,08 & 0,77 \\
\hline
\end{tabular}


Tabela 10 - Análise fitossociológica da ecounidade bambuzal no fragmento da Usina Capuava. Somente as 10 espécies mais importantes em IVC estão classificadas em categorias sucessionais (CS). $M=$ indivíduos mortos, $C=$ indivíduos não identificados por estarem cobertos por cipós; Ind=número de indivíduos; $\mathrm{ABt=área} \mathrm{basal} \mathrm{total} \mathrm{da} \mathrm{espécie;}$ $\mathrm{DA}=$ densidade absoluta da espécies; $\mathrm{DR}=$ densidade relativa da espécies; $\mathrm{Do} A=$ dominância absoluta da espécie; DoR=dominância relativa da espécie; $I V C=$ =índice de valor de cobertura da espécie.

\begin{tabular}{|c|c|c|c|c|c|c|c|c|}
\hline Espécie & $\overline{\mathbf{C S}}$ & Ind & $\overline{\mathbf{A B t}}$ & $\overline{\mathbf{D A}}$ & $\overline{\mathbf{D R}}$ & $\overline{\mathbf{D o A}}$ & DoR & $\overline{\mathbf{I V C}}$ \\
\hline $\mathrm{C}$ & & 12 & 0,356 & 136,36 & 20,34 & 4,048 & 38,86 & $59,20 \|$ \\
\hline Acacia polyphylla & $\mathrm{O}$ & 3 & 0,129 & 34,09 & 5,08 & 1,463 & 14,05 & $19,13 \mid$ \\
\hline$M$ & & 5 & 0,084 & 56,82 & 8,47 & 0,958 & 9,20 & 17,67 \\
\hline Inga $s p$ & $\mathrm{O}$ & 7 & 0,043 & 79,55 & 11,86 & 0,485 & 4,65 & 16,52 \\
\hline |Cecropia sp & $\mathrm{P}$ & 5 & 0,055 & 56,82 & 8,47 & 0,625 & 6,00 & 14,48 \\
\hline Balfourodendron riedelianum & O) & 3 & 0,037 & 34,09 & 5,08 & 0,426 & 4,09 & $9,17 \|$ \\
\hline Galipea multiflora & $\mathrm{RS}$ & 3 & 0,012 & 34,09 & 5,08 & 0,133 & 1,28 & 6,36 \\
\hline |Urera baccifera & $\mathrm{P}$ & 2 & 0,020 & 22,73 & 3,39 & 0,230 & 2,21 & 5,60 \\
\hline Syagrus romanzoffiana & $\mathrm{O}$ & 1 & 0,034 & 11,36 & 1,69 & 0,382 & 3,67 & 5,36 \\
\hline Alchornea glandulosa & $\mathrm{O}$ & 2 & 0,012 & 22,73 & 3,39 & 0,141 & 1,35 & 4,74 \\
\hline Ocotea diospyrifolia & $\mathrm{T}$ & 2 & 0,012 & 22,73 & 3,39 & 0,141 & 1,35 & 4,74 \\
\hline Annona cacans & $\mathrm{O}$ & 1 & 0,026 & 11,36 & 1,69 & 0,296 & 2,84 & 4,54 \\
\hline |Vernonia diffusa & & 1 & 0,021 & 11,36 & 1,69 & 0,239 & 2,29 & 3,99 \\
\hline Holocalyx balansae & & 2 & 0,004 & 22,73 & 3,39 & 0,047 & 0,45 & 3,84 \\
\hline Astronium graveolens & & 1 & 0,016 & 11,36 & 1,69 & 0,183 & 1,76 & 3,45 \\
\hline Aegiphila sellowiana & & 1 & 0,009 & 11,36 & 1,69 & 0,101 & 0,97 & 2,67 \\
\hline |Celtis glycicarpa & & 1 & 0,008 & 11,36 & 1,69 & 0,095 & 0,91 & 2,61 \\
\hline |Citronella megaphylla & & $1 \mid$ & 0,008 & 11,36 & 1,69 & 0,094 & 0,90 & 2,59 \\
\hline Jacaranda micrantha & & 1 & 0,008 & 11,36 & 1,69 & 0,093 & 0,89 & 2,58 \\
\hline Rhaminidium elaeocarpum & & 1 & 0,006 & 11,36 & 1,69 & 0,065 & 0,62 & 2,32 \\
\hline Securinega guaraizsa & & 1 & 0,005 & 11,36 & 1,69 & 0,059 & 0,56 & 2,26 \\
\hline Allophyllus edulis & & 1 & 0,005 & 11,36 & 1,69 & 0,058 & 0,56 & 2,25 \\
\hline Metrodorea nigra & & 1 & 0,003 & 11,36 & 1,69 & 0,031 & 0,30 & 2,00 \\
\hline Jacaratia spinosa & & 1 & 0,002 & 11,36 & 1,69 & 0,024 & 0,23 & 1,93 \\
\hline
\end{tabular}


Tabela 11 - Análise fitossociológica da ecounidade capoeira alta no fragmento da Usina Capuava. Somente as dez espécies mais importantes em IVC estão classificadas em categoria sucessional (CS). $M=$ =indivíduos mortos, $C$ =indivíduos não identificados por estarem cobertos por cipós; $\mathrm{P}=$ =pioneiras; $\mathrm{O}=$ oportunistas; $\mathrm{T}=$ tolerantes; $\mathrm{RS}=$ reprodutoras à sombra;

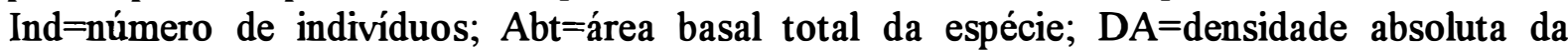
espécies; $\mathrm{DR}=$ densidade relativa da espécies; $\mathrm{Do} A=$ dominância absoluta da espécie; $\mathrm{DoR}=$ dommância relativa da espécie; $\mathrm{IVC}=$ índice de valor de cobertura da espécie.

\begin{tabular}{|c|c|c|c|c|c|c|c|c|}
\hline Espécie & $\mathbf{C S}$ & Ind & $\overline{\mathbf{A B t}}$ & $\overline{\overline{\mathbf{D A}}}$ & DR & DoA & DoR & IVC \\
\hline $\mathbf{M}$ & & 68 & 3,193 & 77,96 & 7,68 & 3,661 & 18,86 & 26,54 \\
\hline $\mathbf{C}$ & & 86 & 1,918 & 98,60 & 9,72 & 2,199 & 11,33 & 21,05 \\
\hline Acacia polyphylla & $\overline{0}$ & 37 & 1,989 & $\overline{42,42}$ & 4,18 & 2,280 & 11,75 & 15,93 \\
\hline Croton floribundus & 0 & 44 & 1,292 & 50,44 & 4,97 & 1,481 & 7,63 & $12,60 \|$ \\
\hline Astronium graveolens & $\mathrm{O}$ & 51 & 0,361 & 58,47 & 5,76 & 0,414 & 2,13 & 7,90 \\
\hline Metrodorea nigra & $\mathrm{RS}$ & 53 & 0,185 & 60,76 & 5,99 & $0,213 \mid$ & 1,10 & 7,08 \\
\hline Bauhinia forficata & $\mathrm{P}$ & 34 & 0,479 & 38,98 & 3,84 & 0,549 & 2,83 & $6,67 \|$ \\
\hline Centrolobium tomentosum & 0 & 21 & $0,491 \mid$ & 24,08 & 2,37 & $0,563 \mid$ & 2,90 & $5,28 \|$ \\
\hline Securinega guaraiuva & $\mathrm{T}$ & 20 & 0,389 & 22,93 . & 2,26 & 0.446 & 2,30 & $4,56 \|$ \\
\hline Aspidosperma polyneuron & $\mathrm{T}$ & 28 & $0,225 \mid$ & 32,10 & 3,16 & 0,258 & 1,33 & 4,49 \\
\hline Inga sp & $\mathrm{O}$ & 27 & $0,184 \mid$ & 30,95 & 3,05 & 0,211 & 1,08 & 4,14 \\
\hline Ficus $s p$ & $\mathrm{O}$ & 8 & 0,534 & 9,17 & 0,90 & 0,612 & 3,16 & 4,06 \\
\hline Piptadenia gonoacar & $\mathrm{O}$ & 9 & 0,316 & 10,32 & 1,02 & 0,362 & $1,87 \mid$ & 2,88 \\
\hline Galipea multiflora & & 20 & 0,100 & 22,93 & 2,26 & 0,115 & 0,59 & 2,85 \\
\hline Syagrus romanzoffiana & & 8 & 0,319 & 9,17 & 0,90 & 0,365 & 1,88 & 2,79 \\
\hline |Croton salutaris & & 12 & 0,234 & 13,76 & 1,36 & 0,269 & 1,38 & 2,74 \\
\hline Holocalyx balansae & & 10 & 0,258 & 11,46 & 1,13 & 0,296 & 1,53 & 2,66 \\
\hline Esenbeckia leiocarpa & & 9 & 0,267 & 10,32 & 1,02 & 0,307 & 1,58 & 2,60 \\
\hline Machaerium stiptatum & & 16 & 0,124 & $18,34 \mid$ & $1,81 \mid$ & 0,143 & 0,73 & 2,54 \\
\hline Diatenoptenx sorbifolia & & 6 & 0,281 & 6,88 & $0,68 \mid$ & 0,322 & 1,66 & 2,34 \\
\hline muito alta & & 1 & 0,331 & 1,15 & $0,11 \mid$ & 0,380 & 1,96 & 2,07 \\
\hline Trichilia pallida & & 14 & 0,061 & 16,05 & 1,58 & 0,070 & 0,36 & 1,94 \\
\hline Nectandr & & 8 & 0,174 & 9,17 & 0,90 & 0,199 & $1,03 \mid$ & 1,93 \\
\hline Aegiphi & & 9 & 154 & 10,32 & 1,02 & 0,177 & 0,91 & 1,93 \\
\hline Daphnopsis fasciculata & & 7 & 0,177 & 8,03 & 0,79 & 0,203 & 1,05 & 1,84 \\
\hline Cecropiasp & & 5 & 0,214 & 5,73 & 0,56 & 0,246 & $1,27 \mid$ & 1,83 \\
\hline Urera baccifera & & 16 & 0,004 & 18,34 & 1,81 & 0,004 & 0,02 & 1,83 \\
\hline Esenbeckia febrifuga & & 13 & 0,052 & $14,90 \mid$ & 1,47 & 0,060 & 0,31 & 1,78 \\
\hline Allophyllus edulis & & $11 \mid$ & 0,054 & $|12,61|$ & 1,24 & 0,062 & 0,32 & 1,56 \\
\hline |Actinostemum communis & & 12 & 0,034 & 13,76 & 1,36 & 0,039 & 0,20 & 1,56 \\
\hline Machaerium nictitans & & $7 \mid$ & $0,120 \mid$ & $8,03 \mid$ & 0,79 & $0,137 \mid$ & $\mid 0,71$ & 1,50 \\
\hline |Zanthoxylum hiemale & & 12 & $0,023 \mid$ & 13,76 & 1,36 & 0,027 & 0,14 & 1,49 \\
\hline Balfourodendron riedelianum & & 81 & 0,077 & 9,17 & 0,90 & 0,088 & 0,46 & 1,36 \\
\hline Alchornea glandulosa & & 4 & $0,151 \mid$ & 4,59 & $0,45 \mid$ & 0,173 & 0,89 & 1,34 \\
\hline Aspidosperma ramiflorum & & 4 & 0,136 & 4,59 & 0,45 & 0,156 & 0,80 & 1,26 \\
\hline Chrysophyllum gonocarpum & & 8 & 0,054 & $9,17 \mid$ & 0,90 & 0,061 & 0,32 & 1,22 \\
\hline Sebastiania serrata & & 8 & $\mid 0,026$ & 9,17 & $0,90 \mid$ & 0,030 & 0,15 & 1,06 \\
\hline Cariniana legalis & & 3 & 0,120 & 3,44 & 0,34 & 0,138 & 0,71 & 1,05 \\
\hline Machaerium vestitum & & 5 & 0,057 & 5,73 & 0,56 & 0,065 & 0,34 & 0,90 \\
\hline
\end{tabular}




\begin{tabular}{|c|c|c|c|c|c|c|c|}
\hline Zanthoxylum chiloperone & $\overline{5}$ & $\overline{|0,050|}$ & $\overline{\mid 5,73}$ & 0,56 & 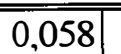 & $\mid \overrightarrow{0,30}=$ & 0,86 \\
\hline Trichilia catigua & 6 & 0,028 & 6,88 & 0,68 & 0,032 & 0,17 & $\overrightarrow{0,84 \|}$ \\
\hline Celtis glycicarpa & 3 & 0,082 & 3,44 & $0,34 \mid$ & $0,094 \mid$ & 0,48 & $0,82 \|$ \\
\hline Asteraceae & 3 & $0,081 \mid$ & 3,44 & 0,34 & 0,093 & 0,48 & 0,82 \\
\hline Cordia ecalyculata & 5 & $0,041 \mid$ & 5,73 & 0,56 & 0,048 & 0,24 & 0,81 \\
\hline Guapira opposita & 6 & $0,021 \mid$ & 6,88 & 0,68 & 0,024 & 0,12 & 0,80 \\
\hline Ocotea elegans & 3 & 0,076 & 3,44 & 0,34 & 0,088 & 0,45 & 0,79 \\
\hline |cf Solanum inaequale & 3 & 0,074 & 3,44 & 0,34 & 0,085 & 0,44 & $0,77 \|$ \\
\hline Rhaminidium elaeocarpum & 3 & 0,070 & 3,44 & 0,34 & 0,080 & 0,41 & 0,75 \\
\hline Jacaratia spinosa & 3 & 0,066 & 3,44 & 0,34 & 0,076 & 0,39 & 0,73 \\
\hline |Hymenaea courbaril & 4 & 0,046 & 4,59 & 0,45 & 0,053 & 0,27 & 0,73 \\
\hline Neomitrantes glomerata & 4 & 0,043 & 4,59 & 0,45 & 0,049 & 0,25 & 0,71 \\
\hline Seguieria langsdorffii & 3 & 0,050 & 3,44 & 0,34 & $0,057 \mid$ & 0,30 & $0,63 \|$ \\
\hline Cordia trichotoma & 3 & 0,044 & 3,44 & 0,34 & 0,051 & 0,26 & 0,60 \\
\hline Cabralea canjerana & 3 & 0,033 & 3,44 & 0,34 & 0,037 & 0,19 & $0,53 \|$ \\
\hline |Rollinia sylvatica & 3 & 0,032 & 3,44 & 0,34 & $0,037 \mid$ & 0,19 & $0,53 \|$ \\
\hline Endlicheria paniculata & 3 & 0,024 & 3,44 & 0,34 & 0,028 & $0,14 \mid$ & 0,48 \\
\hline Cariniana estrellensis & 3 & 0,024 & 3,44 & 0,34 & 0,027 & 0,14 & 0,48 \\
\hline Pisonia ambigua & 3 & 0,023 & 3,44 & 0,34 & 0,027 & $0,14 \mid$ & $\overline{0,48}$ \\
\hline |Jacaranda micrantha & 2 & 0,039 & 2,29 & 0,23 & 0,044 & 0,23 & 0,45 \\
\hline |Chlorophora tinctoria & 3 & 0,019 & 3,44 & 0,34 & 0,022 & 0,11 & 0,45 \\
\hline |Ocotea corymbosa & 3 & 0,019 & 3,44 & 0,34 & 0,021 & 0,11 & 0,45 \\
\hline Eriotheca candolleana & 3 & 0,018 & 3,44 & 0,34 & $0,021 !$ & 0,11 & 0,45 \\
\hline Lonchocarpus guilleminianus & 2 & 0,037 & 2,29 & $0,23 \mid$ & 0,042 & 0,22 & 0,44 \\
\hline Guazuma ulmifolia & 2 & 0,036 & 2,29 & 0,231 & 0,041 & 0,21 & 0,44 \\
\hline |Copaifera langsdorffii & 2 & 0,033 & 2,29 & 0,23 & 0,038 & 0,20 & 0,42 \\
\hline Actinostemum concolor & 3 & 0,010 & 3,44 & 0,34 & 0,012 & 0,06 & 0,40 \\
\hline |Guatteria nigrescens & 3 & 0,009 & 3,44 & 0,34 & 0,010 & 0,05 & 0,39 \\
\hline |Trichilia clausenii & 3 & 0,008 & 3,44 & 0,34 & 0,009 & 0,05 & 0,39 \\
\hline |Zanthoxylum rhoifolium & 2 & 0,026 & 2,29 & 0,23 & 0,029 & 0,15 & 0,38 \\
\hline Ind A & 1 & 0.045 & 1,15 & 0,11 & 0,051 & 0,26 & 0,38 \\
\hline Vernonia diffusa & 1 & 0,045 & 1,15 & 0,11 & $0,051\}$ & 0,26 & 0,38 \\
\hline Cordia superba & 2 & 0,025 & 2,29 & 0,23 & 0,029 & 0,15 & 0,38 \\
\hline Bastardiopsis densiflora & 1 & 0,042 & 1,15 & 0,11 & 0,049 & 0,25 & 0,36 \\
\hline Annona cacans & 1 & 0,042 & 1,15 & 0,11 & 0,048 & 0,25 & 0,36 \\
\hline |Coutarea hexandra & 3 & 0,000 & 3,44 & 0,34 & 0,000 & 0,00 & 0,34 \\
\hline Prunus sellowii & 2 & 0,016 & 2,29 & 0,23 & 0,018 & 0,09 & 0,32 \\
\hline Peltophorum dubium & 21 & 0,015 & 2,29 & 0,23 & 0,018 & 0,09 & 0,32 \\
\hline Mavtenus aquifolium & 21 & 0,014 & 2,29 & 0,23 & 0,016 & 0,08 & 0,31 \\
\hline Cordia sellowiana & 21 & $0,011 \mid$ & 2,29 & 0,23 & 0,012 & 0,06 & 0,29 \\
\hline Cryptocaria aschersoniana & 21 & $0,011 \mid$ & 2,29 & 0,23 & 0,012 & 0,06 & 0,29 \\
\hline Pera glabrata & 21 & 0,009 & 2,29 & 0,23 & 0,010 & 0,05 & 0,28 \\
\hline Eugenia morcrviana & 21 & 0,008 & 2,29 & 0,23 & 0,010 & 0,05 & 0,28 \\
\hline Eugenia sp2 & 1 & 0,027 & 1,15 & 0,11 & 0,031 & 0,16 & 0,27 \\
\hline Sloanea monosperma & 2 & 0,008 & 2,29 & 0,23 & 0,009 & 0,04 & 0,27 \\
\hline Sweetia fruticosa & 2 & 0,006 & 2,29 & 0,23 & 0,007 & 0,04 & 0,26 \\
\hline Camponesia aff. guoviroba & 2 & 0,005 & 2,29 & 0,23 & 0,006 & 0,03 & 0,26 \\
\hline
\end{tabular}




\begin{tabular}{|c|c|c|c|c|c|c|c|}
\hline Cedrella fissilis & 1 & 0,024 & 1,15 & 0,11 & 0,028 & 0,14 & 0,26 \\
\hline Ocotea sp. & 1 & 0,024 & 1,15 & 0,11 & 0,028 & 0,14 & 0,26 \\
\hline Sapium glandulosum & 1 & 0,022 & 1,15 & 0,11 & 0,026 & 0,13 & 0,25 \\
\hline Luehea divaricata & 1 & 0,017 & 1,15 & 0,11 & 0,019 & 0,10 & 0,21 \\
\hline Ocotea silvestris & 1 & 0,014 & 1,15 & 0,11 & 0,016 & 0,08 & 0,20 \\
\hline Piper amalago & 1 & 0,012 & 1,15 & 0,11 & 0,013 & 0,07 & 0,18 \\
\hline Senna multijuga & 1 & 0,011 & 1,15 & 0,11 & 0,013 & 0,07 & 0,18 \\
\hline Ind B & 1 & 0,011 & 1,15 & 0,11 & 0,012 & 0,06 & 0,18 \\
\hline Machaerium aculeatum & 1 & 0,010 & 1,15 & 0,11 & 0,011 & 0,06 & 0,17 \\
\hline Casearia sylvestris & 1 & 0,010 & 1,15 & 0,11 & 0,011 & 0,06 & 0,17 \\
\hline |Colubrina glandulosa & 1 & 0,010 & 1,15 & 0,11 & 0,011 & 0,06 & 0,17 \\
\hline Dicella holosericea & 1 & 0,009 & 1,15 & 0,11 & 0,010 & 0,05 & 0,17 \\
\hline Sloanea cf guianensis & 1 & 0,008 & 1,15 & 0,11 & 0,010 & 0,05 & 0,16 \\
\hline Machaerium villosum & 1 & 0,008 & 1,15 & 0,11 & 0,009 & 0,05 & 0,16 \\
\hline |Rapanea umbellata & 1 & 0,008 & 1,15 & 0,11 & 0,009 & 0,05 & 0,16 \\
\hline |Mimosaceael & 1 & 0,007 & 1,15 & 0,11 & 0,008 & 0,04 & 0,15 \\
\hline Ind C & 1 & 0,007 & 1,15 & 0,11 & 0,008 & 0,04 & 0,15 \\
\hline Euterpe edulis & 1 & 0,006 & 1,15 & 0,11 & 0,007 & 0,04 & 0,15 \\
\hline |Heisteria silvianii & 1 & 0,006 & 1,15 & 0,11 & 0,007 & 0,04 & 0,15 \\
\hline Campomanesia sp & 1 & 0,006 & 1,15 & 0,11 & 0,007 & 0,03 & 0,15 \\
\hline |Poecilanthe parviflora & 1 & 0,005 & 1,15 & 0,11 & 0,006 & 0,03 & 0,14 \\
\hline |Protium wiedgrenii & 1 & 0,002 & 1,15 & 0,11 & 0,006 & 0,03 & 0,14 \\
\hline Picrania warmingiania & 1 & 0,005 & 1,15 & 0,11 & 0,006 & 0,03 & 0,14 \\
\hline Mavtenus robusta & $1 \mid$ & 0,005 & 1,15 & $0,11 \mid$ & 0,005 & 0,03 & 0,14 \\
\hline Amaioua guianensis & 1 & 0,004 & 1,15 & 0,11 & 0,005 & 0,03 & 0,14 \\
\hline Ocotea cf. beulahiae & $1 \mid$ & 0,004 & 1,15 & 0,11 & 0,005 & 0,02 & 0,14 \\
\hline |Coffea arabica & 1) & 0,003 & 1,15 & 0,11 & 0,004 & 0,02 & 0,13 \\
\hline Randia armata & 1) & 0,003 & 1,15 & 0,11 & 0,004 & 0,02 & 0,13 \\
\hline Linociera cf mandiocana & $1]$ & 0,003 & 1,15 & $0,11\}$ & 0,003 & 0,02 & 0,13 \\
\hline |Citronella megaphvlla & $1 \mid$ & 0,003 & 1,15 & 0,11 & 0,003 & 0,02 & 0,13 \\
\hline IInd D & $\overline{11}$ & 0,003 & 1,15 & $\mid 0,11$ & $\mid 0,003$ & 0,02 & 0,13 \\
\hline Xylopia brasiliensis & 1 & 0,002 & 1,15 & $\dot{0,11 \mid}$ & 0.003 & 0,01 & 0,13 \\
\hline |Cupania vernalis & 1 & 0,002 & 1,15 & 0,11 & 0,003 & 0,01 & 0,13 \\
\hline Tapirira guianensis & 1 & 0,002 & 1,15 & 0,11 & 0,003 & 0,011 & 0,13 \\
\hline Trichilia elegans & 1 & 0,002 & 1,15 & 0,11 & 0,003 & 0,011 & 0,13 \\
\hline Eugenia spl & 1 & 0,002 & 1,15 & $0,11 \mid$ & 0,002 & 0,011 & 0,13 \\
\hline Simira sampaioana & 1 & 0,002 & 1,15 & 0,11 & 0,002 & 0,01 & 0,13 \\
\hline
\end{tabular}


Tabela 12 - Análise fitossociológica da ecounidade mata madura no fragmento da Usina Capuava. Somente as dez espécies mais importantes em IVC classificadas em categoria sucessional (CS). $M=$ =indivíduos mortos, $C=$ individuos não identificados por estarem cobertos por cipós; $\mathrm{P}=$ =pioneiras; $\mathrm{O}=$ oportunistas; $\mathrm{T}=$ tolerantes; $\mathrm{RS}=$ reprodutoras à sombra; Ind=número de indivíduos; $\mathrm{ABt}$ =área basal total da espécie; $\mathrm{DA}=$ densidade absoluta da espécies; $\mathrm{DR}=$ densidade relativa da espécies; $\mathrm{Do} A=$ dominância absoluta da espécie; $\mathrm{DoR}=$ dominância relativa da espécie; $\mathrm{IVC}=$ índice de valor de cobertura da espécie.

\begin{tabular}{|c|c|c|c|c|c|c|c|c|}
\hline Espécie & $\overline{\mathrm{CS}}$ & Ind & ABBt & $\overline{\overline{\mathbf{D A}}}$ & $\overline{\mathbf{D R}}$ & $\overline{\text { DoA }}$ & DoR & IVC \\
\hline Esenbeckia leiocarpa & $\bar{T}$ & 10 & 0,608 & 177,46 & 13,51 & 10,786 & 30,69 & 44,20 \\
\hline $\bar{M}$ & & 3 & 0,299 & 53,24 & 4,05 & 5,308 & 15,10 & 19,16 \\
\hline Machaerium nictitans & $\bar{P}$ & 4 & $\begin{array}{ll}0,228 \\
4\end{array}$ & 70,98 & 5,41 & 4,044 & 11,51 & 16,91 \\
\hline Diatenoptenx sorbifolia & $\mathbf{O}$ & 3 & \begin{tabular}{l|l}
3 & 0,251
\end{tabular} & 53,24 & 4,05 & 4,456 & 12,68 & 16,73 \\
\hline Actinostemum communis & RS & 9 & \begin{tabular}{|l|l|}
9,053 \\
\end{tabular} & 159,72 & 12,16 & 0,944 & 2,69 & 14,85 \\
\hline Holocalyx balansae & $\mathrm{T}$ & 1 & || 0,258 & 17,75 & 1,35 & 4,576 & 13,02 & 14,37 \\
\hline Metrodorea nigra & RS & 10 & 0,000 & \begin{tabular}{|l|}
177,46 \\
\end{tabular} & 13,51 & 0,000 & 0,00 & $13,51 \|$ \\
\hline |Allophyllus edulis & RS & 9 & $\begin{array}{l}9,010 \\
\end{array}$ & 159,72 & 12,16 & 0,176 & 0,50 & 12,66 \\
\hline |Actinostemum concolor & $\mathrm{RS}$ & 7 & 7) 0,022 & 124,22 & 9,46 & 0,382 & 1,09 & 10,55 \\
\hline Neomitrantes glomerata & $\mathrm{O}$ & 4 & \begin{tabular}{l|l}
$4 \mid$ & 0,025 \\
\end{tabular} & 70,98 & 5,41 & 0,441 & 1,25 & 6,66 \\
\hline Aegiphila sellowiana & $\mathbf{P}$ & 1 & 1) 0,095 & 17,75 & 1,35 & 1,678 & 4,77 & 6,13 \\
\hline Aspidosperma polyneuron & & 3 & $3 \mid 0,033$ & 53,24 & 4,05 & 0,579 & 1,65 & 5,70 \\
\hline Urera baccifera & & & 2) 0,051 & 35,49 & 2,70 & 0,897 & 2,55 & 5,25 \\
\hline Galipea multiflora & & 3 & $3 \mid \begin{array}{l}0,012 \\
3 \mid\end{array}$ & 53,24 & 4,05 & 0,204 & 0,58 & 4,64 \\
\hline Aspidosperma ramiflorum & & 2 & \begin{tabular}{l|l}
20,010 \\
2
\end{tabular} & 35,49 & 2,70 & 0,169 & $\overline{0,48}$ & $3,1 \varepsilon$ \\
\hline Colubrina glandulosa & & 1 & \begin{tabular}{l|l}
$1 \mid$ & 0,023 \\
\end{tabular} & 17,75 & 1,35 & 0,415 & 1,18 & $2,53 \|$ \\
\hline Mavtenus aquifolium & & 1 & 1) 0,003 & 17,75 & 1,35 & 0,056 & 0,16 & 1,51 \\
\hline Securinega guaraiuva & & 1 & 1) 0,002 & 17,75 & 1,35 & 0,036 & 0,10 & 1,45 \\
\hline
\end{tabular}


Tabela 13 - Classificação das espécies mais importantes, em IVC, na Usina Capuava, em categorias sucessionais segundo o autor deste trabalho, e outros três autores (CATHARINO (1989) não classifica, apenas comenta sobre aspectos ecológicos e relativos ao porte das espécies).

\begin{tabular}{|c|c|c|c|c|}
\hline Espécie & $\begin{array}{l}\text { TABANEZ } \\
\text { (observação } \\
\text { pessoal) }\end{array}$ & $\begin{array}{l}\text { GANDOLFI, } \\
1991\end{array}$ & LORENZI, 1992 & CATHARINO, 1989 \\
\hline Acacia & Oportunista & Não classificada & Não classificada & $\begin{array}{l}\text { Comum nas matas e } \\
\text { capoeiras }\end{array}$ \\
\hline $\begin{array}{l}\text { Actinostemum } \\
\text { communis }\end{array}$ & $\begin{array}{l}\text { Reprodutora } \\
\text { sombra }\end{array}$ & Não classificada & Não classificada & $\begin{array}{l}\text { Arvoreta comum no } \\
\text { sub-bosque de matas } \\
\text { e capoeirões }\end{array}$ \\
\hline $\begin{array}{l}\text { Aegiphila } \\
\text { sellowiana }\end{array}$ & Oportunista & Secundária inicial & $\begin{array}{l}\text { Heliófita, ocorre em } \\
\text { associações } \\
\text { secundárias }\end{array}$ & $\begin{array}{l}\text { Comum nas áreas em } \\
\text { regeneração, pioneira }\end{array}$ \\
\hline $\begin{array}{l}\text { Actinostemum } \\
\text { concolor }\end{array}$ & $\begin{array}{l}\text { Reprodutora } \\
\text { sombra }\end{array}$ & Secundária tardia & Não classificada & Não classificada \\
\hline \begin{tabular}{|l} 
Alchornea \\
glandulosa
\end{tabular} & Oportunista & Não classificada & $\begin{array}{l}\text { Helióftich pioneira, } \\
\text { ocorre também na } \\
\text { mata primária }\end{array}$ & Ocorre em capoeiras \\
\hline $\begin{array}{l}\text { Allophyllus } \\
\text { edulis }\end{array}$ & $\begin{array}{l}\text { Reprodutora } \\
\text { sombra }\end{array}$ & Pioneira & $\begin{array}{l}\text { Esciófita, pioneira, } \\
\text { comum no interior de } \\
\text { mata primária }\end{array}$ & Arvoreta \\
\hline $\begin{array}{l}\text { Annona } \\
\text { cacans }\end{array}$ & Oportunista & Não classificada & $\begin{array}{l}\text { Heliófita, pioneira, } \\
\text { ocorre tanto na floresta } \\
\text { primána densa como } \\
\text { nas formações } \\
\text { secundárias }\end{array}$ & Não classificada \\
\hline $\begin{array}{l}\text { Aspidosperma } \\
\text { polyneuron }\end{array}$ & Tolerante & Não classificada & $\begin{array}{l}\text { Esciófié do interior } \\
\text { de mata primária }\end{array}$ & \begin{tabular}{llr} 
Comum & \multicolumn{2}{r}{ desde } \\
estádios & iniciais de \\
sucessão & até mata \\
madura & & \\
\end{tabular} \\
\hline \begin{tabular}{|l} 
Astronium \\
graveolens
\end{tabular} & Oportunista & Não classificada & Não classificada & $\begin{array}{l}\text { Comum em matas e } \\
\text { capoeiras }\end{array}$ \\
\hline $\begin{array}{l}\text { Bauhinia } \\
\text { forficata }\end{array}$ & Pioneira & Não classificada & $\begin{array}{llr}\begin{array}{l}\text { Heliófiaa } \\
\text { interior }\end{array} & \text { da } & \text { no } \\
\text { primána } & & \\
\end{array}$ & \begin{tabular}{|l|} 
Comum nas \\
capoeiras, carrascais \\
e beiras de mata
\end{tabular} \\
\hline $\begin{array}{l}\text { Balfourodendr } \\
\text { on riedelianum }\end{array}$ & Oportunista & Não classificada & $\begin{array}{l}\text { Heliófica, e pioneira, } \\
\text { comum em clareiras na } \\
\text { mata primánia }\end{array}$ & $\begin{array}{l}\text { Ocorre em matas e } \\
\text { capoeirões }\end{array}$ \\
\hline Cecropia sp & Pioneira & Não classificada & Não classificada & Não classificada \\
\hline $\begin{array}{l}\text { Centrolobium } \\
\text { tomentosum }\end{array}$ & Oportunista & Não classificada & $\begin{array}{lr}\text { Heliófifa, ocorre tanto } \\
\text { no interior da floresta } \\
\text { primána como em } \\
\text { estágios iniciais } & \text { de } \\
\text { sucessão } & \\
\end{array}$ & $\begin{array}{l}\text { Ocorre em matas e } \\
\text { capoeiras }\end{array}$ \\
\hline
\end{tabular}




\begin{tabular}{|c|c|c|c|c|}
\hline $\begin{array}{l}\text { Croton } \\
\text { floribundus }\end{array}$ & Oportunista & Pioneira & $\begin{array}{l}\text { Heliófita, pioneira, } \\
\text { ocorre também no } \\
\text { interior da mata que } \\
\text { sofreu interferência }\end{array}$ & $\begin{array}{l}\text { Ocorre em matas e } \\
\text { capoeiras }\end{array}$ \\
\hline \begin{tabular}{|l|} 
Diatenopteryx \\
sorbifolia
\end{tabular} & Oportunista & Não classificada & Heliófita, pioneira & $\begin{array}{l}\text { Árvore de médio a } \\
\text { grande porte }\end{array}$ \\
\hline $\begin{array}{l}\text { Esenbeckia } \\
\text { leiocarpa }\end{array}$ & Tolerante & Não classificada & Não classificada & $\begin{array}{l}\text { Ocorre em matas e } \\
\text { capoeirões }\end{array}$ \\
\hline Ficus $s p$ & Oportunista & Não classificada & Não classificada & Não classificada \\
\hline $\begin{array}{l}\text { Galipea } \\
\text { multiflora }\end{array}$ & $\begin{array}{l}\text { Reprodutora } \\
\text { à sombra }\end{array}$ & Não classificada & Não classificada & $\begin{array}{l}\text { Arvoreta comum nas } \\
\text { áreas perturbadas e } \\
\text { no sub-bosque de } \\
\text { matas e capoeirões }\end{array}$ \\
\hline $\begin{array}{l}\text { Holocalyx } \\
\text { balansae }\end{array}$ & Tolerante & Não classificada & \begin{tabular}{|l|} 
Ombrófila clímax, \\
ocorre no interior da \\
mata primána
\end{tabular} & $\begin{array}{l}\text { Ocorre em matas e } \\
\text { capoeirões }\end{array}$ \\
\hline Inga $s p$ & Oportunista & Não classificada & Não classificada & Não classificada \\
\hline $\begin{array}{l}\text { Jacaranda } \\
\text { micrantha }\end{array}$ & Oportunista & Pioneira & $\mid \begin{array}{l}\text { Heliófita, pode ocorrer } \\
\text { no interior de mata } \\
\text { densa }\end{array}$ & Não classificada \\
\hline $\begin{array}{l}\text { Machaerium } \\
\text { nictitans }\end{array}$ & Pioneira & Não classificada & \begin{tabular}{|lr} 
Heliófita, & pioneira, \\
comumnas & formações \\
secundárias
\end{tabular} & Não classificada \\
\hline $\begin{array}{l}\text { Metrodorea } \\
\text { nigra }\end{array}$ & $\begin{array}{l}\text { Reprodutora } \\
\text { à sombra }\end{array}$ & Não clas & \begin{tabular}{|l|} 
Esciófita, ocorre no \\
interior da mata densa
\end{tabular} & Arvoreta \\
\hline $\begin{array}{l}\text { Neomitrantes } \\
\text { glomerata }\end{array}$ & Oportunista & Não classificada & Não classificada & Não classificada \\
\hline $\begin{array}{l}\text { Ocotea } \\
\text { diospyrifolia }\end{array}$ & Tolerante & Não classificada & Não classificada & Não classificada \\
\hline $\begin{array}{l}\text { Piptadenia } \\
\text { gonoacantha }\end{array}$ & Oportunista & Secundária inicial & \begin{tabular}{|l|}
$\begin{array}{l}\text { Heliófita, ocorre em } \\
\text { associações } \\
\text { secundárias }\end{array}$ \\
secos
\end{tabular} & $\begin{array}{l}\text { Pioneira, comum em } \\
\text { áreas em regeneração }\end{array}$ \\
\hline \begin{tabular}{|l} 
Securinega \\
guaraiuva
\end{tabular} & Tolerante & Não classificada & $\mid \begin{array}{rr}\text { Heliófita ou } & \text { esciófita, } \\
\text { caracteristica } & \text { da } \\
\text { floresta primánia densa }\end{array}$ & Ocorre em matas \\
\hline \begin{tabular}{|l} 
Syagnes \\
romanzoffiana
\end{tabular} & Oportunista & Secundária inicial & $\begin{array}{l}\text { Heliófita, comum em } \\
\text { capoeiras }\end{array}$ & Não classificada \\
\hline $\begin{array}{l}\text { Urera } \\
\text { baccifera }\end{array}$ & | Pioneira & Não classificada & Não classificada & $\begin{array}{l}\text { Comum nas clareiras } \\
\text { de matas e capoeiras }\end{array}$ \\
\hline
\end{tabular}




\section{CAPÍTULO 3 \\ CONTROLE DE CIPÓS NO MANEJO DE ECOUNIDADES EM FRAGMENTOS DE FLORESTA DE PLANALTO}

\subsection{INTRODUÇÃO}

O processo de formação de clareiras, e subsequente ocupação destas por espécies arbóreas, é o processo básico de renovação da floresta. No entanto em fragmentos florestais esse processo de regeneração florestal parece ser dificultado. Em locais onde os cipós são muito abundantes o crescimento de vegetação arbórea em clareiras pode ser impedido por anos e até décadas (PUTZ, 1980). Nos fragmentos da região de Piracicaba, pode-se observar claramente esse problema (VIANA et al., 1992; TABANEZ et al., no prelo). Diversos trechos dos fragmentos são totalmente ocupados por cipós, que cobrem todos os indivíduos arbóreos existentes. TABANEZ et al. (no prelo) fornecem dados que demonstram que mesmo no interior de um fragmento, mais de $70 \%$ da cobertura foliar, de um total de cerca de $90 \%$, pode ser devida aos cipós. Neste trabalho, cipó é considerado qualquer planta, incluindo arbustos escandentes, que seja incapaz de se sustentar sem auxílio de um suporte, seja ela lenhosa ou herbácea, provida ou não de estruturas especiais de fixação.

Além de representar boa parte da biodiversidade das florestas tropicais, os cipós são importantes por comumente não apresentarem caducifolia, e produzirem flores e frutos na época seca (PUTZ \& WINDSOR, 1987) ou em épocas diferentes das espécies arbóreas (MORELLATO, 1991), sendo por isso fonte importante de alimentos na época seca para a fauna. Os cipós apresentam características que os tornam muito agressivos quando comparados às espécies arbóreas, tais como taxa de crescimento extremamente alta (PUTZ, 1984), baixa proporção de espécies decíduas (PUTZ, 1990; PUTZ \& WINDSOR, 1987), maior período de produção de folhas durante o ano do que a vegetação arbórea (PUTZ \& WINDSOR, 1987), grande capacidade de extensão dos tecidos, alta taxa de reprodução vegetativa, e baixa taxa de investimento em tecidos de sustentação (PEÑALOSA, 1985). A fragmentação, ao mudar o microclima da floresta, tomando-a mais iluminada e menos úmida, pode favorecer as espécies pioneiras de cipós, adaptadas a ambientes mais iluminados e mais agressivas que as espécies arbóreas, ao mesmo tempo que essas espécies, principalmente as não pioneiras, são prejudicadas. Isso faz com que, na maioria dos fragmentos florestais, eles se tomem agentes secundários de degradação, havendo uma dominância dos cipós sobre a vegetação arbórea, com danos à sua conservação.

Em função da série de problemas que surge para a conservação dos fragmentos florestais, como o efeito de borda e perda de espécies, atualmente vários autores discutem a necessidade de seu manejo, em particular (VIANA, 1990; VIANA et al., 1992; ENGEL, 1993; VIANA \& TABANEZ, submetido), assim como para todo o sistema de áreas protegidas (GRUMBINE, 1994), que podem ser entendidas como fragmentos de ecossistemas. Essas áreas protegidas, consideradas normalmente como áreas contínuas, estão submetidas às mesmas pressões que os fragmentos (JANZEN, 1983), em maior ou menor grau. Propostas de manejo que discutem fatores como tamanho mínimo e forma dos fragmentos, e presença de corredores entre eles têm sido publicadas (BURKEY, 1989; FAHRIG \& MERRIAM, 1985; GAME, 1980; MWALYOSI, 1991). No entanto, mesmo para fatores como tamanho, forma e uso de corredores entre fragmentos, que são pontos 
básicos da dinâmica dos fragmentos, há críticas ao consenso da maioria de que grandes e arredondados fragmentos e corredores entre eles seja sempre a melhor estratégia de conservação (GAME, 1980; ROBINSON et al., 1992; SIMBERLOFF, 1982; SIMBERLOFF \& COX, 1987). Independentemente da vantagem ou desvantagem de pequenos fragmentos quando comparados com os grandes, a maioria das paisagens já se encontra bastante fragmentada. Os pequenos fragmentos podem representar uma grande parte do total da área florestal remanescente (ex. TABANEZ et al., 1994), e é importante saber conservá-los (SHAFER, 1995). Nesse contexto surge o manejo de fragmentos florestais. Esse manejo pode, devido a emergência das questões ambientais, ser baseado em intuição e impressões, devendo ser, no entanto, desenvolvido como qualquer outra ciência, com o suporte de trabalhos anteriores, testados por experimentos, com monitoramento de parâmetros fundamentais, e com resultados publicados (BRADSHAW, 1993).

\subsubsection{Problema de pesquisa}

Os problemas de conservação de fragmentos florestais sugerem a necessidade de estratégias específicas de manejo. Em fragmentos de floresta estacional semidecidual a cobertura de grandes trechos dos fragmentos por espécies de cipós parecem dificultar o processo natural de regeneração da vegetação arbórea em clareiras. Muito pouco se sabe sobre a influência dessas espécies sobre a dinâmica de sucessão natural nesses fragmentos.

Este trabalho procura responder às seguintes questões: i) os fragmentos florestais são auto-sustentáveis? ii) é possível auxiliar o processo de regeneração das espécies arbóreas através do manejo da população de cipós?

\subsubsection{Hipóteses}

i) a sucessão nos fragmentos florestais está estagnada, fazendo com que não sejam auto-sustentáveis; sucessão.

ii) o cipó é, em clareiras de fragmentos florestais, um fator de estagnação da

\subsubsection{Predições}

i) as clareiras sem intervenção devem apresentar baixa taxa de regeneração de espécies arbóreas, e pequeno crescimento dos indivíduos dessas espécies já existentes;

ii) o manejo da clareira através do controle de cipós, e do controle de cipós mais plantio de enriquecimento, proporciona a facilitação do processo de sucessão da vegetação arbórea, com aumento significativo no recrutamento de indivíduos de espécies arbóreas, na densidade de indivíduos arbóreos e em sua área basal.

\subsubsection{Objetivos}

O objetivo desse trabalho é estudar o efeito do manejo na dinâmica de regeneração em fragmentos de floresta estacional semidecidual. 


\subsection{MATERIAL E MÉTODOS}

\subsubsection{Obtenção dos dados}

\subsubsection{Manejo de capoeira baixa}

Este trabalho tem como objetivo o desenvolvimento de uma metodologia de manejo de florestas nativas que tem como base a caracterização da vegetação em ecounidades (ver capítulo 2). Este manejo visa basicamente limitar o crescimento de cipós em capoeira baixa, favorecendo sua ocupação por espécies arbóreas.

O experimento foi instalado na ecounidade capoeira baixa, com cinco repetições e consta dos seguintes tratamentos:

Tratamento 1 - Corte de cipós e plantio de enriquecimento - corte de todo o cipó, com plantio posterior de espécies arbóreas, utilizando-se a associação 1 (capixingui, monjoleiro, paineira e jequitibá-rosa). Periodicamente, sempre que necessário, foi feito novo corte de cipós.

Tratamento 2 - Idem ao anterior, mas utilizando-se, no plantio, a associação 2 (paupólvora, pau-d'alho, ipê e jatobá).

Tratamento 3 - Idem ao tratamento 2, mas utilizando-se, no plantio, a associação 3 (guassatonga, eucalipto, tamboril e pau-marfim).

Tratamento 4 - Corte de cipós - corte de todo o cipó, com cortes sucessivos sempre que necessário.

Tratamento 5 - Parcelas testemunhas, sem nenhum tratamento.

Os tratamentos 1 a 3 diferem do tratamento 4 , na prática, basicamente por causarem uma movimentação do solo localizada, por ocasião do plantio, além de um controle mais constante da rebrota do cipó ( 4 cortes de cipó de manutenção por ano para os tratamentos com plantio contra um corte anual para o tratamento sem plantio).

Todos os indivíduos de espécies arbóreas originalmente existentes foram deixados nas parcelas que passaram pelo corte de cipós.

O trabalho de manejo de capoeira baixa foi todo desenvolvido em um só fragmento, na Usina Capuava (veja descrição e mapa do local no capítulo 2).

Para localização dos trechos de CB no fragmento, foi feito um sobrevôo com trike, anotando-os em um mapa. Esse aparelho, semelhante a um ultraleve, difere deste por ter a asa igual à de uma asa-delta. Permite o sobrevôo do piloto mais um passageiro, e pode ser muito útil para observações de florestas. Posteriormente, esses trechos foram localizados por terra. Os trechos com tamanho mímimo estimado em 100 metros quadrados foram utilizados para 0 experimento (cinco por tratamento, no total de vinte e cinco). 
As parcelas estabelecidas têm tamanhos vanáveis. Isso ocorreu porque, como os trechos de capoeira baixa utilizados no experimento ocorrem naturalmente no fragmento, exigir um tamanho grande impediria o uso de muitos trechos de tamanho menor, provavelmente impedindo a localização dos 25 trechos necessários. Definir as parcelas com um tamanho muito pequeno desperdiçaria uma grande área disponível para experimentação. Assim, optou-se por utilizar os trechos de capoeira baixa de tamanhos diferentes. Os 25 trechos de CB encontrados foram divididos entre os diversos tratamentos através de um sorteio. A menor parcela para os tratamentos 1 a 3 (corte de cipó mais plantio) tem $328 \mathrm{~m}^{2}$, e a maior $1.064 \mathrm{~m}^{2}$ (com o plantio de 41 e 133 mudas das quatro espécies, respectivamente). A menor parcela do tratamento 4 (corte de cipó sem plantio) tem $178,7 \mathrm{~m}^{2}$, e a maior $472,5 \mathrm{~m}^{2}$. A menor e a maior parcela testemunha tem $254,5 \mathrm{~m}^{2}$ e $629,4 \mathrm{~m}^{2}$, respectivamente.

A resposta das parcelas de capoeira baixa ao manejo foi acompanhada através de inventários anuais de árvores preexistentes com DAP igual ou superior a $5 \mathrm{~cm}$. Para essas plantas era medido o DAP, o diâmetro de copa em duas orientações e a altura.

A resposta das parcelas de capoeira baixa ao manejo foi acompanhada também através de medições semestrais no número de plantas de regeneração natural presentes em subparcelas. Essa subparcelas são mostradas na figura 1. Seu formato é quadrado, com $3 \mathrm{~m}$ de lado, em número de 4 por parcela, localizadas uma em cada ponto cardeal, a 2 metros de distância da projeção das copas das árvores da borda da parcela. São subdivididas em 3 quadrados, um com $3 \mathrm{~m} X 3 \mathrm{~m}$, outro com $2 \mathrm{~m} X 2 \mathrm{~m}$ e outro com $1 \mathrm{~m} X 1 \mathrm{~m}$. No quadrado de $1 \mathrm{~m}^{2}$ são inventariados todos os indivíduos de espécies arbóreas com $5 \mathrm{~cm}$ ou mais de altura. No quadrado de $4 \mathrm{~m}^{2}$ são inventariados os individuos $\mathrm{com} 50 \mathrm{~cm}$ ou mais de altura. No quadrado de $9 \mathrm{~m}^{2}$ são inventariados os indivíduos com $1,5 \mathrm{~m}$ ou mais de altura. Para esses indivíduos são medidos o DAP, o diâmetro da copa em duas orientações e a altura. Para os indivíduos menores, com altura entre $5 \mathrm{~cm}$ e $1,5 \mathrm{~m}$, medidos nos outros quadrados, só foi medida a altura.

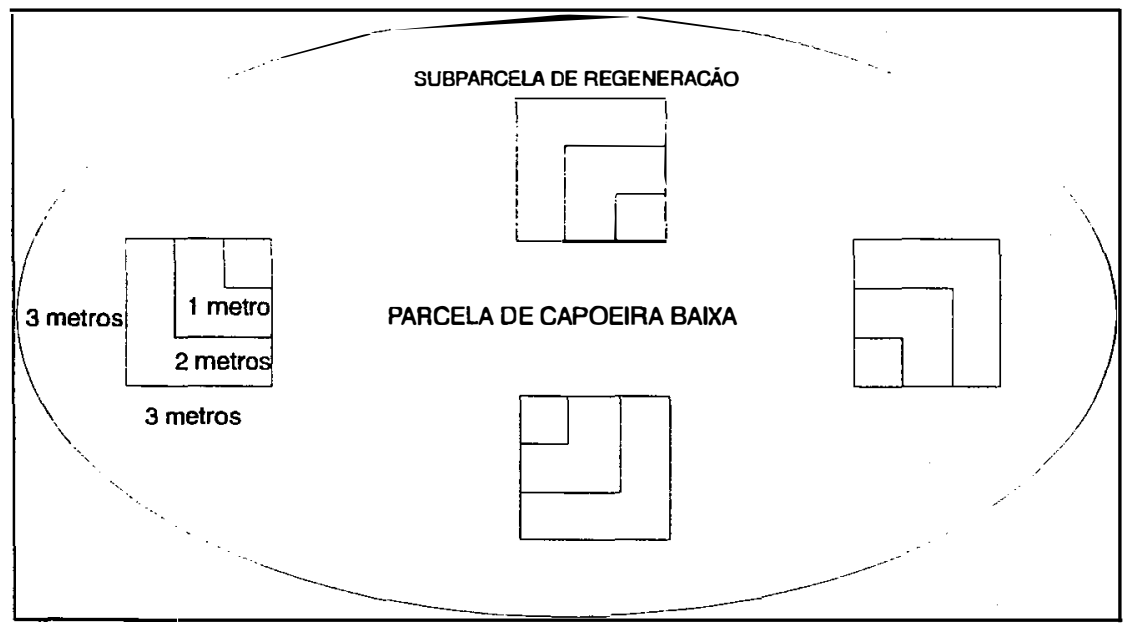

Figura 1 - Parcela esquemática de capoeira baixa, onde se observam as subparcelas de acompanhamento de regeneração natural. 
O corte de cipós, assim como o plantio de enriquecimento, foi realizado em janeiro de 1994, e foi feito deixando-se todos os indivíduos arbóreos, mesmo pequenas arvoretas.

Todas as operações foram feitas com acompanhamento de gasto de mão-de-obra para quantificação de custos de todos os tratamentos.

\subsubsection{Manejo de capoeira alta}

Este experimento tem como objetivo o desenvolvimento de uma metodologia de manejo de ecounidades em menor grau de degradação de florestas nativas, a capoeira alta (ver capítulo 2). Este manejo visa basicamente limitar o crescimento de cipós, favorecendo a vegetação arbórea.

\section{O experimento constou dos seguintes tratamentos:}

Tratamento 1 - Corte de cipós - corte de todo o cipó, com cortes sucessivos sempre que necessário. Este tratamento não constou de plantio na medida em que a ecounidade capoeira alta já apresenta uma densidade relativamente de indíviduos arbóreos, ainda que grandemente afetada pelos cipós.

Tratamento 2 - Parcela testemunha, sem nenhuma interferência.

O trabalho de manejo de capoeira alta, assim como o de capoeira baixa, foi todo desenvolvido em um só fragmento, na Usina Capuava (veja descrição e mapa do local no capítulo 2).

As parcelas têm $30 \mathrm{~m} X 30 \mathrm{~m}$, para efeito de levantamento da vegetação. $O$ corte de cipós, no entanto, foi feito em uma área de $50 \mathrm{~m} \mathrm{X} \mathrm{50m,} \mathrm{para} \mathrm{evitar} \mathrm{que} \mathrm{cipós} \mathrm{que} \mathrm{estejam}$ sobre árvores vizinhas às parcelas tenham condições de invadí-las pelas copas das árvores.

Foram utilizadas cinco repetições. Posteriormente ao corte de cipós, foi feito um inventário da vegetação existente nas parcelas, que será repetido regularmente. Esse inventário incluiu todos os indivíduos arbóreos da parcela com DAP igual ou maior que $5 \mathrm{~cm}$.

O corte de cipós foi realizado em janeiro de 1995 , e foi feito deixando-se todos os indivíduos de espécies arbóreas, mesmo pequenas arvoretas.

Todas as operações foram acompanhadas quanto aos custos. A mão-de-obra utilizada foi volante (diaristas).

\subsubsection{Análise dos dados}

Os dados sobre o crescimento das espécies utilizadas no plantio de enriquecimento são discutidos em capítulo à parte (capítulo 4). 


\subsubsection{Resultados do manejo em capoeira baixa}

Os dados relativos aos indivíduos plantados são mostrados e discutidos em capítulo a parte (4), não sendo considerados em nenhum instante nesse capítulo.

\subsection{Crescimento de árvores preexistentes}

Os dados referem-se a duas medições anuais: Tl, feita imediatamente após a instalação do experimento, e T2, feita 12 meses após a instalação do experimento. $\mathrm{O}$ crescimento de árvores preexistentes, com DAP maior ou igual a $5 \mathrm{~cm}$, foi analisado comparando-se em cada tempo (dentro de $\mathrm{T} 1$ e dentro de $\mathrm{T} 2$ ) o inventário de cada tratamento com os outros, utilizando-se um teste $F$ de um fator, e em caso de significância, um teste de Tukey. Também foi comparada a variação absoluta para os diferentes tratamento, dos inventários de T1 para T2, utilizando-se os mesmos testes. Finalmente foi feita também a comparação dos inventários em $\mathrm{T} 1$ e T2, dentro de cada tratamento, através de um teste $\mathrm{T}$ de Student.

\subsection{Regeneração natural}

Os dados analisados referem-se a três medições semestrais: T1, feita cerca de 1 mês após a instalação do experimento; T2, feita cerca de 6 meses após a instalação do experimento, e T3, feita após cerca de 12 meses após a instalação do experimento. A dinâmica de regeneração de individuos de espécies arbóreas com altura igual ou superior a $5 \mathrm{~cm}$ foi analisada comparando-se dentro de T1, T2 e T3 o inventário de cada tratamento com os outros, utilizando-se um teste $\mathrm{F}$ de um fator, e em caso de significância, um teste de Tukey. Também foi comparada a variação absoluta, dos inventários de T1 par T2, deste para T3, e deste para T1, utilizando-se os mesmos testes. Finalmente foi feita também a comparação dos inventários em $\mathrm{T} 1 \operatorname{com} \mathrm{T} 2$, e $\mathrm{T} 1 \operatorname{com} \mathrm{T} 3$, dentro de cada tratamento, através de um teste T de Student.

\subsubsection{Resultados do manejo em capoeira alta}

Em função do tempo de acompanhamento do experimento ser relativamente curto, o experimento de manejo de capoeira alta será apenas analisado quanto aos seus custos.

\subsection{RESULTADOS E DISCUSSÃO}

\subsubsection{Manejo de capoeira baixa}

Algumas das espécies mais comuns encontradas nas parcelas de capoeira baixa foram Acacia paniculata Willd. (Mimosaceae), Celtis iguanaea (Jacquin) Sargent (Ulmaceae), Dicella bracteosa (Adr. Juss.) Griseb. (Malpighiaceae) e Pirostegia venusta Miers. (Bignoniaceae). Particularmente as duas primeiras espécies, dominam amplos trechos de várias parcelas, e apresentam crescimento bastante intenso. Foi observado para Celtis iguanaea crescimento de até $3 \mathrm{~cm}$ por dia, no verão. 


\subsubsection{Crescimento de árvores preexistentes}

O efeito do tratamento sobre o crescimento de árvores preexistentes (com DAP igual ou maior que $5 \mathrm{~cm}$ ) não foi muitoexpressivo, ainda que as parcelas dos tratamentos 1 a 4 tenham apresentado crescimento positivo, enquanto as testemunhas apresentaram crescimento negativo. Isso pode ser explicado pelo curto período de tempo de acompanhamento (12 meses). Trabalhos que estudam o crescimento em árvores adultas normalmente consideram períodos de vários anos, para que os valores de incremento sejam maiores (ex. LANG \& KNIGHT, 1983; SWAINE et al., 1987). Espera-se que nos próximos anos os valores sejam mais significativos. As tabelas 1,2 e 3 mostram os valores encontrados em $\mathrm{T} 1$, e $\mathrm{T} 2$ para área basal/ha, densidade, e área de copa. $\mathrm{O}$ efeito das diferentes associações de plantio utilizadas nos tratamentos 1 a 3 sobre o crescimento de árvores preexistentes nesses primeiros meses após a instalação do experimento deve ser muito semelhante (efeito do plantio e do controle de cipós); logo, foi também colocado nas tabelas a média para esses três tratamentos, para ser comparada com os tratamentos 4 e 5 (corte de cipós sem plantio e testemunha).

Para área basal, em $\mathrm{T} 1$ todos os tratamento eram estatisticamente $(\mathrm{p}=0,05)$ iguais. No tempo 2 já havia diferença, embora essa diferença fosse significativa apenas para parcelas sem plantio (tratamento $4 ; p=0,05$ ) em relação aos outros tratamentos. Apesar de ter havido um incremento nos tratamentos 1 a 3 , e uma diminuição nas testemunhas, essa diferença de comportamento não foi significativa. $O$ tratamento 4 mostra resultados tão diferentes dos outros em boa parte devido a uma intensa regeneração de Ricinus communis (mamona) em uma de suas parcelas. Nesta parcela, no T2, 91,3\%, 95,1\% e $94,2 \%$ de sua área basal/ha, plantas/ha, e área de copa/ha, respectivamente, pertenciam à essa espécie. Entretanto a retirada dos dados referentes a essa espécie durante a análise estatística não a alterou. A tabela 15 mostra os dados de T1 e T2 com um teste que compara a variação na área basal, de T1 para T2, dentro de cada tratamento. Nesta tabelas percebe-se que há uma pequena significância $(p=0,50)$ para o tratamento 1 , assim como para os tratamentos 1 a 3 , quando considerados em conjunto. Para o tratamento 4 a significância é alta $(p=0,05)$. Na figura 2 pode ser observada mais facilmente a diferença entre T1 e T2 dentro de cada tratamento.

Tabela 1 - Área basal média $\left(\mathrm{m}^{2} / \mathrm{ha}\right)$ em T1 e T2 nas parcelas do experimento de manejo de capoeira baixa $(D A P \geq 5 \mathrm{~cm})$. $1-2-3($ com plantio)=média entre as parcelas dos tratamentos $1 \mathrm{a}$ 3 , com plantio de enriquecimento. $\mathrm{Tl}$ =medição realizada na instalação do experimento; T2=medição realizada 12 meses após instalação do experimento; Variação (\%)=variação percentual em relação a $T 1$.

\begin{tabular}{|c|c|c|c|}
\hline Tratamento & T1 & T2* & Variação (\%) \\
\hline 1 & 1,53 & $2,31^{0.50}$ & 50,98 \\
\hline 2 & 2,67 & 3,18 & 19,10 \\
\hline 3 & 3,20 & 3,67 & 14,69 \\
\hline 4 (sem plantio) & 4,25 & $9,08^{0,05}$ & 113,65 \\
\hline 5 (testemunha) & 3,46 & 2,48 & $-98,00$ \\
\hline 1-2-3 (com plantio) & 2,47 & $3,06^{0.50}$ & 23,89 \\
\hline
\end{tabular}

*números sobrescritos referem-se à significância estatística (teste $t$ de Student) na comparação entre tempos 1 e 2 dentro de cada tratamento. 
A tabela 2 mostra a variação em densidade de plantas de T1 para T2 (ver também figura 3). A única diferença estatística entre os tratamentos em T1 era entre os tratamentos 4 e 5 . Já em T2 o tratamento 4 se diferenciava de todos os outros. A tabela 2 mostra os dados de T1 e T2 com um teste que compara a variação no número de plantas/ha, de $\mathrm{T} 1 \mathrm{~T} 2$, dentro de cada tratamento. Observa-se uma pequena significância $(\mathrm{p}=0,5)$ para $\mathrm{o}$ tratamento 1, e uma significância maior para o tratamento 4 e para os tratamento 1 a 3 quando comparados em conjunto $(\mathrm{p}=0,25)$.

Em relação à área de copa/ha as mudanças foram mais significativas do que para as variáveis anteriores (área basal e densidade). Isso porque as árvores, quando cobertas por cipós nas capoeiras baixas, mantém copas subdesenvolvidas, desproporcionais ao diâmetro de seus troncos. Quando liberadas da competição com os cipós, após o seu corte, rapidamente aumentam de copa. Para o teste mostrado na tabela 3 , as diferenças seguem o mesmo padrão da variável densidade, mas com significância muito maior. A variação entre T1 e T2 pode ser observada mais facilmente consultando-se a figura 4.

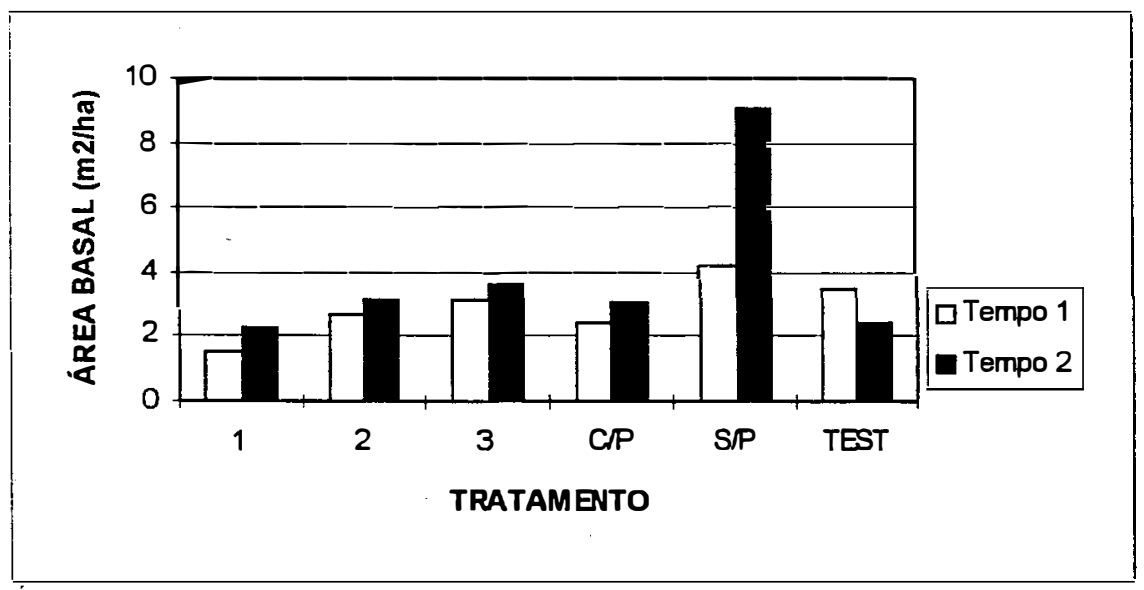

Figura 2 - Ârea basal média nas parcelas do experimento de manejo de capoeira baixa na instalação do experimento (Tempo 1) e 12 meses após (Tempo 2), para árvores com DAP $\geq$ $5 \mathrm{~cm} .1,2$ e 3 = parcelas dos tratamentos 1,2 e 3 , respectivamente; $C / P=$ média das parcelas dos tratamentos 1,2 e 3 (com plantio); $\mathrm{S} / \mathrm{P}=$ parcelas do tratamento 4 (sem plantio); Test = parcelas testemunhas.

Para as três variáveis o coeficiente de variação observado entre parcelas de um mesmo tratamento foi alto, variando de 27,45 a $142,98 \%$. Essa valor bastante alto mostra a dificuldade em se trabalhar com ambientes naturais, onde são muitas as variáveis sem controle. 
Tabela 2 - Densidade média de árvores (indivíduos/ha) em T1 e T2 nas parcelas do experimento de manejo de capoeira baixa (DAP $\geq 5 \mathrm{~cm}$ ). 1,2,3=média entre as parcelas dos tratamentos 1 a 3 , com plantio de enriquecimento. $T 1=$ =medição realizada na instalação do experimento; T2=medição realizada 12 meses após instalação do experimento; Variação $(\%)=$ variação percentual em relação a $\mathrm{T} 1$.

\begin{tabular}{||c|l|l|l||}
\hline Tratamento & \multicolumn{1}{|l||}{} & & \\
\hline 1 & 241,37 & $341,08^{0,50}$ & Variação (\%) \\
\hline $\mathbf{2}$ & 259,91 & 311,27 & 41,31 \\
\hline $\mathbf{3}$ & 252,01 & 334,56 & 19,76 \\
\hline $\mathbf{4}$ (sem plantio) & 445,00 & $1.287,69^{0,25}$ & 32,76 \\
\hline 5 (testemunha) & 148,01 & 116,57 & $-21,24$ \\
\hline $1,2,3$ & 251,10 & $328,97^{0,25}$ & 31,01 \\
\hline
\end{tabular}

*números sobrescritos referem-se à significância estatística (teste t de Student) na comparação entre tempos 1 e 2 dentro de cada tratamento.

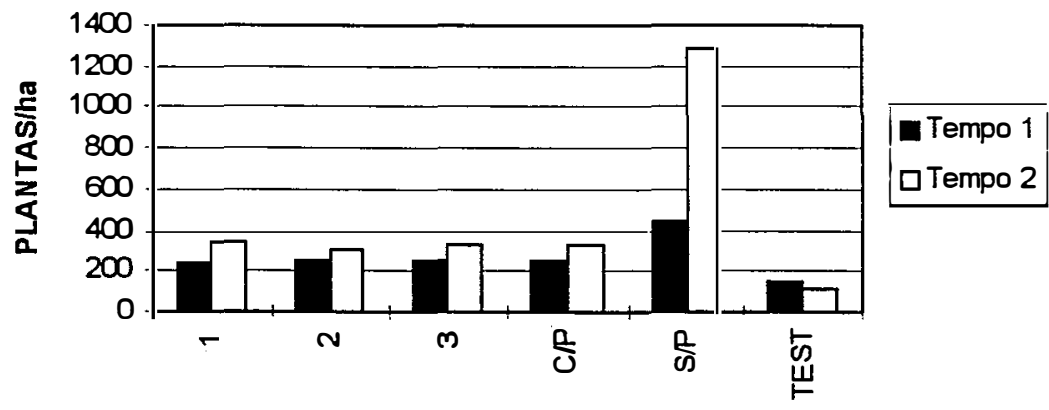

TRATAMENTO

Figura 3 - Densidade média de indivíduos arbóreos (DAP $\geq 5 \mathrm{~cm})$ nas parcelas do experimento de manejo de capoeira baixa na instalação do experimento (Tempo 1) e 12 meses após (Tempo 2). 1,2 e $3=$ parcelas dos tratamentos 1,2 e 3 , respectivamente; $\mathbf{C} / \mathbf{P}=$ média das parcelas dos tratamentos 1,2 e 3 (com plantio); $\mathrm{S} / \mathrm{P}=$ parcelas do tratamento 4 ( sem plantio); Test $=$ parcelas testemunhas.

Tabela 3 - Área média de copa de vegetação arbórea $\left(\mathrm{m}^{2} / \mathrm{ha}\right)$ em T1 e T2 nas parcelas do experimento de manejo de capoeira baixa (DAP $\geq 5 \mathrm{~cm}$ ). 1,2,3=média entre as parcelas dos tratamentos 1 a 3 , com plantio de enriquecimento. Tl=medição realizada na instalação do experimento; T2=medição realizada 12 meses após instalação do experimento; Variação $(\%)=$ variação percentual em relação a $\mathrm{T} 1$.

\begin{tabular}{||c|l|l|l||}
\hline \multicolumn{1}{|l|}{ Tratamento } & T1 & T2* & Variação (\%) \\
\hline \hline $\mathbf{1}$ & 538,16 & $2.038,01^{0.025}$ & 278,70 \\
\hline $\mathbf{2}$ & 767,19 & $1.358,24^{0.25}$ & 100,50 \\
\hline $\mathbf{3}$ & 438,75 & $1.999,84^{0.25}$ & 355,80 \\
\hline 5 (sem plantio) & $1.914,7$ & $5.855,93^{0.10}$ & 205,84 \\
\hline $\mathbf{1 , 2 , 3}$ & 426,86 & 629,26 & 47,42 \\
\hline
\end{tabular}

*números sobrescritos referem-se à significância estatística (teste t de Student) na comparaçẫo entre tempos 1 e 2 dentro de cada tratamento. 


\subsubsection{Regeneração natural}

A resposta das parcelas de capoeira baixa ao manejo foi bastante forte. No entanto, a variação na intensidade da resposta dentro de cada tratamento foi muito grande, fazendo com que fossem poucas as diferenças significativas. A heterogeneidade ambiental afeta grandemente a germinação de sementes e o estabelecimento de plântulas, principalmente em espécies de sementes pequenas (HARPER, 1977). Diferenças na microtopografia, disponibilidade de água, atividade da fauna, altura da vegetação ao redor, tamanho da parcela, e efeito residual da geada dentro e entre parcelas devem explicar grande parte dessa variabilidade.

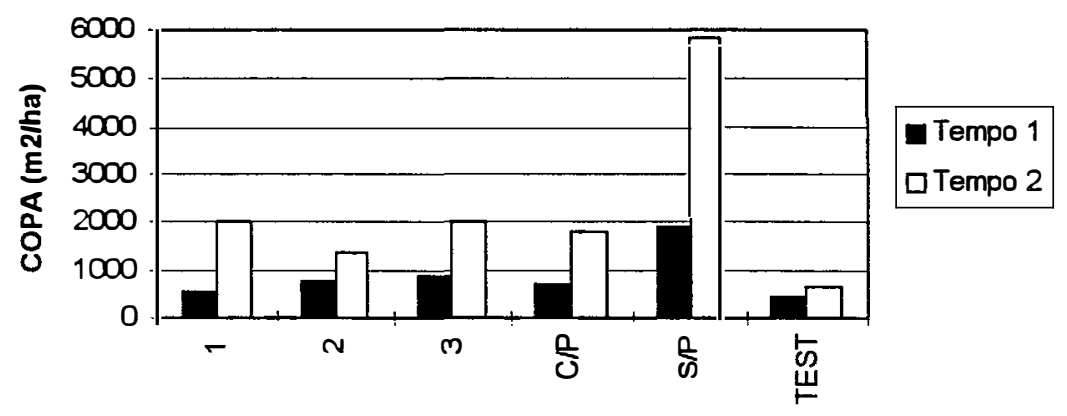

TRATAMENTO

Figura 4 - Área média de copa $\left(\mathrm{m}^{2} / \mathrm{ha}\right)$ de indivíduos arbóreos $(\mathrm{DAP} \geq 5 \mathrm{~cm})$ nas parcelas do experimento de manejo de capoeira baixa na instalação do experimento (Tempo 1) e 12 meses após (Tempo 2). 1, 2 e $3=$ parcelas dos tratamentos 1,2 e 3 , respectivamente; $\mathbf{C} / \mathbf{P}=$ média das parcelas dos tratamentos 1,2 e 3 (com plantio); $\mathrm{S} / \mathrm{P}=$ parcelas do tratamento 4 (sem plantio); Test $=$ parcelas testemunhas.

Nos testes $\mathrm{F}$ utilizados, comparando-se os tratamentos entre si em cada tempo ( $T 1, T 2$ e T3), não foi encontrada nenhuma diferença significativa $(p=0,05)$. No entanto no teste $\mathrm{T}$ de Student utilizado, comparando-se $\mathrm{T} 1$ com $\mathrm{T} 2$, e $\mathrm{T} 1$ com T3 para área basal/ha, plantas/ha e copa/ha, dentro de cada tratamento foram encontrados vários resultados significativos, a diferentes níveis de significância (tabelas 4, 5 e 6). Os mesmos resultados são mostrados nas figuras 5, 6 e 7. O efeito das diferentes associações de plantio utilizadas nos tratamentos 1 a 3 sobre a regeneração natural nesses primeiros meses após a instalação do experimento deve ser muito semelhante (efeito do plantio e do controle de cipós), e pode-se observar pelas figuras 5 a 7 que as parcelas sob esses tratamentos apresentam a mesma tendência para as três variáveis consideradas. Logo, foi também colocado nas tabelas e nos gráficos a média para esses tratamentos, para ser comparado com os tratamentos 4 e 5 (corte de cipós sem plantio e testemunha). 
Tabela 4 - Área basal média $\left(\mathrm{m}^{2} / \mathrm{ha}\right)$ em T1, T2 e T3 nas parcelas do experimento de manejo de capoeira baixa (altura $\geq 1,5 \mathrm{~m}$ ). 1,2,3=média entre as parcelas dos tratamentos 1 a 3, com plantio de enriquecimento. Tl=medição cerca de 1 mês após instalação do experimento; T2=medição realizada 6 meses após instalação do experimento; T3=medição realizada 12 meses após instalação do experimento.

\begin{tabular}{|c|c|c|c|}
\hline Tratamento & T1 & T2* & $\mathrm{T}^{*}{ }^{*}$ \\
\hline 1 & 1,21 & $2,34^{0.50}$ & $4,45^{0,25}$ \\
\hline 2 & 3,62 & 4,70 & $11,68^{0.50}$ \\
\hline 3 & 1,58 & $2,71^{0,50}$ & $4,80^{0,25}$ \\
\hline $1,2,3$ & 2,14 & $3,25^{0,50}$ & $6,98^{0.10}$ \\
\hline 4 (sem plantio) & 1,55 & 1,94 & 2,38 \\
\hline 5 (testemunha) & 9,32 & 9,39 & $2,09^{0,50}$ \\
\hline
\end{tabular}

*números sobrescritos referem-se à significància estatística (teste t de Student) na comparação entre tempos 1 e 2 dentro de cada tratamento.

O Tl para plantas/ha (tabela 5 e figura 6) não equivale à situação original da parcelas, já que todo o levantamento de regeneração natural nas parcelas foi feito cerca de 30 dias após o corte de cipós e o plantio nas parcelas, período suficiente para que houvesse o surgimento de muitas plântulas. Isso é particularmente observado no gráfico 6 , pela grande diferença em número de plantas para as parcelas dos tratamentos 1 a 4 e do tratamento 5 (testemunhas), no Tl. Observa-se também que para todos os tratamentos (exceção da testemunhas) ocorre uma redução acentuada no número de plantas, significativa para a maioria deles, no T2. No T3 essa redução continua e passa a ser significativa para todos os tratamentos. Para as parcelas testemunhas ocorre um aumento relativamente grande na densidade do $\mathrm{T} 1$ para o $\mathrm{T} 2$. No entanto esse aumento é pouco significativo $(\mathrm{p}=0,50)$, porque é praticamente todo devido a apenas uma espécie de sub-bosque (Allophyllus edulis) que germinou muito em duas subparcelas (das 20 relativas às 5 parcelas testemunhas), onde a cobertura de cipó é um pouco menor. A grande maioria dessas plântulas já havia morrido por ocasião do inventário no T3.

Tabela 5 - Densidade média (plantas/ha) em T1, T2 e T3 nas parcelas do experimento de manejo de capoeira baixa (altura $\geq 5 \mathrm{~cm}$ ). 1,2,3=média entre as parcelas dos tratamentos 1 a 3 , com plantio de enriquecimento. $\mathrm{Tl}$ =medição cerca de 1 mès após instalação do experimento; T2=medição realizada 6 meses após instalação do experimento; T3=medição realizada 12 meses após instalação do experimento.

\begin{tabular}{||c|l|l|l||}
\hline \multicolumn{1}{||}{ Tratamento } & $\mathbf{T 1}$ & $\mathbf{T} 2^{*}$ & $\mathbf{T} 3^{*}$ \\
\hline $\mathbf{1}$ & $11.444,44$ & $5.861,11^{0.25}$ & $5.055,56^{0.25}$ \\
\hline $\mathbf{2}$ & $34.736,11$ & $6.209,44^{0.25}$ & $5.138,89^{0.25}$ \\
\hline $\mathbf{3}$ & $24.125,00$ & $14.041,67$ & $9.777,78^{0.50}$ \\
\hline $\mathbf{1 , 2 , 3}$ & $23.435,20$ & $8.704,07^{0.10}$ & $6.657,40^{0,05}$ \\
\hline 5 (sem plantio) & $11.638,89$ & $2.611,11^{0.50}$ & $1.638,89^{0.50}$ \\
\hline 5 (testemunha) & $6.458,33$ & $24.000,00^{0.50}$ & $11.430,56$ \\
\hline
\end{tabular}

*números sobrescritos referem-se à significància estatística (teste $t$ de Student) na comparação entre tempos 1 e 2 dentro de cada tratamento. 
Após um surgimento intenso de novas plantas, em função da instalação do experimento, esse processo diminui de intensidade pela própria ocupação do espaço disponível, e pela alteração química do ambiente provocada pelas plantas que crescem (HARPER, 1977), enquanto que a maioria das plantas surgidas morre. Plântulas em clareiras sofrem alta mortalidade, conforme indivíduos de crescimento mais intenso suplantam os de crescimento mais lento (WELDEN et al., 1991). Também com o passar do tempo há a ocupação do espaço, em algumas parcelas formando-se um denso "stand" de plantas adultas. Essas populações através do sombreamento, retirada de umidade e nutrientes do solo, produção de substâncias alelopáticas e ocupação do espaço fisico podem fazer o recrutamento de novas plântulas se tomar extremamente dificil (ANGEVINE \& CHABOT, 1979).

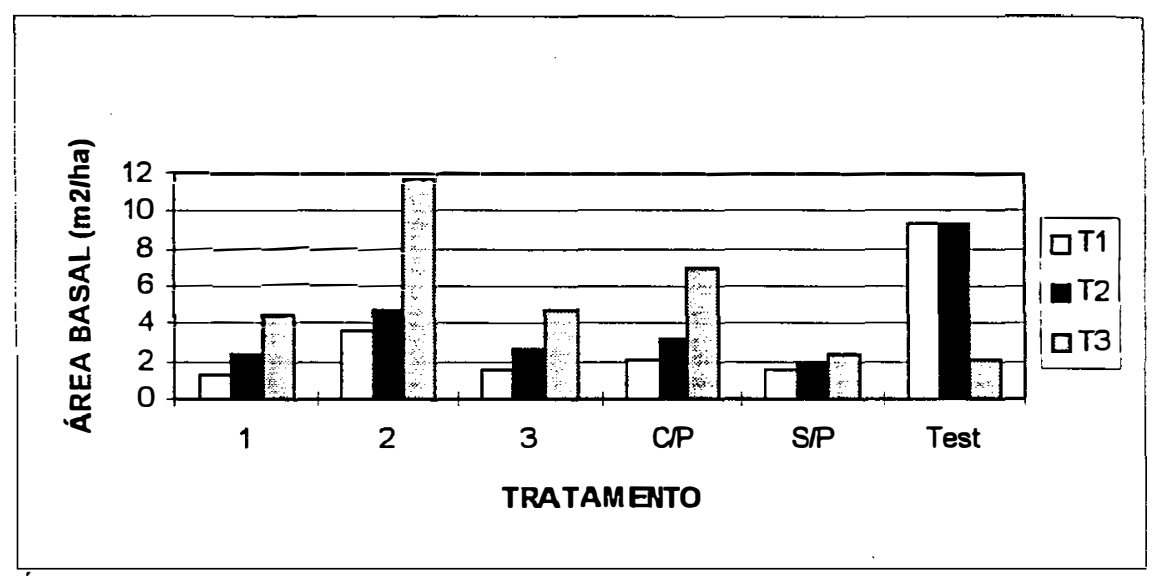

Figura 5 - Área basal média nas parcelas do experimento de manejo de capoeira baixa na instalação do experimento (T1), 6 meses (T2) e 12 meses após (T3), para indivíduos de espécies arbóreas (altura $\geq 5 \mathrm{~cm}$ ). 1, 2 e 3 = parcelas dos tratamentos 1,2 e 3 (com plantio), respectivamente; $\mathrm{C} / \mathrm{P}=$ média das parcelas com plantio; $\mathrm{S} / \mathrm{P}=$ parcelas sem plantio; Test $=$ parcelas testemunhas.

A variação no número de plântulas entre as quatro sub-parcelas de cada parcela foi bastante alta. Segundo BROWN (1993) plântulas crescendo em diferente pontos de uma mesma clareira estão sujeitas a diferenças microclimáticas significativas, principalmente decorrentes da incidência de radiação fotossinteticamente ativa. Assim, esses resultados estão em concordância com os dados encontrados por este autor em Boméo, podendo-se esperar grande diversidade entre as subparcelas (por exemplo, em função do sol estar ao norte mais meses por ano, no hemisfério sul, as sub-parcelas sul recebem mais luz, mas também podem apresentar maior déficit hídrico do que as sub-parcelas norte). 


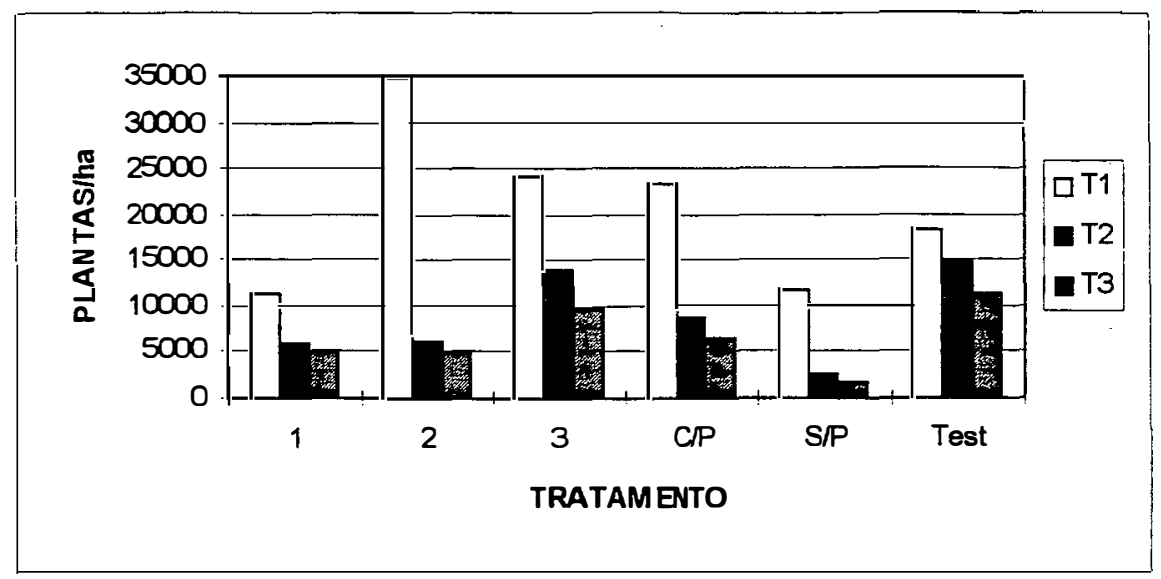

Figura 6 - Densidade média (plantas/ha) nas parcelas do experimento de manejo de capoeira baixa na instalação do experimento (T1), 6 meses (T2) e 12 meses após (T3), para indivíduos

de espécies arbóreas (altura $\geq 5 \mathrm{~cm}$ ). 1,2 e $3=$ parcelas dos tratamentos 1,2 e 3 (com plantio), respectivamente; $\mathrm{C} / \mathrm{P}=$ média das parcelas com plantio; $\mathrm{S} / \mathrm{P}=$ parcelas sem plantio; Test $=$ parcelas testemunhas.

A densidade na primeira medição, e o seu decréscimo nas medições subsequentes nas parcelas do tratamento 4 é menor do que nas parcelas dos tratamentos 1 a 3. Isso acontece porque nessas parcelas a germinação de sementes ocorreu somente imediatamente após o primeiro corte de cipós, enquanto que nas parcelas com plantio isso ocorreu por um tempo mais longo e com maior intensidade. Além disso, a mortalidade das plantas novas é maior nas parcelas sem plantio. Isso possivelmente ocorre porque a competição com os cipós é maior nessas parcelas. Nas parcelas com plantio, o cipó é mantido, através de um maior número de cortes de cipó de manutenção, mais baixo do que nas parcelas sem plantio, para que não prejudique as mudas plantadas. Além disso, nas parcelas com plantio houve o revolvimento do solo no coveamento, o que provocou a germinação do banco de sementes, principalmente de indivíduos de Solanum granuloso-leprosum e alguns de Trema micrantha. Muitas dessas plantas, que nasceram ao lado das mudas plantadas, foram cortadas por ocasião das medições de crescimento. Isso porque a concorrência dessas plantas com as mudas poderia alterar os dados de crescimento, assim como pelo fato dessas plantas terem uma longevidade muito curta quando comparadas com as espécies plantadas, ou seja, haveria o risco de perda das mudas plantadas e de sua substituição por uma espécie que rapidamente estaria morta. Mesmo na prática, independente da pesquisa científica, é provável que o melhor procedimento fosse esse. Em algumas parcelas sem plantio houve uma germinação intensa de mamona (Ricinus communis), o que fez com que fosse alta a germinação imicial nessas parcelas. Essa espécie, possuindo uma semente bastante grande, provavelmente pode germinar sob o espesso folhedo observado na maioria das parcelas de capoeira baixa, independentemente de qualquer revolvimento do solo. Aparentemente suas sementes vêm das bordas da estrada que margeia o fragmento. Espécies pioneiras típicas, no entanto, não são capazes de fazer o mesmo, o que limita a germinação de suas sementes às parcelas onde houve o revolvimento do solo, ou onde a camada de folhedo é menos espessa. A capoeira baixa normalmente apresenta mais serrapilheira que a capoeira alta, devido à maior produção de biomassa foliar dos cipós em relação às árvores, em função da taxa de crescimento extremamente alta (PUTZ, 1984), maior período de produção de folhas durante o ano do que a vegetação arbórea (PUTZ \& WINDSOR, 1987) e grande capacidade de extensão dos tecidos (PEÑALOSA, 1985). Essa serrapilheira inibe a germinação 
das sementes de espécies arbóreas pioneiras, agindo como uma cobertura vegetal (VAZQUEZYANES et al., 1990; MOLOFSKY \& AUGSPURGER, 1992). Isso pode ser mais um fator que dificulta a ocupação das clareiras pelas espécies arbóreas em fragmentos florestais. Esse fato pôde ser observado com bastante clareza em um fragmento estudado anteriormente (dados não publicados e VIANA \& TABANEZ, no prelo). Nesse fragmento, a população de espécies arbóreas pioneiras é bastante baixa, não obstante o banco de sementes possuir grande número de suas sementes, e uma grande percentagem de sua área ser ocupada por capoeira baixa. Esse fragmento sofreu um incêndio recente (agosto de 1994), o que resultou em uma regeneração intensa por parte dessas espécies pioneiras. Além do choque térmico causado pelo fogo, houve também a destruição da serrapilheira e da cobertura de cipós, que provavelmente impediam essas espécies de ocupar as áreas de capoeira baixa.

Para a área basal o $\mathrm{T} l$ pode ser considerado como situação original, anterior ao tratamento (tabela 4 e figura 5). Esse parâmetro só é medido em plantas maiores que $1,5 \mathrm{~m}$, que dificilmente estariam com essa altura por ocasião do primeiro inventário se nascidas após a instalação do experimento. Para os tratamentos 1,2 e 3, e para a média entre eles, ocorre um incremento muito forte na área basal, seja pelo recrutamento de novos indivíduos, seja pelo crescimento dos que já existiam. Esse incremento, pouco significativo de $T 1$ para $T 2$, aumenta bastante de significância de $T 1$ para $T 3(p=0,5$ para $p=0,10$, no caso dos tratamentos 1 a 3 considerados conjuntamente). Para as parcelas sem plantio esse incremento é bem menor, principalmente pela falta de recrutamento de novos indivíduos, e não significativo. Deve-se ressaltar que para o caso de indivíduos com altura superior a cerca de um metro na época de instalação do experimento, o efeito do tratamento nas parcelas com e sem plantio é o mesmo (corte de cipós). Por isso a diferença é realmente no recrutamento de novos indivíduos. Para as testemunhas não há praticamente nenhuma alteração de Tl para T2, e uma forte redução do T1 para o T3. Essa redução é devida à morte de um único indivíduo relativamente grande.

Tabela 6 - Área média de copa de vegetação arbórea $\left(\mathrm{m}^{2} / \mathrm{ha}\right)$ em T1, T2 e T3 nas parcelas do experimento de manejo de capoeira baixa (altura $\geq 1,5 \mathrm{~m}$ ). 1,2,3=média entre as parcelas dos tratamentos 1 a 3 , com plantio de enriquecimento. Tl=medição cerca de 1 mês após instalação do experimento; $T 2=$ =edição realizada 6 meses após instalação do experimento; T3=medição realizada 12 meses após instalação do experimento.

\begin{tabular}{||c|l|l|l||}
\hline Tratamento & T1 & T2 & T3 \\
\hline $\mathbf{1}$ & 875,04 & $2.943,97^{0.25}$ & $7.162,12^{0,05}$ \\
\hline $\mathbf{2}$ & $2.524,80$ & $2.763,56$ & $5.297,60^{0.50}$ \\
\hline $\mathbf{3}$ & 184,81 & $3.051,31^{0.05}$ & $11.288,93^{0.05}$ \\
\hline $\mathbf{1 , 2 , 3}$ & $1.194,89$ & $2.919,61^{0.05}$ & $\mathbf{7 . 9 1 6 , 2 0 ^ { 0 , 0 5 }}$ \\
\hline $\mathbf{4}$ (sem plantio) & $1.071,64$ & $1.707,64$ & $\mid 4.440,47^{0,25}$ \\
\hline 5 (testemunha) & $1.239,98$ & $1.323,29$ & $1.080,27$ \\
\hline
\end{tabular}

*números sobrescritos referem-se à significância estatística (teste $t$ de Student) na comparação entre tempos 1 e 2 dentro de cada tratamento.

A variação de área de copa segue o mesmo padrão que o da área basal (tabela 6 e figura 7). É interessante notar que as parcelas com plantio já apresentam, em T3, uma área média de copa próxima a $10.000 \mathrm{~m}^{2} / \mathrm{ha}$, o que equivale dizer que elas já estão, na média, 
após 18 meses de tratamento, com quase toda sua área coberta por vegetação arbórea. Para as testemunhas praticamente não há alteração.

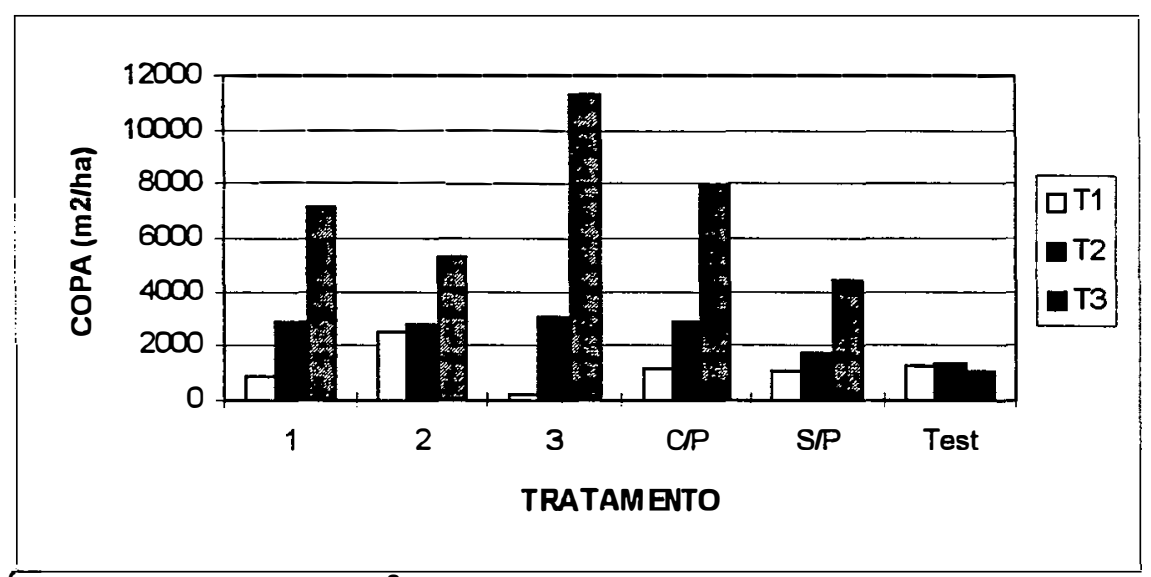

Figura 7 - Área média de copa $\left(\mathrm{m}^{2} / \mathrm{ha}\right)$ nas parcelas do experimento de manejo de capoeira baixa na instalação do experimento (T1), 6 meses (T2) e 12 meses após (T3), para indivíduos

de espécies arbóreas (altura $\geq 5 \mathrm{~cm}$ ). 1,2 e 3 =parcelas dos tratamentos 1,2 e 3 (com plantio), respectivamente; $\mathrm{C} / \mathrm{P}=$ média das parcelas com plantio; $\mathrm{S} / \mathrm{P}=$ parcelas sem plantio; Test $=$ parcelas testemunhas .

Novamente, para as três variáveis o coeficiente de variação observado entre parcelas de um mesmo tratamento foi alto, variando de 45,17 a $180,68 \%$. Essa valor bastante alto mostra a dificuldade em se trabalhar com ambientes naturais, onde são muitas as variáveis sem controle.

\subsubsection{Custos}

As parcelas foram abertas entre 13 de janeiro e 18 de fevereiro. A tabela 7 traz o custo por hectare do manejo de capoeira baixa pelos tratamentos 1 a 3 , baseado nos gastos de instalação desse experimento. A tabela 8 mostra o custo para o tratamento 4.

Os cortes de manutenção são feitos com maior freqüência nas parcelas com plantio (4/ano) do que nas parcelas sem plantio (1/ano), porque naquelas o cipó deve ser mantido mais baixo para não prejudicar as mudas plantadas. $\mathrm{O}$ rendimento do corte de cipó de manutenção nas parcelas sem plantio é estimado em $200 \%$ do rendimento do corte de manutenção das parcelas com plantio (tratamentos 1 a 3). Isso porque nesse tratamento não há mudas plantadas, que exigem uma grande atenção quando essa operação realizada. 
Tabela 7 - Custo total para 1 ha do manejo de capoeira baixa, em dólares americanos (taxa de câmbio $=\mathrm{R} \$ 1,00=\mathrm{US} \$ 0,95)$, pelos tratamentos 1 e 2 . Para o tratamento 3 , onde se utiliza 0 eucalipto, o custo total das mudas cai para US\$681,25, e o custo total de instalação para US $\$ 1693,93^{1}$.

\begin{tabular}{|c|c|c|c|}
\hline Atividade & Item & Custo unitário (US\$) & Custo total (US\$) \\
\hline Corte de cipó & 52,9 dias-homem ${ }^{2}$ & $6,08^{5}$ & 321,63 \\
\hline Coveamento & 17,1 dias-homem ${ }^{3}$ & $6,08^{5}$ & 103,97 \\
\hline Plantio & 10,7 dias-homem ${ }^{4}$ & $6,08^{5}$ & 65,06 \\
\hline Mudas & 1250 mudas $^{4}$ & $0,62^{6}$ & 775,00 \\
\hline Total/instalação & & & $1.265,66$ \\
\hline $\begin{array}{ll}\text { Manutenção } & - \\
\text { cortes de cipó em } & 2 \\
\text { anos }\end{array}$ & $\begin{array}{l}10,7 \text { dias- } \\
\text { homem/corte }^{7}\end{array}$ & $6,08^{5}$ & 520,45 \\
\hline $\begin{array}{l}\text { Total da instalação } \\
\text { ( } 2 \text { anos) }\end{array}$ & & & $1.786,11$ \\
\hline
\end{tabular}

1 - calculado com preços da muda retirada no viveiro do IPEF/Depto. de Ciências Florestais da ESALQ/USP em setembro de 1995:

312,5 mudas de espécie nativa pioneira/ha $X \mathrm{R} \$ 0,55=\mathrm{R} \$ 171.88=\mathrm{US} \$ 163,29$

625 mudas de espécies secundárias/ha X R $\$ 0,75=\mathrm{R} \$ 468,75=\mathrm{US} \$ 445,31$

312,5 mudas de eucalipto/ha X R $\$ 0,25=R \$ 78,13=$ US\$74,22

Total de gasto com mudas $=$ US $\$ 682,82$

2 - calculado com base em 58 dias-homem para $10.968,4 \mathrm{~m}^{2}$ (189, $1 \mathrm{~m}^{2} / \mathrm{dia}$-homem).

3 - calculado com base em 16 dias-homem para $9.344,0 \mathrm{~m}^{2}\left(584,0 \mathrm{~m}^{2} /\right.$ dia-homem).

4 - calculado com base em um espaçamento de $2 \mathrm{~m} \mathrm{X} \mathrm{4m} \mathrm{(1250} \mathrm{mudas/ba).}$

5 - diária para trabalhadores volantes em Piracicaba, em setembro de 1995.

6 - preço médio da muda de espécie nativa retirada no viveiro do IPEF/Depto. de Ciências Florestais da ESALQ/USP em setembro de 1995 ( $\mathrm{R} \$ 0,75$ por muda para espécies secundárias e $\mathrm{R} \$ 0,55$ por muda para espécies pioneiras).

7 - calculado com base na média de dois cortes, um com rendimento de $1.168,0 \mathrm{~m}^{2} / \mathrm{dia}$ homem $(8 \mathrm{dias}$-homem para $9.344,0 \mathrm{~m}^{2}$-feito somente nas parcelas com plantio, tratamentos 1,2 e 3 ) e outro com um rendimento de $698,6 \mathrm{~m}^{2} / \mathrm{dia}$ homem ( 15,7 dias-homem para $10.968,4 \mathrm{~m}^{2}$-feito nas parcelas com e sem plantio, tratamentos 1 a 4 ).

Tabela 8 - Custo total para 1 ha do manejo de capoeira baixa, em dólares americanos (taxa de câmbio $=\mathrm{R} \$ 1,00=\mathrm{US} \$ 0,95)$, pelo tratamento 4 .

\begin{tabular}{||l|l|l|l||}
\hline Atividade & Item & Custo unitário (US\$) & Custo total (US\$) \\
\hline Corte de cipó & 52,9 dias-homem & \\
\hline Totalinstalação & & $6,08^{2}$ & 321,63 \\
\hline $\begin{array}{l}\text { Manutenção - 2 } \\
\text { cortes de cipó em 2 } \\
\text { anos }\end{array}$ & $\begin{array}{l}5,4 \text { dias- } \\
\text { homem/corte }\end{array}$ & $6,08^{2}$ & 321,63 \\
\hline $\begin{array}{l}\text { Total da instalação } \\
\text { (2 anos) }\end{array}$ & & 65,66 \\
\hline
\end{tabular}

1 - calculado com base em 58 dias-homem para $10.968,4 \mathrm{~m}^{2}\left(189, \mathrm{~m}^{2} /\right.$ dia-homem).

2 - diária para trabalhadores volantes em Piracicaba, em setembro de 1995.

3 - calculado com base em $50 \%$ da média de dois cortes, um com rendimento de $1.168 .0 \mathrm{~m}^{2} / \mathrm{dia}$ homem (8 dias-homem para $9.344,0 \mathrm{~m}^{2}$-feito somente nas parcelas com plantio, tratamentos 1,2 e 3) e outro com um rendimento de 698,6 $\mathrm{m}^{2} /$ dia homem ( 15,7 dias-homem para $10.968,4 \mathrm{~m}^{2}$-feito nas parcelas com e sem plantio, tratamentos 1 a 4$)$.

Os gastos para os tratamentos 1 a 3 são relativamente altos. Entre outras razões para isso está o fato de que o serviço é feito em pequenos trechos, e não em uma área contínua; os locais de plantio são no interior da mata, o que torna necessário o transporte de 
ferramentas e mudas em picadas por 50 a 100 metros em geral; devido ao caráter científico do trabalho não houve uma preocupação exagerada com os custos; a escala feita foi pequena. No entanto esses gastos são semelhantes ao custo de replantio de florestas nativas, por exemplo nas áreas da CESP, onde o custo é ao redor de US\$1.500,00 (Prof. Dr. Paulo Y. Kageyama, comunicação pessoal), e tem a grande vantagem de que a biodiversidade em um fragmento manejado é muito maior que qualquer plantio heterogêneo que possa ser feito. Deve-se esperar que esses custos possam ser diminuídos com a experiência nesse tipo de manejo, e com o desenvolvimento de novas práticas. Esses gastos são bem maiores que os gastos para o tratamento 4. Entretanto os resultados do manejo têm mostrado maior eficiência na recuperação da vegetação arbórea para os tratamentos 1 a 3 que para o tratamento 4. Somente o contínuo acompanhamento desse experimento poderá responder se a economia de US $\$ 1.398,82$ entre os custos dos dois tratamentos é compensada por uma recuperação efetiva da estrutura arbórea nas áreas manejadas pelo tratamento 4 . Observações pessoais sugerem que as áreas sob esse tratamento tendem a diminuir a intensidade de resposta ao manejo ao longo do tempo, na medida em que as árvores preexistentes, e as primeiras plantas surgidas logo após a instalação do experimento, atinjam seu potencial máximo de resposta. Com a falta de surgimento de novas plantas, causada pelo reaparecimento do cipó, a tendência deve ser a diminuição a quase zero do incremento em densidade, área basal e copa para esses tratamento, enquanto os tratamentos 1 a 3 continuam a mostrar incremento nessas variáveis, não só pela regeneração natural que continua por um tempo maior, mas também pelo crescimento das árvores plantadas.

\subsubsection{Conclusão}

A variação dos parâmetros área basal/ha e área de copa/ha no levantamento de regeneração mostra um efeito mais efetivo dos tratamentos que envolvem plantio de enriquecimento que do tratamento sem plantio. Isso provavelmente é devido ao fato do acompanhamento da regeneração, ao considerar plantas a partir de $1,5 \mathrm{~m}$ de altura para essas duas variáveis, ter maior capacidade (maior sensibilidade temporal) para mostrar as mudanças ocorridas nesses primeiros 18 meses pós-tratamento do que o acompanhamento de árvores preexistentes, que só considera plantas a partir de $5 \mathrm{~cm}$ de DAP. Além disso, o acompanhamento da regeneração foi feito por 18 meses, contra 12 meses do acompanhamento de árvores preexistentes.

O efeito do manejo sobre a estrutura da $\mathrm{CB}$ foi bastante grande nos primeiros 18 meses após o manejo. Os custos mostram que esse manejo, ainda que somente uma proposta inicial, é economicamente factível, quando comparado ao custo de revegetação, por exemplo. Ao mesmo tempo, os riscos de extinção de espécies de cipó no manejo de CB parecem bastante reduzidos. Foi observado que as espécies de cipó que ocorrem na CB o fazem de maneira concentrada, ou seja, cada espécie domina grandes percentuais em cada trecho de CB. Assim, cada trecho desta ecounidade normalmente possui poucas espécies de cipó, porque cada uma ocupa uma grande área. Além disso as espécies se repetem muito nas diversas parcelas estudadas, sugerindo que sejam poucas espécies, pioneiras e mais agressivas, as responsáveis pela ocupação de CB. Assim o manejo com controle de cipós estaria limitando o desenvolvimento de poucas espécies. 


\subsubsection{Manejo de capoeira alta}

O experimento de manejo em capoeira alta está sendo acompanhado com medições semestrais de regeneração natural e anual em árvores com DAP $\geq 5 \mathrm{~cm}$. Até o momento ainda não há segundas medições para verificar o efeito do manejo nesta ecounidade. No entanto os resultados obtidos com o manejo em capoeira baixa sugerem que o manejo na capoeira alta possa ser eficiente na recuperação desta ecounidade.

\subsubsection{Custos}

Os custos do manejo da CA são mostrados na tabela 9. O rendimento do corte de cipó de manutenção é estimado em $400 \%$ do rendimento do primeiro corte. Isso porque o corte da rebrota do cipó é muito mais rápido do que o corte inicial.

Tabela 9 - Custo total para 1 ha do manejo de capoeira alta, em dólares americanos (taxa de câmbio $=\mathrm{R} \$ 1,00=\mathrm{US} \$ 0,95$ ).

\begin{tabular}{|c|c|c|c|}
\hline Atividade & Item & Custo unitário (US\$) & Custo total (US\$) \\
\hline Corte de cipó & 12,7 dias-homem ${ }^{1}$ & $6,08^{3}$ & 77,22 \\
\hline Total/instalação & & & 77,22 \\
\hline $\begin{array}{l}\text { Manutenção - } 1 \text { cortes de cipó } \\
\text { em } 2 \text { anos }\end{array}$ & $\begin{array}{l}, 2 \text { dias- } \\
\text { homem/corte }\end{array}$ & $6,08^{3}$ & 38,91 \\
\hline Total da instalação (2 anos) & & & 116,13 \\
\hline
\end{tabular}

\subsubsection{Conclusão}

\subsubsection{Perspectivas para o manejo de fragmento florestais}

A formação de clareiras é um processo da dinâmica natural das florestas. Os dados do fragmento da Usina Capuava sugerem, no entanto, que nos fragmentos de florestas de planalto não ocorre a regeneração da vegetação arbórea nessas clareiras. Essas clareiras se transformam rapidamente em capoeira baixa, intensamente dominadas por algumas espécies de cipós, muito agressivas e que impedem, a curto e médio prazo a regeneração de espécies arbóreas. Os resultados expostos neste trabalho reforçam as opiniões de que é necessário o manejo para conservar os fragmentos de florestas estacionais semideciduais, e mostram o resultado efetivo deste manejo (para os primeiros 18 meses) e a viabilidade econômica de praticá-lo.

É importante observar que as espécies pioneiras de cipó, mais que uma causa de degradação, parecem ser sua conseqüência, causada pela fragmentação desse ecossistema, e pela perturbação antrópica, principalmente na forma de extração madeireira. $O$ controle de cipó sozinho não deve garantir a recuperação desses fragmentos, assim como, se bem manejados, estes podem passar a prescindir desse tipo de manejo. 


\subsubsection{Proposta preliminar de manejo}

Esse experimento prevê o acompanhamento da vegetação por vários anos, quando então será possível discutir com maior propriedade esse método de manejo para fragmentos de floresta estacional semidecidual. Ao mesmo tempo novos métodos poderão ser sugeridos com os dados que forem sendo obtidos. Todavia já é possível, com os dados obtidos até o momento, sugerir uma proposta preliminar de manejo.

Devido ao custo relativamente alto do manejo da $\mathrm{CB}$, ao baixo custo do manejo de CA, e ao maior percentual da área dos fragmentos ocupados por esta ecounidade (ver capítulo 2), o manejo deve privilegiar esta última, sempre que o percentual de CB não ultrapassar cerca de $10 \%$ da área do fragmento. Quando esse percentual for maior, o manejo deve ser feito nas duas ecounidades. A quantificação do percentual de cada ecounidade pode ser feito através de levantamentos expeditos por pessoas bem treinadas. Quando o manejo for feito na $\mathrm{CB}$, pode ser feito em toda a área ocupada por ela, dependendo da disponibilidade de recursos financeiros. No manejo de CA o manejo não deve ser feito em toda a área, para que o risco de extinção de alguma espécie de cipó seja minimizado. Esse manejo pode ser feito em lotes referentes a $10 \%$ da área do fragmento ocupado por CA por ano, com um corte inicial, outro após 10 meses, e um cerca de um ano após, em cada trecho. Em dez anos todo o fragmento teria sido manejado, a um baixo custo. Após esse período o manejo deve ser recomeçado, a partir do primeiro trecho. Nesse período, entre um corte e outro, a vegetação arbórea se desenvolverão com menor concorrência, e as espécies de cipó provavelmente não serão completamente erradicadas da área, apenas terão sua densidade diminuída. Os trechos de CA que forem, com o tempo, se assemelhando à MM podem dispensar qualquer manejo. Por esta proposta é possível manejar, com apenas um funcionário, cerca de $118 \mathrm{ha} \mathrm{de} \mathrm{CA}$, em dez anos ${ }^{1}$. A falta de resultados para o manejo de CA faz com que essa proposta seja antes uma sugestão de pesquisa do que uma proposta prática de manejo. Sua aplicação depende dos resultados que forem sendo obtidos com a pesquisa.

Essa proposta, além de muito preliminar, não considera vários aspectos pertinentes à conservação de fragmentos florestais, como o efeito de borda, a questão do grau de isolamento e da forma do fragmento, e tópicos relativos à fauna, principalmente de polinizadores e dispersores. No entanto, estudar esses itens não é proposta deste trabalho, devendo ser estudados em trabalhos específicos, para que, combinados com esse e outros trabalhos semelhantes, possam auxiliar no desenvolvimento de métodos mais abrangentes para a conservação dos fragmentos.

\footnotetext{
${ }^{1}$ Considerando 226 dias de trabalho por ano, fazendo corte inicial (150 dias) e mais dois cortes de manutenção (38 dias/corte) em 11,8ha por ano.
} 


\section{CAPÍTULO 4}

\section{USO DE PLANTIO DE ENRIQUECIMENTO NO MANEJO DE ECOUNIDADES EM FRAGMENTOS DE FLORESTAS DE PLANALTO}

\subsection{INTRODUÇÃO}

Há várias décadas o plantio de essências nativas já era utilizado para a reconstituição de florestas nativas (NOGUEIRA, 1977; SILVA, 1992). Mais recentemente esse plantio tem sido feito em uma escala mais ampla, com desenvolvimento de métodos específicos (KAGEYAMA et al., 1990; BERTALOT \& HARKALY, 1992; KAGEYAMA et al., 1992). Esses métodos usam o conceito de grupos ecológicos para associar diferentes espécies, com diferentes características ecológicas.

Outro método que utiliza o plantio de espécies nativas é o plantio de enriquecimento, normalmente compreendido como o plantio de mudas em espaçamento bastante amplo, dentro da floresta nativa após exploração madeireira, para auxiliar a regeneração natural (BAUR, 1968). Esse método tem sido considerado em áreas onde é muito arriscado basear a recuperação da floresta somente pela regeneração natural (Aubreville, 1953b, citado por BAUR, 1968).

Trabalhos realizados em fragmentos florestais na região de Piracicaba têm mostrado que há dificuldades para a regeneração de espécies arbóreas nesses locais (Capítulo 2 e 3; VIANA, et al., 1992; TABANEZ \& VIANA, 1994). Nessas áreas, o plantio de enriquecimento pode ser um método auxiliar na recuperação da estrutura florestal e de populações de espécies arbóreas empobrecidas numericamente. A vegetação arbórea, plantada ou não, pode também ser usada para abafar locais dominados por cipós, a fim de limitar seu crescimento (BAUR, 1968).

\subsubsection{Problema de pesquisa}

O comportamento de espécies nativas em plantios tem sido estudado apenas recentemente, normalmente em situação de plantio de revegetação. $O$ plantio de espécies nativas na recuperaçãode de fragmentos florestais ainda não foi estudado.

Esse trabalho procura mostrar a melhor asssociação, de três propostas, para o plantio de enriquecimento na recuperação de fragmentos florestais.

\subsubsection{Hipótese}

i) diferentes associações de espécies comportam-se diferentemente quanto ao crescimento quando usadas em plantio de enriquecimento.

\subsubsection{Objetivos}

Esse trabalho faz parte de um projeto que estuda métodos de manejo para recuperação da estrutura florestal de fragmentos (capítulo 3). Seu objetivo é testar o plantio de enriquecimento com diferentes associações de espécies nativas. 


\subsection{MATERIAL E MÉTODOS}

\subsubsection{Obtenção dos dados}

\subsubsection{Manejo de capoeira baixa}

Este experimento tem como objetivo o desenvolvimento de um método de manejo de capoeira baixa (capítulo 2) de florestas nativas. Este manejo visa basicamente limitar o crescimento de cipós, favorecendo a regeneração das espécies arbóreas.

tratamentos:

O experimento foi instalado na ecounidade capoeira baixa, e consta dos seguintes

Tratamento 1 - Corte de cipós e plantio de enriquecimento - corte de todo o cipó, com plantio posterior de espécies arbóreas, utilizando-se a associação 1 (capixingui, monjoleiro, paineira e jequitibá-rosa). Periodicamente, sempre que necessário, foi feito novo corte de cipós.

Tratamento 2 - Idem ao anterior, mas utilizando-se, no plantio, a associação 2 (paupólvora, pau-d'alho, ipê e jatobá).

Tratamento 3 - Idem ao tratamento 2, mas utilizando-se, no plantio, a associação 3 (guassatonga, eucalipto, tamboril e pau-marfim).

Tratamento 4 - Corte de cipós - corte de todo o cipó, com cortes sucessivos sempre que necessário.

Tratamento 5 - Parcela testemunha, sem nenhum tratamento.

\subsubsection{Instalação das parcelas}

O projeto de manejo foi todo desenvolvido no fragmento da Usina Capuava (capítulo 3).

Para localização dos trechos de CB no fragmento, foi feito um sobrevôo com trike, anotando-os em um mapa. Esse aparelho, semelhante a um ultraleve, difere deste por ter a asa igual à de uma asa-delta. Permite o sobrevôo do piloto mais um passageiro, e pode ser muito útil para observações de florestas. Posteriormente, esses trechos foram localizados por terra. Os trechos com tamanho mínimo estimado em 100 metros quadrados foram utilizados para o experimento (cinco por tratamento, no total de vinte e cinco).

As parcelas têm tamanhos variáveis. Isso ocorreu porque, como os trechos de capoeira baixa utilizados no experimento ocorrem naturalmente no fragmento, exigir uma tamanho grande impediria o uso de muitos trechos de tamanho menor, provavelmente impedindo a localização dos 25 trechos necessários. Definir as parcelas com um tamanho muito pequeno desperdiçaria uma grande área disponível para experimentação. Assim, optou-se por utilizar os trechos de capoeira baixa de tamanhos diferentes. Os 25 trechos de CB encontrados foram divididos entre os diversos tratamentos através de um sorteio. A menor parcela para os 
tratamentos 1 a 3 (corte de cipó mais plantio) tem $328 \mathrm{~m}^{2}$, e a maior $1.064 \mathrm{~m}^{2}$ (com o plantio de 41 e 133 mudas das quatro espécies, respectivamente). A menor parcela do tratamento 4 (corte se cipó sem plantio) tem $178,7 \mathrm{~m}^{2}$, e a maior $472,5 \mathrm{~m}^{2}$. A menor e a maior parcela testemunha tem $254,5 \mathrm{~m}^{2}$ e $629,4 \mathrm{~m}^{2}$, respectivamente.

Neste capítulo o método é apenas discutido em relação ao comportamento das espécies utilizadas no plantio de enriquecimento. Para resultados do manejo deve-se consultar o capítulo 3.

\subsection{Espécies utilizadas no plantio de enriquecimento}

A tabela 1 mostra os nomes científicos e as familias das espécies utilizadas neste experimento. A tabela 2 mostra as associações utilizadas neste experimento, e a categoria sucessional em que as espécies foram consideradas para a montagem dos módulos de plantio (ver abaixo).

Tabela 1 - Espécies utilizadas no experimento de manejo de capoeira baixa.

\begin{tabular}{||l|l|l||}
\hline Espécie & Família & Nome vulgar \\
\hline Tabebuia sp & Bignoniaceae & Ipê \\
\hline Chorisia speciosa St. Hil. & Bombacaceae & Paineira \\
\hline Hymenaea courbaril L. & Caesalpinaceae & Jatobá \\
\hline Croton floribundus Spreng. & Euphorbiaceae & Capixingui \\
\hline Casearia sylvestris Swartz & Flacourtiaceae & Guassatonga \\
\hline Cariniana legalis (Mart.) Kuntze & Lecythidaceae & Jequitibá-rosa \\
\hline Acacia polyphlla DC. & Mimosaceae & Monjoleiro \\
\hline Enterolobium contortisiliquum (Vell.) Morong & Mimosaceae & Tamboril \\
\hline Eucalyptus urophylla S. T. Blake & Myrtaceae & Eucalipto \\
\hline Galesia gorazema (Vell.) Moq. & Phytolaccaceae & Pau-d'alho \\
\hline Balfourodendron riedelianum (Engl.) Engl. & Rutaceae & Pau-marfim \\
\hline Trema micrantha (L.) Blum. & Ulmaceae & Pau-pólvora \\
\hline \hline
\end{tabular}

Tabela 2 - Associações utilizadas no experimento de manejo de capoeira baixa, e categoria sucessional a que pertence cada espécie.

\begin{tabular}{||c|l|l|l|l||}
\hline \hline Associação & Pioneira 1 & Pioneira 2 & Não pioneira 1 & Não pioneira 2 \\
\hline 1 & Pau-pólvora & Pau-d'alho & Ipê & Jatobá \\
\hline $\mathbf{2}$ & Capixingui & Monjoleiro & Paineira & Jequitibá-rosa \\
\hline $\mathbf{3}$ & Eucalipto & Casearia & Tamboril & Pau-marfim \\
\hline
\end{tabular}


O plantio nos tratamentos 1 a 3 foi realizado utilizando-se associações de espécies arbóreas que reúne espécies pioneiras e não pioneiras. $O$ plantio foi feito em módulos de 16 metros quadrados, com 2 metros entre limhas e 4 entre plantas, em quincônscio. Cada associação constou de quatro espécies, duas pioneiras e duas não pioneiras (figura 1). $\mathrm{O}$ critério utilizado para classificar as espécies nos quatro diferentes grupos sucessionais foi o de velocidade de crescimento (critério silvicultural), e não o critério de estratégia de regeneração em florestas naturais (critério evolutivo-ecológico) usado para classificar as espécies no capítulo B. As categorias sucessionais conșideradas, pioneira 1 e 2 , não pioneira 1 e 2 apresentam velocidade de crescimento em ordem decrescente. As espécies utilizadas em cada associação são complementares nas características de porte, velocidade de crescimento, produção de alimentos para a fauna, e capacidade de sombreamento. Ou seja, quando se usou em uma associação uma espécie de pequeno porte, complementou-se com uma outra de grande porte, e assim sucessivamente. Essas espécies foram escolhidas entre as nativas da região, com exceção do eucalipto, em função dos seguintes parâmetros, com ênfase para os cinco primeiros:

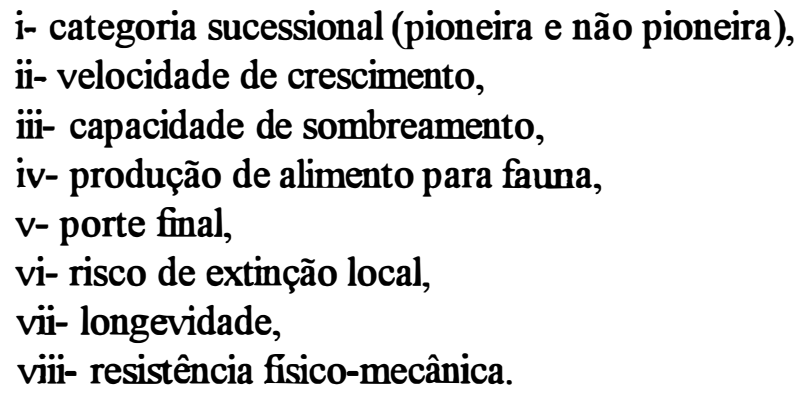

Esses parâmetros foram considerados os mais importantes para obter-se a recuperação mais rápida possível da estrutura florestal Assim, velocidade de crescimento e porte final são importantes para que as árvores corram menores riscos de serem envolvidas por cipós. Capacidade de sombreamento é importante para que as árvores possam sombrear o ambiente e tomá-lo pouco propício a serem dominados por cipós. A produção de alimentos para a fauna é importante para que sejam atraídas espécies animais com potencial dispersor. Longevidade é importante para que os indivíduos perdurem por mais tempo e resistência fisico-mecânica para que possam suportar melhor uma eventual infestação por cipós. $O$ risco de extinção local foi levado em consideração pensando-se em diminuir o risco de extinção de algumas espécies mais raras.

Apesar de espécies exóticas serem comumente exemplos de espécies invasoras e que causam grandes danos aos ambientes naturais (BERGER, 1993), o eucalipto foi utilizado por reunir diversas características desejáveis para o experimento, e por não se regenerar sob floresta (CALEGARIO et al., 1993). Esse ipo de uso para espécies não nativas já tem sido utilizado, como no caso do Pinus sp, por exemplo (CUSTODIO FILHO et al., 1989). 


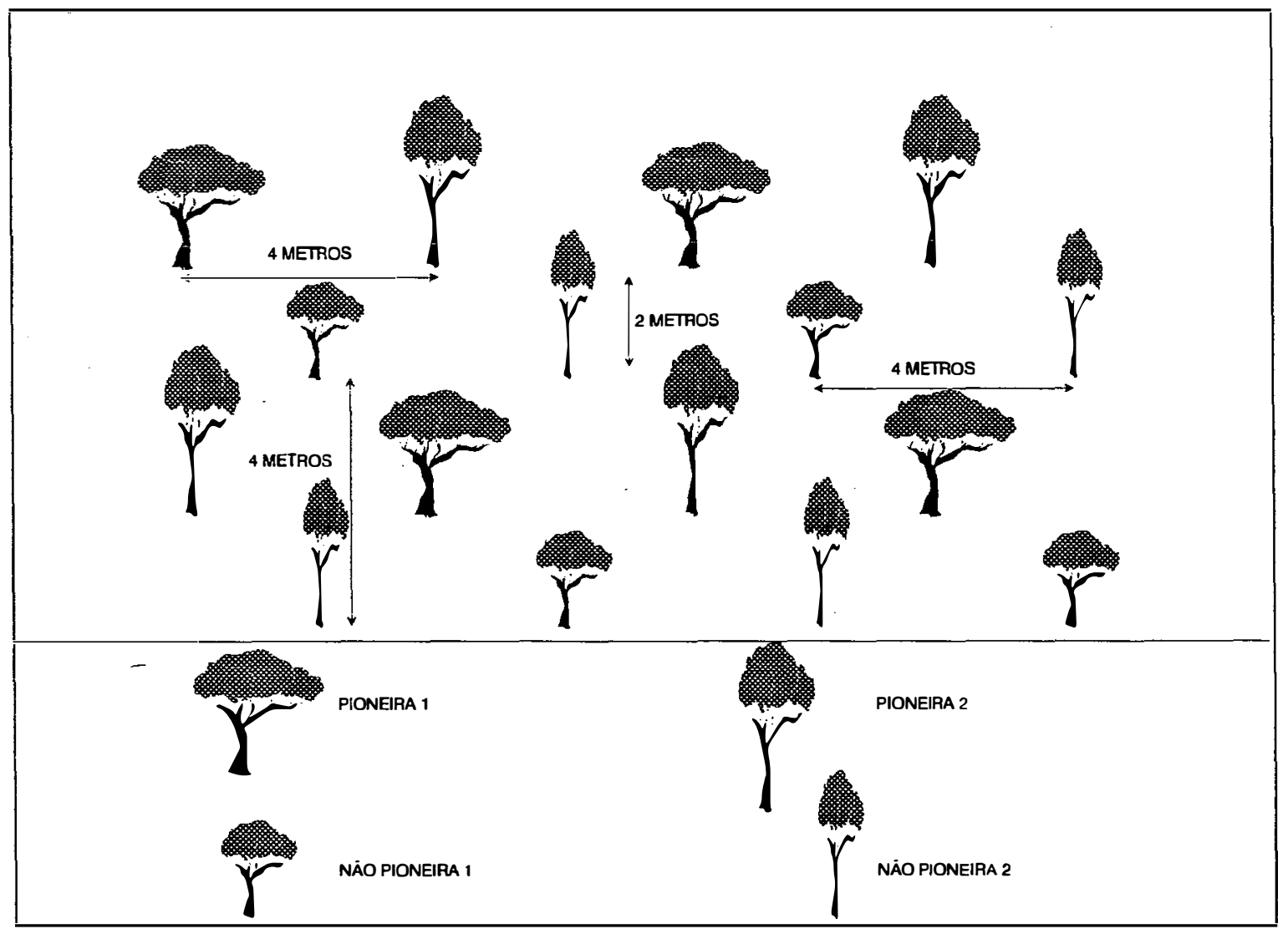

Figura 1 - Esquema de plantio utilizado no plantio de enriquecimento do experimento de manejo de capoeira baixa.

As mudas para o plantio inicial foram doadas pelo viveiro da SODEMAP (Sociedade de Defesa do Meio Ambiente de Piracicaba) e pelo viveiro do Departamento de Botânica da ESALQ/USP. Para o plantio pós-geada, as mudas foram doadas pelo viveiro Cambuhi em Matão, e compradas no viveiro do Departamento de Ciências Florestais da ESALQ/USP e do IPEF e viveiro Vale Verde, de Limeira.

Não foi aplicada nenhuma forma de adubação ou qualquer outro tratamento silvicultural às mudas por ocasião do plantio. Tratamentos posteriores se limitaram ao corte de cipós ao redor da planta, quatro vezes por ano.

\subsection{Acompanhamento do crescimento de mudas plantadas}

Esse acompanhamento foi feito através de medições semestrais de altura, diâmetro de colo, e diâmetro de copa (na orientação norte-sul).

\subsubsection{Análise dos dados}

Os dados analisados referem-se a três medições semestrais (T1, T2 e T3). As diferenças de crescimento entre parcelas, e entre diferentes espécies da mesma parcela foi feita utilizando um teste $F$ de dois fatores hierarquizados, e em caso de significância, um teste Tukey. As diferenças de crescimento entre diferentes espécies de mesma categoria 
sucessional e de diferentes associações foi feita utilizando-se um teste $F$ de um fator, e em caso de significância um teste Tukey. Para comparação da mortalidade entre diferentes espécies de diferentes associações utilizou-se o mesmo teste.

Tabela 3 - Caracterização das espécies utilizadas no plantio de enriquecimento do experimento de manejo de capoeira baixa, quanto aos seguintes atributos: velocidade de crescimento (cresc), porte final (porte), capacidade de sombreamento (sombra) e produção de alimentos para a fauna (fauna). 1- bom, 2- médio, 3- fraco. $\mathrm{Pl}=$ pioneira $1 ; \mathrm{P} 2$ = pioneira $2 ; \mathrm{NP1}=$ não pioneira $1 ; \mathrm{NP2}$ $=$ não pioneira 2 .

\begin{tabular}{|c|c|c|c|c|c|c|}
\hline Associação & Espécie & Cat & Cresc & Porte & Sombra & Fauna \\
\hline \multirow[t]{4}{*}{1} & Capixingui & P1 & 1 & 3 & 1 & 3 \\
\hline & Monjoleiro & P2 & 2 & 1 & 3 & 3 \\
\hline & Paineira & NP1 & 2 & 1 & 2 & 2 \\
\hline & Jequitibá & NP2 & 2 & 1 & 1 & 3 \\
\hline \multirow[t]{4}{*}{2} & Pau-pólvora & P1 & 1 & 3 & 2 & 1 \\
\hline & Pau-d'alho & P2 & 2 & 1 & 2 & 3 \\
\hline & Ipê & NP1 & 2 & 2 & 1 & 3 \\
\hline & Jatobá & NP2 & 3 & 1 & 1 & 1 \\
\hline \multirow[t]{4}{*}{3} & Guassatonga & P1 & 1 & 3 & 2 & 1 \\
\hline & Eucalipto & $\mathbf{P} 2$ & 1 & 1 & 1 & 3 \\
\hline & Tamboril & NP1 & 1 & 1 & 2 & 3 \\
\hline & Pau-marfim & NP2 & 2 & 1 & 1 & 3 \\
\hline
\end{tabular}

\subsection{RESULTADOS E DISCUSSÃO}

\subsubsection{Plantio de enriquecimento}

Um problema para as análises de crescimento pós-manejo da vegetação foi a geada que ocorreu na região de Piracicaba em junho de 1994, poucos meses após a instalação do experimento. A geada ocorreu entre os dias 26 e 29, e foi causada por uma frente fria que ocasionou a queda da temperatura, que chegou a $-0,4^{\circ} \mathrm{C}$. Esta foi a menor temperatura desde o dia 21/07/1981 na região (dados do Departamento de Meteorologia da ESALQ/USP). As árvores plantadas nos experimentos de manejo de CB foram bastante prejudicadas por essas geadas. A vegetação do fragmento em si quase não foi afetada. Isso porque mais próximo ao solo a geada é mais forte (MOTA, 1975), e, provavelmente, porque as mudas, com muitas folhas novas, estavam mais sensiveis que as árvores ao redor. A vegetação do fragmento também não deve ter sido muito afetada porque dentro da floresta a temperatura é mais estável, em função do microclima criado pela própria vegetação. Já as 
mudas estavam em áreas limpas, e portanto mais sujeitas aos extremos de temperatura. Segundo moradores locais essas foram as geadas mais fortes desde 1975.

A mortalidade das mudas nos primeiros seis meses do experimento pode ser vista na tabela 4. Essa mortalidade é principalmente devida à geada, mas também, em menor grau, à seca, que ocorreu entre junho e setembro na região, e, segundo moradores antigos, também foi a maior dos últimos vinte anos. A precipitação em agosto e setembro, que tem como média histórica valores de 30,51 e $62,76 \mathrm{~mm}$, respectivamente, foi de 0,0 e $0,5 \mathrm{~mm}$, respectivamente, em 1994. Houve grande variação quanto à mortalidade nas diferentes parcelas, como se pode perceber pelos coeficientes de variação para cada associação. Isso provavelmente ocorreu devido às diferenças microclimáticas entre as diferentes parcelas. Parte da mortalidade pode também ser creditada a ataques de formigas cortadeiras (saúva, Atta sp), de dificil combate dentro da floresta, principalmente no caso do eucalipto.

Tabela 4 - Percentual de mortalidade por parcela devido à geada, média entre parcelas, e coeficiente de variação entre elas, para as diferentes associações de plantio do experimento de manejo de capoeira baixa.

\begin{tabular}{||l|l|l||}
\hline \hline Associação & Mortalidade média & Coeficiente de variação (\%) \\
\hline $\mathbf{1}$ & 25,92 & 75,36 \\
\hline $\mathbf{2}$ & 33,67 & 27,08 \\
\hline $\mathbf{3}$ & 15,35 & 65,89 \\
\hline
\end{tabular}

Não era previsto nenhum replantio após aquele ocorrido cerca de um mês após o plantio, feito para substituir mudas que haviam morrido logo após o plantio. No entanto, dado o grande dano causado pela geada, e por ser esta um evento bastante raro na região (pelo menos na intensidade observada), foi decidido pelo replantio das mudas mortas por ela. Este foi realizado na última semana de janeiro de 1995. O fato das medições de crescimento inchúrem indivíduos com um ano de diferença de idade implica em dificuldades adicionais para análise estatística dos dados. Em função disso, por exemplo, o crescimento semestral das mudas é todo analisado em percentual de incremento. A longo prazo, o fato não causará maiores problemas de análise estatística, já que este é um experimento de longo prazo, proporcionalmente muito maior que essa diferença de idade (Prof. Dr. H. T. Couto, comunicação pessoal).

A tabela 5 mostra a mortalidade por espécie. Essa mortalidade, juntamente com os dados de crescimento no primeiro semestre (ver abaixo) podem ser utilizados como importantes indicativos da resistência dessas espécies a esse fenômeno climático, particularmente para a instalação de plantios em regiões sujeitas a ele mais freqüentemente. Espécies com menor mortalidade e maior taxa de crescimento em altura e copa (os dois parâmetros mais afetados pela geada), como pau-marfim e tamboril, são as mais resistentes.

Apesar da análise estatística recomendável ser a comparação da mortalidade somente entre espécies da mesma associação, ela foi comparada entre as espécies de todas as associações. Isso porque foi considerado que até a época de ocorrência da geada o crescimento das mudas era pequeno e a influência que cada associação causava nas suas espécies era muito suili para influenciar a susceptibilidade de cada uma ao evento. 
Tabela 5 - Mortalidade por espécie para as espécies utilizadas no plantio de enriquecimento, em três medições. $\mathrm{T} 1=$ =medição realizada cerca de 15 dias após plantio; T2=medição realizada 6 meses após plantio; T3=medição realizada 12 meses após plantio. A mortalidade em T2 e T3 são relativas ao total de mudas existentes em $\mathrm{T} 1$ e $\mathrm{T} 2$ respectivamente, e em $\mathrm{T} 1$ é relativa ao total de mudas utilizadas no plantio.

\begin{tabular}{||c|l|l|l|l||}
\hline \hline Associação & Espécie & $\begin{array}{l}\text { Mortalidade(\%) } \\
\text { T1 }\end{array}$ & $\begin{array}{l}\text { Mortalidade(\%) } \\
\text { T2* }\end{array}$ & $\begin{array}{l}\text { Mortalidade(\%) } \\
\text { T3 }\end{array}$ \\
\hline $\mathbf{3}$ & Pau-marfim & 3,49 & $2,00^{\mathrm{a}}$ & $5,02^{\mathrm{a}}$ \\
\hline $\mathbf{3}$ & Tamboril & 2,27 & $4,00^{\mathrm{a}}$ & $2,00^{\mathrm{a}}$ \\
\hline $\mathbf{2}$ & Ipê & 0,84 & $4,45^{\mathrm{a}}$ & $8,35^{\mathrm{a}}$ \\
\hline $\mathbf{3}$ & Guassatonga & 1,11 & $10,22^{\mathrm{ab}}$ & $16,06^{\mathrm{ab}}$ \\
\hline $\mathbf{1}$ & Paineira & 1,12 & $12,41^{\mathrm{ab}}$ & $1,96^{\mathrm{a}}$ \\
\hline $\mathbf{1}$ & Monjoleiro & 0,00 & $22,40^{\mathrm{ab}}$ & $7,07^{\mathrm{a}}$ \\
\hline $\mathbf{2}$ & Pau-d'alho & 0,85 & $28,88^{\mathrm{ab}}$ & $7,36^{\mathrm{a}}$ \\
\hline $\mathbf{2}$ & Jatobá & 1,71 & $29,72^{\mathrm{ab}}$ & $14,68^{\mathrm{a}}$ \\
\hline $\mathbf{1}$ & Jequitibá & 1,20 & $31,50^{\mathrm{ab}}$ & $7,79^{\mathrm{a}}$ \\
\hline $\mathbf{1}$ & Capixingui & 2,00 & $36,93^{\mathrm{abc}}$ & $4,19^{\mathrm{a}}$ \\
\hline $\mathbf{3}$ & Eucalipto & 6,10 & $47,03^{\mathrm{bc}}$ & $133,10^{\mathrm{b}}$ \\
\hline $\mathbf{2}$ & Pau-pólvora & 4,27 & $71,23^{\mathrm{c}}$ & $9,54^{\mathrm{a}}$ \\
\hline
\end{tabular}

Médias seguidas de mesma letra não diferem significativamente $(\mathrm{p}=0,05)$ pelo teste de Tukey.

*Mortalidade devida principalmente à geada.

O baixo número de espécies que são estatisticamente diferentes em relação à mortalidade causada pela geada é devido a alta variabilidade da mortalidade entre parcelas. Como exemplo temos a comparação entre pau-marfim e capixingui, ou entre guassatonga e eucalipto, que apesar de apresentarem mortalidade completamente diferentes entre si, não apresentam diferença significativa estatisticamente. A alta mortalidade do pau-pólvora, do eucalipto e do capixingui é de certa maneira esperada, pelo intenso crescimento que apresentaram imediatamente após o plantio, que fez com que chegassem à época da geada com grande quantidade de folhas novas, mais sensíveis à queda de temperatura. A mortalidade no T3 só difere estatisticamente para o eucalipto, que sofreu forte mortalidade por ataque de formiga-saúva. A guassatonga também mostra uma mortalidade bastante alta, ainda que não diferente estatisticamente das outras espécies. Essa alta mortalidade é provavelmente reflexo do crescimento lento que esta espécie tem apresentado. Apesar de pioneira, entre T2 e T3 o seu crescimento foi o mais baixo em copa, e o quarto mais baixo em colo e altura.

A tabela 6 mostra o crescimento em colo das mudas plantadas. $O$ crescimento em colo é aquele que pode ser analisado para comparar as espécies, independente da resistência à geada de cada uma (esse crescimento não foi afetado por ela, ao contrário de altura e copa que foram muito afetados, algumas espécies apresentando até crescimento negativo-tabelas 7 e 8). Assim o grau de prejuizo devido à geada, que foi muito variável entre parcelas (tabela 4) foi o responsável pelos altos coeficientes de variação observados para o crescimento de altura e copa. Esses coeficientes de variação muito altos fazem com que grandes diferenças de crescimento médio para copa e altura não sejam significativos estatisticamente, como se pode observar nas tabelas 7 e 8 . Essa grande variabilidade provocada pela geada entre as parcelas causou o mesmo problema inclusive no intervalo T2-T3 (tabelas 7 
e 8), período em que muitos indivíduos estavam se recuperando dos seus efeitos. $\mathrm{O}$ crescimento em altura e copa é, para esse experimento, mais importante que o crescimento em colo, porque é a altura e a copa que darão às mudas plantadas a capacidade de sombreamento e conseqüente abafamento do cipó.

Tabela 6 - Incremento percentual médio em colo entre T1 e T2 (T1-T2) e entre T2 e T3 (T2T3) para as espécies utilizadas no plantio de enriquecimento. $\mathrm{T} 1=$ =medição realizada cerca de 15 dias após plantio; T2=medição realizada 6 meses após plantio; T3=medição realizada 12 meses após plantio.

\begin{tabular}{|c|c|c|c|c|}
\hline Cat Sucessional & Associação & Espécie & T1-T2* & T2-T3* \\
\hline P1 & 2 & Pau-pólvora & $146,70^{\mathrm{a}}$ & $133,17^{\mathrm{a}}$ \\
\hline P1 & 1 & Capixingui & $96,61^{a b}$ & $103,20^{\mathrm{a}}$ \\
\hline P1 & 3 & Guassatonga & $42,31^{\mathrm{b}}$ & $55,95^{\mathrm{a}}$ \\
\hline$\overline{\mathbf{P 2}}$ & 3 & Eucalipto & $209,86^{a}$ & $114,99^{\mathrm{a}}$ \\
\hline $\mathbf{P 2}$ & 2 & Pau-d'alho & $74,32^{b}$ & $54,82^{\mathrm{a}}$ \\
\hline $\mathbf{P 2}$ & 1 & Monjoleiro & $66,59^{b}$ & $87,08^{a}$ \\
\hline NP1 & 1 & Paineira & $112,72^{\mathrm{a}}$ & $71,89^{a}$ \\
\hline NP1 & 3 & Tamboril & $69,31^{a}$ & $74,82^{a}$ \\
\hline NP1 & 2 & Ipê & $30,60^{a}$ & $80,42^{\mathrm{a}}$ \\
\hline NP2 & 3 & Pau-marfim & $55,55^{\mathrm{a}}$ & $79,58^{\mathrm{a}}$ \\
\hline NP2 & 1 & Jequitibá & $38,31^{\mathrm{a}}$ & $11,45^{\mathrm{b}}$ \\
\hline NP2 & 2 & Jatobá & $16,40^{b}$ & $26,27^{b}$ \\
\hline
\end{tabular}

*Médias seguidas de mesma letra não diferem significativamente $(\mathrm{p}=0,05)$ pelo teste de Tukey (válido dentro de cada categoria sucessional).

Algumas espécies apresentaram crescimento superior a de espécies de categoria sucessional de crescimento mais intenso. Um exemplo é o pau-marfim, que pertencente ao grupo NP2 cresceu mais que o ipê, do grupo NP1. No entanto somente em um caso essa diferença foi significativa $(\mathrm{p}=0,05)$, que é o crescimento em colo e altura do $\mathrm{T} 1$ para T2 para o eucalipto, que apresentou maior crescimento do que a guassatonga. Isso mostra o potencial muito grande para o eucalipto como espécie para utilização em áreas onde se queira baratear a recuperação (crescimento intenso, baixo preço das mudas, e possibilidade de aproveitamento da madeira). Deve-se frisar que essa espécie, assim como todas as outras utilizadas nesse experimento, não sofreu nenhum tipo de tratamento, como fertilização ou tratamento fitossanitário, à excessão do corte de cipós ao redor da muda.

Algumas espécies pioneiras apresentaram crescimento bastante pequeno para a categoria sucessional a que pertencem No caso do monjoleiro houve um crescimento pequeno em diâmetro de colo, mas muito bom em altura entre T1 e T2. Já no caso da guassatonga o crescimento foi pequeno para as duas variáveis. 
Tabela 7 - Incremento percentual médio em altura entre tempos 1 e 2 (T1-T2) e entre 2 e 3 (T2-T3) para as espécies utilizadas no plantio de enriquecimento. T1-medição realizada cerca de 15 dias após plantio; T2=medição realizada 6 meses após plantio; T3=medição realizada 12 meses após plantio.

\begin{tabular}{|c|c|c|c|c|}
\hline Cat Sucessional & Associação & Espécie & T1-T2* & T2-T3* \\
\hline P1 & 1 & Capixingui & $228,67^{a}$ & $345,31^{\mathrm{a}}$ \\
\hline P1 & 3 & Guassatonga & $7,60^{a}$ & $118,48^{\mathrm{a}}$ \\
\hline $\mathbf{P 1}$ & 2 & Pau-pólvora & $-27,16^{a}$ & $358,14^{a}$ \\
\hline P2 & 1 & Monioleiro & $14758^{\mathrm{a}}$ & $13620^{\mathrm{a}}$ \\
\hline P2 & 3 & Eucalipto & $84,26^{\mathrm{a}}$ & $178,07^{\mathrm{a}}$ \\
\hline $\mathbf{P 2}$ & 2 & Pau-d'alho & $6,16^{a}$ & $173,97^{\mathrm{a}}$ \\
\hline NP1 & 1 & Paimeira & $33,36^{\mathrm{a}}$ & $129,04^{\mathrm{a}}$ \\
\hline NP1 & 3 & Tamboril & $26,38^{a}$ & $68,05^{a}$ \\
\hline NP1 & 2 & Ipê & $-19,82^{a}$ & $219,28^{a}$ \\
\hline NP2 & 3 & Pau-marfim & $51,99^{a}$ & $109,38^{\mathrm{a}}$ \\
\hline NP2 & 2 & \begin{tabular}{|l|} 
Jatobá \\
\end{tabular} & $-15,09^{\mathrm{a}}$ & $68,69^{a}$ \\
\hline NP2 & 1 & Jequitibá & $-23,33^{a}$ & $129,08^{\mathrm{a}}$ \\
\hline
\end{tabular}

*Médias seguidas de mesma letra não diferem significativamente $(\mathrm{p}=0,05)$ pelo teste de Tukey (válido dentro de cada categoria sucessional).

\subsubsection{Conclusão}

As espécies utilizadas neste experimento mostraram bom potencial para uso em plantio de enriquecimento no manejo de fragmentos florestais. Em um ano algumas espécies cresceram tanto quanto $1.363,60 \%$ em altura (capixingui) ou $566,17 \%$ em colo e $3.188,53 \%$ em copa (eucalipto). Esse crescimento poderia ser ainda maior caso não tivesse oconido a forte geada que ocorreu em junho de 1994, logo após o plantio. O eucalipto mostrou-se bastante promissor como espécie para recuperação da estrutura da floresta, apesar de não ser nativa, devido às características que o levaram a ser usado no experimento e ao seu crescimento observado.

Juntamente com o plantio de enriquecimento, e o corte de cipós de manutenção nas parcelas, parece ser fundamental o corte de cipós na vegetação que circunda a $\mathrm{CB}$ (normalmente uma área de $\mathrm{CA}$ ). $\mathrm{O}$ crescimento das mudas plantadas mais próximas às bordas, a uma altura que não pode ser alcançada pelos instrumentos de corte permite a entrada dos cipós pela área não manejada ao redor. Isso pode ser evitado com o corte do cipó em uma faixa de 5 a $10 \mathrm{~m}$ de largura ao redor da CB. Essa operação, equivalente ao corte de cipós em capoeira alta, não deve aumentar muito o custo de manejo (veja os custos de manejo de CA no capítulo 3). 
Tabela 8 - Incremento percentual médio em copa entre tempos 1 e 2 (T1-T2) e entre 2 e 3 (T2-T3) para as espécies utilizadas no plantio de enriquecimento. T1=medição realizada cerca de 15 dias após plantio; T2=medição realizada 6 meses após plantio; T3=medição realizada 12 meses após plantio.

\begin{tabular}{|c|c|c|c|c|}
\hline Cat Sucessional & Associação & Espécie & T1-T2* & T2-T3* \\
\hline P1 & 1 & Capixingui & $163,00^{\mathrm{a}}$ & $472,95^{\mathrm{ab}}$ \\
\hline P1 & 3 & Guassatonga & $6,01^{a}$ & $125,15^{b}$ \\
\hline P1 & 2 & Pau-pólvora & $-8,50^{a}$ & $1179,24^{\mathrm{a}}$ \\
\hline $\mathbf{P 2}$ & 3 & |Eucalipto & $177,09^{b}$ & $1086,81^{\mathrm{a}}$ \\
\hline $\mathbf{P 2}$ & $\overline{1}$ & Monjoleiro & $89,48^{\mathrm{ab}}$ & $142,05^{\mathrm{a}}$ \\
\hline $\mathbf{P 2}$ & 2 & Pau-d'alho & $-11,17^{a}$ & $212,73^{a}$ \\
\hline NP1 & 1 & Paineira & $59,01^{\mathrm{a}}$ & $153,79^{\mathrm{a}}$ \\
\hline NP1 & 3 & Tambonil & $19,75^{\mathrm{a}}$ & $1013,05^{\mathrm{a}}$ \\
\hline NP1 & 2 & Ipê & $-11,32^{\mathrm{a}}$ & $288,51^{a}$ \\
\hline NP2 & 3 & |Pau-marfim & $16,93^{\mathrm{a}}$ & $574,67^{\mathrm{a}}$ \\
\hline NP2 & 1 & Jequitibá & $-11,60^{a}$ & $209,43^{\mathrm{a}}$ \\
\hline NP2 & 2 & Jatobá & $-27,89^{a}$ & $465,70^{\mathrm{a}}$ \\
\hline
\end{tabular}

*Médias seguidas de mesma letra não diferem significativamente $(\mathrm{p}=0,05)$ pelo teste de Tukey (válido dentro de cada categoria sucessional). 


\section{CAPÍTULO 5}

\subsection{CONCLUSÕES}

\subsubsection{Conclusões gerais}

Esse trabalho mostra dados de um período relativamente curto de um experimento de longo prazo. O coeficiente de variação observado foi alto, o que era esperado, já que em florestas naturais há muitas variáveis envolvidas que não podem ser controladas. Além disso esse tipo de experimentação é algo relativamente recente. No entanto os resultados mostrados nos capítulos anteriores mostram que:

i) o levantamento expedito é tecnicamente viável na medida em que as esounidades mapeadas com base na fisionomia são correlacionadas com dados quantitativos do componente arbóreo da vegetação. Assim, a proporção de cada ecounidade dentro de um fragmento dará idéia do grau de desenvolvimento da vegetação arbórea, e do estado geral de conservação do fragmento. O levantamento expedito permite a execução de trabalhos com vistas à conservação em curto espaço de tempo, e com baixo aporte de recursos, sempre que não for necessário um alto nivel de detalhamento no trabalho.

ii) o manejo da capoeira baixa, ecounidade comum nos fragmentos de floresta estacional semidecidual do interior do estado de São Paulo, pode representar um meio de recuperar a vegetação arbórea nesses fragmentos. $\mathrm{O}$ manejo baseado no controle de cipós e no plantio de enriquecimento mostrou-se bastante eficaz. Esses métodos, aperfeiçoados e associados a outros, podem ser fundamentais no futuro para a conservação desses fragmentos em bom estado.

iii) os resultados positivos obtidos no experimento de capoeira baixa, em apenas 18 meses de acompanhamento, sugerem que o manejo de capoeira alta, com os métodos mostrados nesse trabalho, possam ser eficazes. Além disso, o custo desse manejo se mostrou extremamente acessível. As diferenças na dinâmica entre essas duas ecounidades devem causar diferenças nas respostas ao manejo. Somente o acompanhamento a médio e longo prazo mostrará se esse manejo é eficiente.

\subsubsection{Recomendações para experimentos de manejo}

No estudo da conservação e do manejo de fragmentos florestais devem ter prioridade as pesquisas que possam, no menor tempo possível, responder às questões básicas que tenham relação com a manutenção de sua biodiversidade, estrutura, e processos de dinâmica. As inúmeras informações disponíveis sobre processos da floresta tropical devem ser somadas às relativamente escassas informações existentes sobre a dinâmica de fragmentos florestais, para que seja possível compreender melhor os processos e atuar sobre eles. 
O estudo de aspectos relacionados mais diretamente à conservação de fragmentos florestais devem ser prioridade. A seguir são dadas algumas sugestões sobre trabalhos que podem ser realizados no manejo de fragmentos florestais, que complementariam este trabalho:

i) reprodução desses experimentos, com maior número de repetições para que possam ser descartadas parcelas muito desviantes do padrão, conseqüentemente obtendo maior homogeneidade entre parcelas e menor coeficiente de variação entre elas;

ii) acompanhamento detalhado da dinâmica de regeneração pós-manejo em relação às espécies mais importantes nesse processo;

iii) aplicação desse experimento com plantio de enriquecimento apenas de espécies não pioneiras, e revolvimento do solo em vários pontos das parcelas para provocar a germinação de sementes das espécies pioneiras.

Outros trabalhos, que enfoquem questões não abrangidas por esse estudo, também devem ser privilegiados. Aspectos relativos ao efeito de borda, à influência da forma e do grau de isolamento na conservação dos fragmentos, e a condições de sobrevivência da fauna nesses fragmentos, principalmente de polinizadores e dispersores, devem ser considerados urgentemente.

\subsubsection{Prioridades para ação}

Conjuntamente às ações de pesquisa deve ser incorporada uma nova prática legal, que preveja facilidades legais ou tributárias para proprietários que estejam interessados em manejar para conservação seus fragmentos, desde que devidamente acompanhados por técnicos competentes. $O$ desenvolvimento de programas de manejo conservacionista de fragmentos florestais, que incluam o controle de cipós e o plantio de enriquecimento, em associação com programas de revegetação, podem não só aumentar o percentual de florestas nativas, como provavelmente garantir boa parte de sua integridade biológica.

\subsection{EPÍLOGO}

\subsubsection{Polêmica do manejo de fragmentos florestais}

O manejo de fragmentos florestais é um assunto bastante polêmico, particularmente no Brasil, opondo muitos pesquisadores, particularmente os preservacionistas puros, os conservacionistas e os desenvolvimentistas. Os primeiros não aceitam qualquer intervenção nos fragmentos, com a alegação de que estaríamos alterando a dinâmica natural da floresta, com riscos para sua sobrevivência. Os desenvolvimentistas sugerem que qualquer dano à natureza possa ser remediado. Os conservacionistas, por outro lado, aceitam o desenvolvimento de práticas de manejo para garantir a sobrevivência desses fragmentos. $O$ mito da intocabilidade das zonas selvagens na política ambiental tem causado sérios problemas ambientais (GÓMEZ-POMPA \& KAUS, 1994). Além disso, é importante considerar, quando se discute o manejo conservacionista de ecossistemas naturais, que os processos naturais, em fragmentos de ecossistemas, já estão em grande parte alterados, embora seja dificil quantificar essa alteração. Em relação aos fragmentos de floresta de planalto, é importante também considerar que em sua maior parte enfrentam problemas graves de conservação, por maior que seja a proteção a que estejam submetidos. Logo, o 
receio de manejá-los por temer justamente as alterações que esse manejo possa causar, me parece redundância. Seria como não tratar um doente por temor aos efeitos colaterais do tratamento. Devemos correr o risco de errar pela ação, jamais pela omissão. 


\section{REFERÊNCIAS BIBLIOGRÁFICAS}

ABATE, T. Environmental rapid-assessment programs have appeal and critics. Bioscience, Washington, 42(7):486-9, 1992.

ACEVEDO-RODRIGUeS, P. \& WOODBURY, R. O. Los bejucos de Puerto Rico. New Orleans, USDA Forest Service, 1985. 331p. (USDA Forest Service SO General Technical Report)

AIZEN, M. A. \& FEINSINGER, P. Forest fragmentation, and plant reproduction in a chaco dry forest, Argentina. Ecology, Ithaca, 75(2):330-51, 1994.

ANDRÉN, H. \& ANGELSTAM, P. Elevated predation rates as an edge effect in habitat islands: experimental evidence. Ecology, Ithaca, 69(2):544-7, 1988.

ANGEVINE, M. W. \& CHABOT, B. F. Seed germination syndromes in higher plants. In: Solbrig, O. T.; Jain, S.; Johnson, G. B.; Raven, P. H., ed. Topics in plant population biology. New York, Columbia University Press, 1979. p.188-206.

BALÉE, W. \& CAMPBELL, D. G. Evidence for the sucessional status of liana forest (Xingu River Basin, Amazonian Brazil). Biotropica, St. Louis, 22(1):36-47, 1990.

BAUR, G. N. The ecological basis of rainforest management. Sydney, Government Printer, 1968. 499p.

BAWA, K S. Breeding systems of tree species of a lowland tropical community. Evolution, Lancaster, 28:85-92, 1974.

BAWA, K S.; PERRY, D. R; BEACH, J. H. Reproductive biology of tropical lowland rain forest trees. I. Sexual sysyems and incompatibility mechanisms. American Journal of Botany, Columbus, 73(3):331-345, 1985.

BERGER, J. J. Ecological restoration and nonindigenous plant species: a review. Restoration Ecology, Cambridge, 1(2):74-82, 1993.

BERTALOT, M. J. A. \& HARKALY, A. H. Projeto de recomposição florestal de áreas da Estância Demétria e vizinhanças. In: CONGRESSO NACIONAL DE ESSÊNCIAS NATIVAS, 2, São Paulo, 1992. Anais. São Paulo, INSTITUTO FLORESTAL, 1992. p.695.

BERTONI, J. E. de A. Composição florística e fitossociológica do Parque Estadual de Vasssununga, Santa Rita do Passa Quatro, SP - Gleba Praxedes. Boletim Técnico do Instituto Florestal, São Paulo, (42): 149-70, 1988

BRADSHAW, A. D. Restoration ecology as a science. Restoration Ecology, Cambridge, 1(2):71-3, 1993. 
BROKAW, N. V. L. The definition of treefall gap and its effect on measures of forest dynamics. Biotropica, St. Louis, 14(2): 158-60, 1982.

BROKAW, N. V. L. Gap-phase regeneration in a tropical forest. Ecology, Ithaca, 66(3):682-7, 1985.

BROWER, J. E. \& ZAR, J. II. Field and laboratory methods for general ecology. Dubuque, WMC Brown Publishers, 1990. 237p.

BROWN, N. The implications of climate and gap microclimate for seedling growth conditions in a Bornean lowland rain forest. Journal of Tropical Ecology, Cambridge, 9:153-68, 1993.

BUDOWSKI, G. Forest sucession in tropical lowlands. Turrialba, San Jose, 13(1):42-4, 1963.

BUDOWSKI, G. Distribution of tropical American rainforest species in the light of sucessional processes. Turrialba, San Jose, 15(1):40-2, 1965.

BURKEY, T. V. Extinction in nature reserves: the effect of fragmentation and the importance of migration between reserve fragments. Oikos, Copenhagen, 55:75-81, 1989.

CALEGÁRIO, N; SOUZA, A. L. de; MARANGON, L. C.; SILVA, A. F. da Parâmetros florísticos e fitossociológicos da regeneração natural de espécies arbóreas nativas no sub-bosque de povoamentos de Eucalyptus. Revista Árvore, Viçosa, 17(1):16-29, 1993.

CAMPBELL, E. J. F. \& NEWBERY, D. McC. Ecological relationships between lianas and trees in lowland rain forest in Sabah, East Malaysia. Journal of Tropical Ecology, Cambridge, 9(4):469-90, 1993.

CATHARINO, E. L. M. Estudos fisionômico-florísticos e fitossociológico em matas residuais secundárias no município de Piracicaba, SP. Campinas, 1989. $181 \mathrm{p}$. (Mestrado - UNICAMP).

CAVASSAN, O. Levatamento fitossociólogico da vegetação arbórea da mata da Reserva Estadual de Bauru utilizando o método de quadrantes. Rio Claro, 1982. 107p. (Mestrado - UNESP).

CAVASSAN, O.; CESAR, O.; MARTINS, F. R. Fitossociologia da vegetação arbórea da Reserva Estadual de Bauru, Estado de São Paulo. Revista Brasileira de Botânica, 7(2):91-106, 1984. 
CESAR, O. \& LEITÃO FILHO, H. F. Estudo florístico quantitativo de mata mesófila semidecídua na fazenda Barreiro Rico, município de Anhembi, SP. Revista Brasileira de Biologia, Rio de Janeiro, 50(1): 133-47, 1990.

CLARK, D. B.; CLARK, D. B.; RICH, P. M. Comparative analysis of microhabitat utilization by saplings of nine tree species in neotropical rain forest. Biotropica, St. Louis, 25(4):397-407, 1993.

COSTA, L. G. da S. Estrutura e dinâmica de trecho de mata mesófila semidecídua, na estação ecológica de Ibicatú, Piracicaba, SP. São Paulo, 1992. 188p. (Mestrado Instituto de Biociências/USP).

CUSTÓDIO FILHO, A.; FRANDO, G. A. D. C.; NEGREIROS, O. C. de; DIAS, A. C. Estudo da vegetação de sub-bosque de um plantio homogêneo de Pinus sp no P. E. Serra do Mar, Caraguatatuba, SP. In: CONGRESSO NACIONAL DE BOTÂNICA, 40, Cuiabá, 1989. Resumos. Cuiabá, SOCIEDADE BRASILEIRA DE BOTÂNICA, 1989. p.536.

DAUBENMIRE, R. F. Plants and environment: a text-book of plant autoecology. New York, John Wiley, 1974. 422p.

DENSLOW, J. S. Gap partioning among tropical rainforest trees. Biotropica, St. Louis, 12(Special supplement):47-55, 1980.

DENSLOW, J. S. Tropical rainforest gaps and tree species diversity. Annual review of ecology and systematics, Palo Alto, 18:431-51, 1987.

DILLENBURG, L. R.; WHIGHAM, D. F.; TERAMURA, A. H.; FORSETH, I. N. Effects of below- and aboveground competition from the vines Lonicera japonica and Parthenocissus quinquefolia on the growth of the tree host Liquidambar styraciflua. Oecologia, New York, 93(1):48-54, 1993.

ENGEL V. L. Silvigênese, dinâmica de fragmentos e a conservação de florestas tropicais. Série Técnica Florestal, Botucatu, 1(1):1-21, 1993.

FAHRIG, L. \& MERRIAM, G. Habitat patch connectivity and population survival. Ecology, Ithaca, 66(6): 1762-8, 1985.

FAHRIG, L. \& MERRIAM, G. Conservation of fragmented populations. Conservation Biology, Cambridge, 8(1):50-9, 1994.

FERREIRA, R. L. C. Análise estrutural da vegetação da Estação Florestal de Experimentação de Açu, RN, como subsídio básico para o manejo florestal. Viçosa, 1988. (Mestrado - UFV). 
FLENLEY, J. R The equatorial rain forest: a geological history. London, Butterworths, 1979. 162p.

FUNDAÇÃO SOS MATA ATLÂNTICA \& INSTITUTO NACIONAL DE PESQUISAS ESPACIAIS. Evolução dos remanescentes florestais e ecossistemas associados do domínio da Mata Atlântica no período 1985-1990 - Relatório. São Paulo, 1993. 46p.

FUTUYMA, D. J. Biologia evolutiva. Ribeirão Preto, Sociedade Brasileira de Genética/CNPq, 1992. 631p.

GAME, M. Best shape for nature reserves. Nature, London, 287(5783):630-1, 1980.

GANDOLFI, S. Estudo florístico e fitossociológico de uma floresta residual na área do Aeroporto Internacional de São Paulo, município de Guarulhos, SP. Campinas, 1991. 232p. (Mestrado - UNICAMP).

GILPIN, M. E. \& SOULÉ, M. E. Minimum viable populations: processes of species extinction. In: Soulé, M. E., ed. Conservation Biology. Sunderland, Sinauer, 1986. p.19-34.

GÓMEZ-POMPA, A. \& KAUS, A. Taming the wilderness myth. Bioscience, Washington, DC., 42(4):271-9, 1994.

GRUMBINE, R E. What is ecosystem management? Conservation Biology, Cambridge, 8 (1):27-38, 1994.

HALLÉ, F; OLDEMAN, R A. A.; TOMLISON, P. B. Tropical trees and forests. Heidelberg, Springer-Verlag, 1978. $441 \mathrm{p}$.

HARPER, J. L. Population biology of plants. New York, Academic Press, 1977. 892p.

HARTSHORN, G. S. Tree falls and tropical forest dynamics. In: Tomlinson, P. B. \& Zimmerman, ed. Tropical trees as living systems. Cambridge, Cambridge University Press, 1978. p.617-38.

HARTSHORN, G. S. Neotropical forest dynamics. Biotropica, St. Louis, 12(suplemento especial):12-30, 1980.

HUBBELL, S. P. \& FOSTER, R B. Diversity of canopy trees in a neotropical forest and implications for conservation. In: Sutton, S. L.; Whitmore, T. C.; Chadwick, A. C., ed. Tropical rain forest: ecology and management. Oxford, Blackwell Scientific, 1983. p.25-41.

JANZEN, D. H. Ecologia vegetal nos trópicos. São Paulo, EPU, 1980. 71p. 
JANZEN, D. H. No park is an island: incerase in interference from outside as park size decreases. Oikos, Copenhagen, 41:402-10, 1983.

JÄRVINEN, O. Conservation of endangered plant populations: single large or several small reserves? Oikos, Copenhagen, 38:301-7, 1982.

KAGEYAMA, P. Y.; BIELLA, L. C.; PALERMO Jr., A. Plantações mistas com espécies nativas com fim de proteção a reservatórios. In: CONGRESSO FLORESTAL BRASILEIRO, 6, Campos do Jordão, 1990. Anais. Cidade, SOCIEDADE BRASILEIRA DE SILVICULTURA \& SOCIEDADE BRASILEIRA DE ENGENHEIROS FLORESTAIS, 1990. p.109.

KAGEYAMA, P. Y.; FRELXÊDAS, V. M.; GERES, W. L. A.; DIAS, J. H. P.; BORGES, A. Consórcio de espécies nativas de diferentes grupos sucessionais em Teodoro Sampaio - SP. In: CONGRESSO NACIONAL SOBRE ESSÊNCIAS NATIVAS, 2, São Paulo, 1992. Anais. São Paulo, INSTITUTO FLORESTAL, 1992. p.527.

KAGEYAMA, P. Y.; REIS, A.; CARPANEZZI, A. A. Potencialidades e restrições da regeneração artificial na recuperação de áreas degradadas. In: SIMPÓSIO NACIONAL RECUPERAÇÃO DE ÁREAS DEGRADADAS, Curitiba, 1992. Anais. Curitiba, UNIVERSIDADE FEDERAL DO PARANÁ \& FUNDAÇÃO DE PESQUISAS FLORESTAIS DO PARANÁ, 1992. p.1.

KAPOS, V. Effects of isolation on the water status of forest patches in the Brazilian Amazon. Journal of Tropical Ecology, Cambridge, 5(2): 173-185, 1989.

LANG, G. E. \& KNIGHT, D. H. Tree growth, mortality, recruitment, and canopy gap formation during a 10-year period in a tropical moist forest. Ecology, Ithaca, 64(5):1075-80, 1983.

LAURANCE, W. F. Edge effects in tropical forest fragments: application of a model for the design of nature reserves. Biological Conservation, Barking, 57:205-19, 1991.

LAURANCE, W. F. \& YENSEN, E. Predicting the impacts os edge effects in fragmented habitats. Biological Conservation, Barking, 55:77-92, 1991.

LEAK, W. B. An expression of diameter distribution for unbalanced, uneven-aged stands and forests. Forest Science. Bethesda, 10(1):39-50, 1964.

LEITÃO FILHO, H.de F. Considerações sobre a florística de florestas tropicais e subtropicais do Brasil. IPEF, Piracicaba, (35):41-6, 1987.

LORENZI, H. Árvores brasileiras. Nova Odessa, Editora Plantarum Ltda, 1992. 352p.

MARTINS, F. R. O método de quadrantes e a fitossociologia de uma floresta residual do interior do Estado de São Paulo: Parque Estadual de Vassununga. São Paulo, 1979. 239p. (Doutorado - Instituto de Biociências/USP). 
MENNINGER, E. A. Flowering vines of the world: an enciclopedia of climbing plants. New York, Hearthside, 1970. 410p.

MOLOFSKY; J.; AUGSPURGER, C. K. The effect of litter on early seedling stablishment in a tropical forest. Ecology, cidade, 73(1):68-77, 1992.

MORELLATO, L. P. C. Estudo da fenologia de árvores, arbustos e lianas de uma floresta semidecídua no sudeste do Brasil. Campinas, 1991. 176p. (Doutorado - UNICAMP).

MOTA, F. S. da. Meteorologia Agrícola. São Paulo, Nobel, 1975. 376p.

MWALYOSI, R. B. B. Ecological evaluation for wildlife corridors and buffer zones for Lake Manyara national Park, Tanzania, and its immediate environment. Biological Conservation, Barking, 57:171-86, 1991.

NEPSTAD, D; UHL, C.; SERRĀO, E. A. Surmounting barriers to forest regeneration in abandoned highly degraded pastures: a case study from Paragominas, Pará, Brasil In: Anderson, A., ed. Alternatives to deforestation in Amazonia. New York, Columbia University Press, 1990. p.216-29.

NOGUEIRA, J. C. B. Reflorestamento heterogêneo com essências nativas. Boletim Técnico do Instituo Florestal, São Paulo, (24):1-77, 1977.

OLDEMAN, R. A. A. Tropical rain forest, architecture, silvigenesis and diversity. In: Sutton, S. L.; Whitmore, T. C.; Chadwick, A. C., ed. Tropical rain forest: ecology and management. Oxford, Blackwell Scientific Publication, 1983. p.131-50.

PAGANO, S. N. Estudo florístico, fitossociológico e de ciclagem de nutrientes em mata mesófila semidecídua, no municípioi de Rio Claro, SP. Campinas, 1985. 201p. (Livre Docência - Instituto de Biociências/UNESP).

PALIK, B. J. \& MURPHY, P. G. Disturbance versus edge effects in sugar-maple/beech forest fragments. Forest Ecology and Management, Amsterdam, 32(2-4): 187-202, 1990.

PEÑALOSA, J. Dinamica do crecimiento de lianas. In: Gomez-Pompa, A. \& del Amo, S., ed. Investigaciones sobre la regeneracion de selvas altas en Vera Cruz, Mexico. Ciudad de Mexico, Editora Alhambra Mexicana, 1985. p.147-69.

PINARD, M. A. \& PUTZ, F. E. Vine infestation of large remnant trees in logged forest in Sabah, Malaysis: biomechanical facilitation in vine succession. Journal of Tropical Forest Science, 6(3):302-9, 1994.

PUTZ, F. E. Liana vs. Trees. Biotropica, St. Louis, 12(3):224-5, 1980. 
PUTZ, F. E. Treefall pits and mounds, buried seeds, and the importance of soil disturbance to pioneer trees on Barro Colorado Island, Panama. Ecology, Ithaca, 64(5):1069-74, 1983.

PUTZ, F. E. Liana biomass and leaf area of a Tierra Firme forest in the Rio Negro basin, Venezuela. Biotropica, St. Louis, 15: 185-9, 1983.

PUTZ, F. E. The natural history of lianas on Barro Colorado Island, Panama. Biotropica, St. Louis, 19:334-41, 1984.

PUTZ, F. E. Liana stem diameter and mortality rates on Barro Colorado Island, Panama. Biotropica, St. Louis, 22(1):103-5, 1990.

PUTZ, F. E. \& WINDSOR, D. M. Liana phenology on Barro Colorado Island, Panama. Biotropica, St. Louis, 19(4):334-41, 1987.

QUER, P. F. Diccionario de botánica. Barcelona, Editorial Labor S. A., 1985. 1244p.

RICHARDS, P. W. Estudio de la vegetación tropical. Unasylva, Roma, 10(4):171-5, 1956.

RICHARDS, P. W. The tropical rain forest. London, Cambridge University Press, 1979. 450p.

ROBINSON, G. R.; HOLT, R. D.; GAINES, M. S.; HAMBURG, S. P.; JOHNSON, M. L.; FITCH, H. S.; MARTINKO, E. A. Diverse and contrasting effects of habitat fragmentation. Science, Washington, DC., 257(5069):524-6, 1992.

RUNKLE, J. R. Pattems of disturbance in some old-growth mesic forests of eastern north America. Ecology, Ithaca, 63(5):1533-1546, 1982.

SCHEMSKE, D. W. \& LANDE, R. The evolution of self-fertilization and inbreeding depression in plants. II. Empirical observations. Evolution, Lancaster, 39(1):41-52, 1985.

SHAFER, C. L. Values and shortcomings of small reserves. Bioscience, Washington, DC. 45(2):80-8, 1995.

SHAFFER, M. Minimum population sizes for species conservation. Bioscience, Washington, DC., 31(2):131-4, 1981.

SILVA, L. O. da Recomposição de matas nativas empreendidas pela CESP. In: CONGRESSO NACIONAL SOBRE ESSÊNCIAS NATIVAS, 2, São Paulo, 1992. Anais. São Paulo, INSTITUTO FLORESTAL, 1992. p.1054. 
SILVA Jr., M. C. \& SILVA, A. F. da Distribuição dos diâmetros dos troncos das espécies mais importantes do cerrado na Estação Florestal de Experimentação de Paraopeba (EFLEX) - MG. Acta Botanica Brasileira. 2(1-2):107-26, 1988.

SIMBERLOFF, D. Big advantages of small refuges. Natural History, 91:6-14, 1982.

SIMBERLOFF, D. \& COX, J. Consequences and costs of conservation corridors. Conservation Biology, 1(1):63-71, 1987.

SKOLE, D. \& TUCKER, C. Tropical deforestation and habitat fragmentation in the Amazon: satellite data from 1978 to 1988. Science, Washington, DC., 260 (5116): 1905-10, 1993.

SOKAL, R. R. \& ROHLF, F. J. Biometry. 2.ed. New York, W. H. Freeman and Company, 1981. 859p.

STEVENS, G. C. Liana as structural parasites: the Bursera simaruba example. Ecology, Ithaca, 68(1):77-81, 1987.

SWAINE, M. D.; HALL, J. B.; ALEXANDER, I. J. Tree population dynamics at Kade, Ghana (1968-1982). Journal of Tropical Ecology, Cambridge, 3(4):331-45, 1987.

TABANEZ, A. A. J.; VIANA, V. M. Biology and management of forest fragments in Brazil's Atlantic moist forest. In: INTERNATIONAL MEETING OF THE SOCIETY FOR CONSERVATION BIOLOGY AND THE ASSOCIATION FOR TROPICAL BIOLOGY, Guadalajara, 1994. Abstracts. Guadalajara, Universidad de Guadalajara/Society for Conservation Biology/Association for Tropical Biology, 1994. p. 155 .

TABANEZ, A. A. J.; VIANA, V. M.; PINHEIRO, L. A. F. V. Ecologia da paisagem de Piracicaba, SP. In: CONGRESSO NACIONAL DE BOTÂNICA, 45, São Leopoldo, 1994. Resumos. São Leopoldo, Universidade do Vale do Rio dos Sinos, 1994. p.76.

TABANEZ, A. A. J.; VIANA, V. M.; DIAS, A. da S. Consequências da fragmentação e do efeito de borda sobre a estrutura, diversidade e sustentabilidade de um fragmento de floresta de planalto de Piracicaba, SP. No prelo.

UHL, C.; CLARK, K; DEZZEO, N.; MAQUIRINO, P. Vegetation dynamics in Amazonian treefall gaps. Ecology, Ithaca, 69(3):751-63, 1988.

UHL, C.; BUSCHBACHER, R; SERRÃO, E. A. S. Abandoned pastures in eastern Amazonia. I. Patterns of plant sucession. Journal of Ecology, Oxford, 76:663-81, 1988.

VAZQUEZ-YANES, C.; OROZCO-SEGOVIA, A.; RINCON, E.; SANCHESCORONADO, M. E.; HUANTE, P.; TOLEDO, J. R.; BARRADO, V. L. Light beneath the litter in a tropical forest: effect on seed germination. Ecology, Ithaca, 71(5):1952$58,1990$. 
VIANA, V. M. Seed dispersal and gap regeneration: the case of three Amazonian tree species. Cambridge, 1989. 270p. (PhD - Harvard University).

VIANA, V. M. Biologia e manejo de fragmentos de florestas naturais. In: CONGRESSO FLORESTAL BRASILEIRO, 6, Curitiba, 1990. Anais. Campos do Jordão, Sociedade Brasileira de Silvicultura?Sociedade Brasileira de Engenheiros Florestais, 1990. p.113.

VIANA, V. M.; TABANEZ, A. A. J.; MARTINEZ, J. L. A. Restauração e manejo de fragmentos florestais. In: CONGRESSO NACIONAL SOBRE ESSÊNCIAS NATIVAS, 2, São Paulo, 1992. Anais. São Paulo, INSTITUTO FLORESTAL, 1992. p.400.

VIANA, V. M. \& TABANEZ, A. A. J. Biology and conservation of forest fragments in the Brazilian Atlantic moist forest. Submetido.

WELDEN, C. W.; HEWETT, S. W.; HUBBEL, S. P.; FOSTER, R. B. Sapling survival, growth, and recruitment: relationship to canopy height in a neotropical forest. Ecology, Ithaca, 71(1):35-50, 1991.

WILLIAMS-LINERA, G. Vegetation structure and environmental conditions of forest edges in Panama. Journal of Ecology, Oxford, 78(2):356-73, 1990.

YOUNG, A. \& MITCHELL, N. Microclimate and vegetation edge effects in a fragmented podocarp-broadleaf forest in New Zealand. Biological Conservation, Barking, 67:6372,1994 